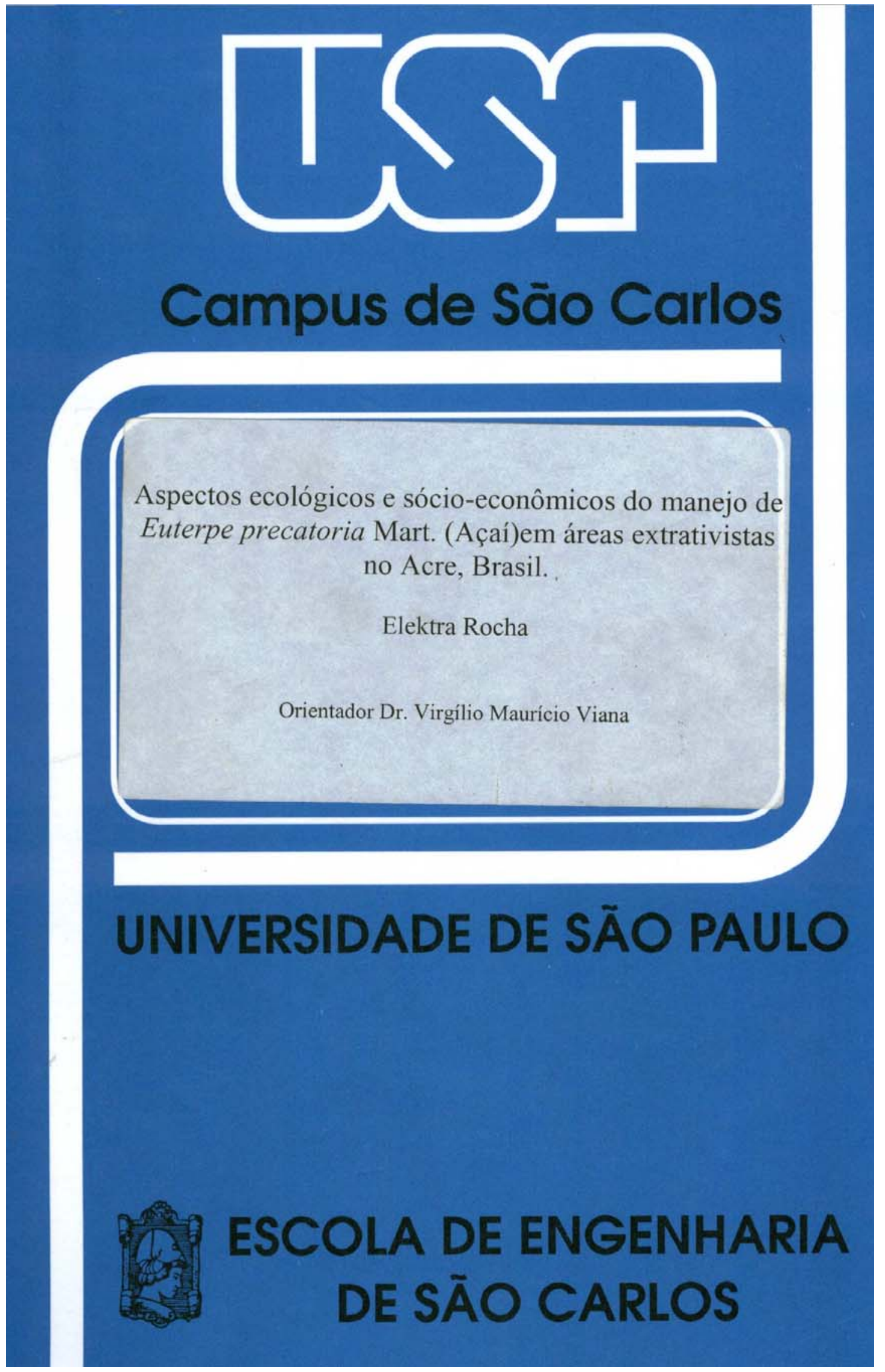




\title{
Aspectos ecológicos e sócio-econômicos do manejo de Euterpe precatoria Mart. (Açaí) em áreas extrativistas no Acre, Brasil.
}

\author{
Elektra Rocha
}

Orientador: Prof. Dr. Virgílio Maurício Viana

Dissertação apresentada à Escola de Engenharia de São Carlos da Universidade de São Paulo, como parte dos requisitos para a obtenção do Título de Mestre em Engenharia Ambiental

\section{São Carlos}

Estado de São Paulo - Brasil

2002 


\section{FOLHA DE JULGAMENTO}

Candidata: Licenciada ELEKTRA ROCHA

Dissertação defendida e julgada em 10-04-2002 perante a Comissão Julgadora:
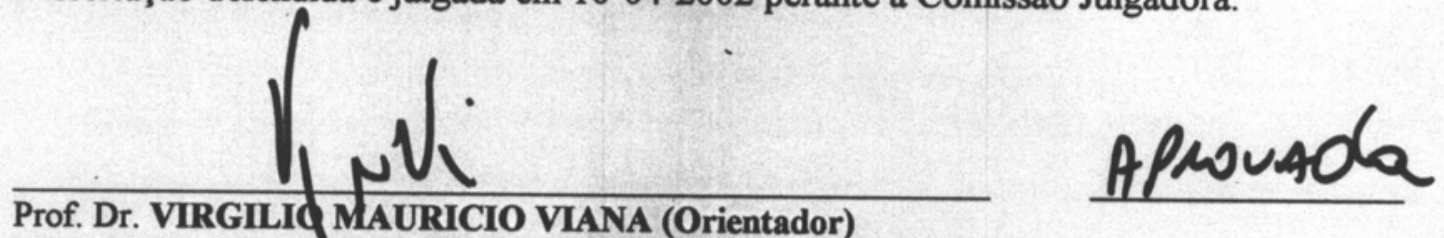

(Escola Superior de Agricultura "Luiz de Queiroz"/USP)

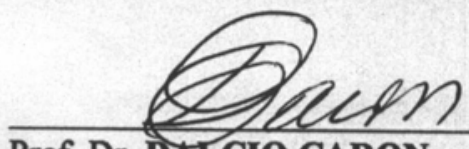

Prof. Dr. DALCIO CARON

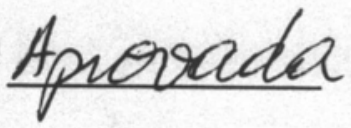

(Escola Superior de Agricultura "Luiz de Queiroz"/USP)
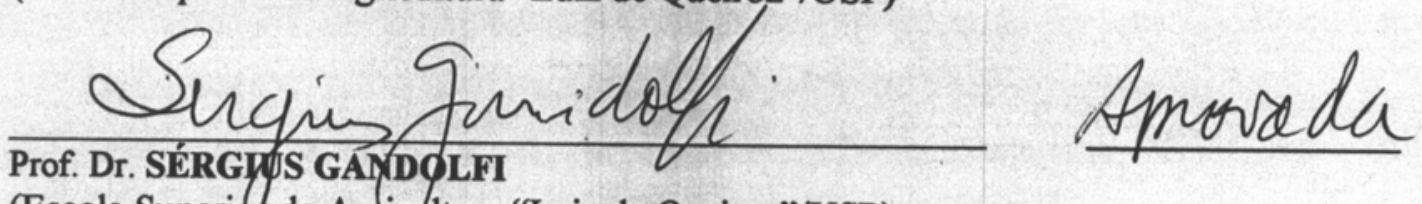

(Escola Superict de Agkicultura "Luiz de Queiroz"/USP)

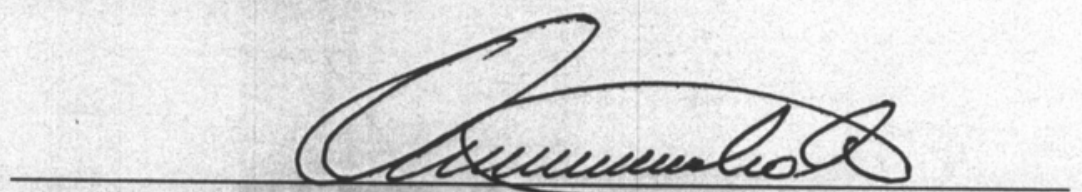

Prof. Doutor VALDIR SCHALCH

Coordenador do Programa de Pós-Graduação

em Ciências da Engenharia Ambiental

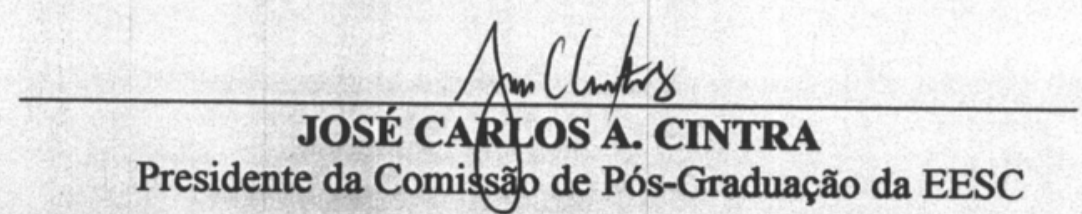




\section{DEDICATÓRIA}

- A todos os seringueiros - que compreendem a necessidade de defender a floresta como condição para a sua própria sobrevivência - sem os quais seria impossível realizar este trabalho e

- À̀ minha mãe que sempre me apoiou a seguir o caminho que escolhi. 


\section{AGRADECIMENTOS}

Agradeço:

Ao Professor Dr. Virgílio Maurício Viana pela orientação e idéias que contribuíram para o trabalho;

Ao Laboratório de Silvicultura Tropical (LASTROP) da ESALQ;

Ao CNPq e ao Fundo Mundial para a Natureza (WWF) pela bolsa de estudo e apoio financeiro respectivamente, imprescindíveis para a realização do trabalho;

Ao Parque Zoobotânico (Universidade Federal do Acre) pelo apoio da infra-estrutura em especial a Marcos Silveira e Foster Brown;

A todos os seringueiros que contribuíram para este trabalho. Em especial às comunidades dos Seringais Rio Branco, Porongaba, Dois Irmãos na Reserva Extrativista Chico Mendes e à comunidade do Seringal Caquetá;

À Associação dos Seringueiros e Pequenos Agricultores do Caquetá (ASPAC) e ao Conselho Nacional do Seringueiro (CNS) do Acre pelo apoio de campo;

Ao Alexandre de Souza e a Karin pelo apoio logístico e pelo apoio da amizade e das relações de trabalho;

Ao professor Dr. Paulo Y. Kageyama (ESALQ) pela oportunidade de discussões relevantes para este trabalho;

Ao professor Dr. Dalcio Caron (ESALQ) e a Mariana Wongtschowski pelo auxílio na metodologia sócio-econômica.

Ao professor Sergius Gandolfi (ESALQ) pelas contribuições no exame de qualificação do trabalho.

Ao Marcelo Alves (ESALQ) e Pião (UNESP/Rio Claro) pela ajuda na estatística;

Ao Alexandre (UNICAMP) pelo conversa e fornecimento do programa do modelo de matriz empregado no estudo;

À Mariana e ao Cleber pela ajuda na revisão do texto final;

Ao Cleber pelo seu apoio e compreensão;

A todos os meus amigos por serem exatamente como são;

À vida por ter me dado esta oportunidade maravilhosa... 


\section{SUMÁRIO}

Resumo ---

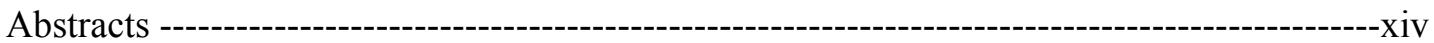

Capítulo 1 - Introdução - -

\section{Capítulo 2 - Ecologia Populacional de Euterpe precatoria Mart. (Açaí)}

2.1 Introdução ---

2.2 Material e Métodos - -

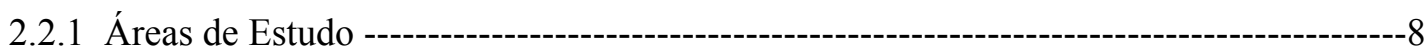

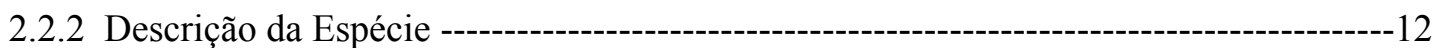

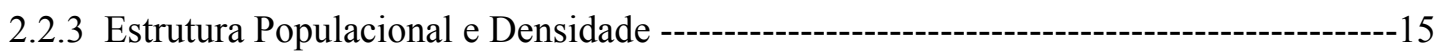

2.2.4 Desenvolvimento dos Indivíduos de Euterpe precatoria -----------------------20

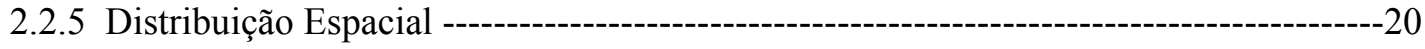

2.2.6 Dinâmica Populacional ---

2.2.7 Estimativa da Abertura do Dossel na Floresta de Baixio e de Terra Firme -------------27

2.2.8 Produção de Frutos e Potencial Produtivo--

2.3 Resultados e Discussão -------

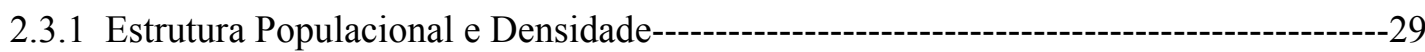

2.3.2 Desenvolvimento dos Indivíduos de Euterpe precatoria -----------------------38

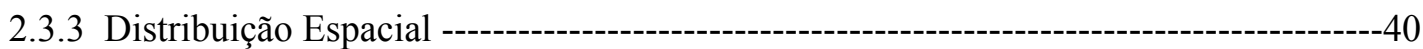

2.3.4 Dinâmica Populacional -------------------------------------------------------------------43

2.3.5 Estimativa da Abertura do Dossel na Floresta de Baixio e de Terra Firme -------------57

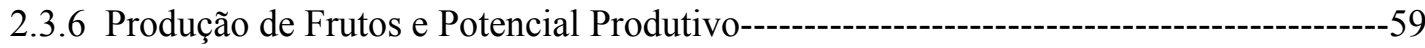

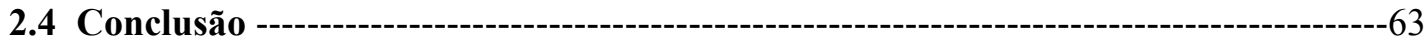

Capítulo 3 -Aspectos Sócio-Econômicos do Sistema de Produção do Seringal

\section{Caquetá}

3.1 Introdução ---

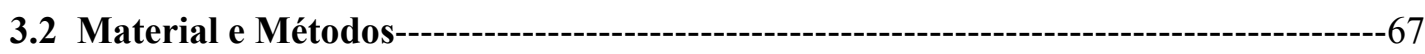

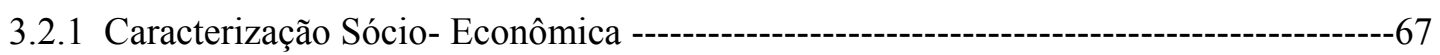

3.2.1.1 Caracterização das Famílias ---

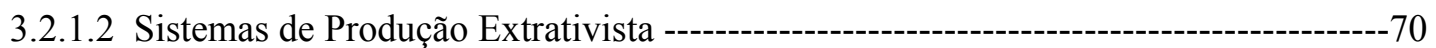

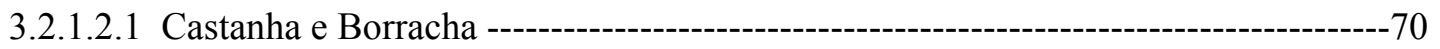

3.2.1.2.2 Açaí---- 
3.2.1.3 Sistemas de Produção de Subsistência$-71$

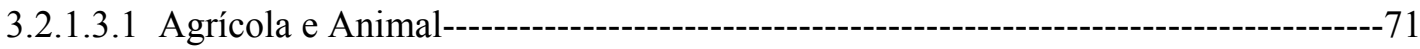

3.2.1.3.2 Extrativismo da Floresta--------

3.2.1.4 Trabalho Remunerado (Diarista) -----------------------------------------------72

3.2.1.5. Diária Local e Outros Usos da Terra Versus Manejo do Açaí-------------------------73

3.3 Resultados e Discussões ---

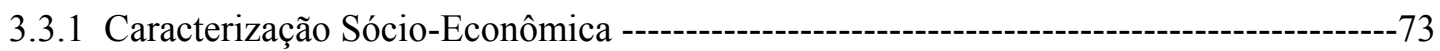

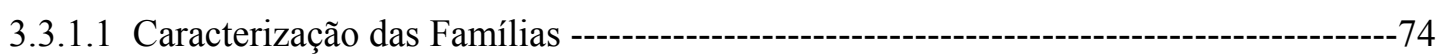

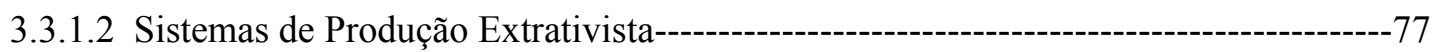

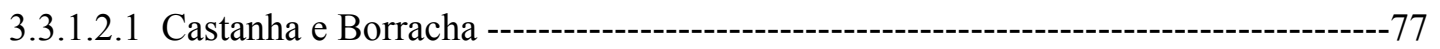

3.3.1.2.2 Açaí----10

3.3.1.3 Sistemas de Produção de Subsistência--

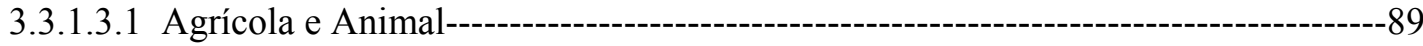

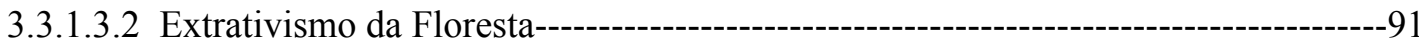

3.3.1.4 Trabalho Remunerado (Diarista) --

3.3.1.5. Diária Local e Outros Usos da Terra Versus Manejo do Açaí.-------------------------92

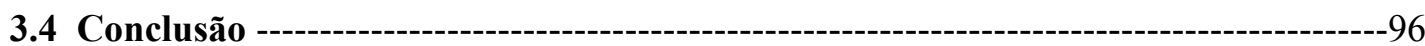

Capítulo 4 - Implicações para o Manejo de Euterpe precatoria Mart. no Seringal Caquetá

4.1 Introdução - -

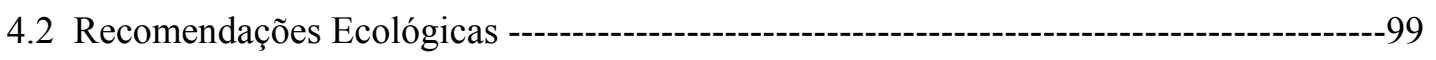

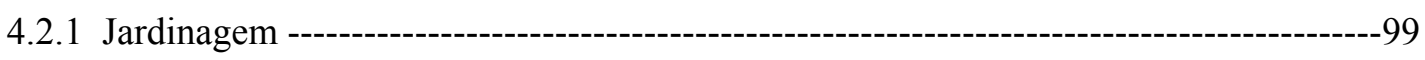

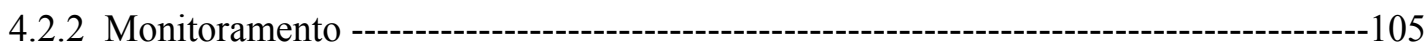

4.3 Recomendações Sócio-Econômicas --

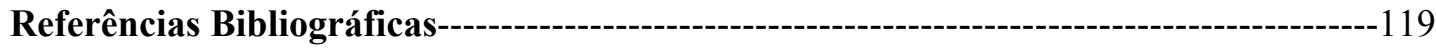

\section{ÍNDICE DE FIGURAS}

Figura 2.1 Localização das áreas de estudo, AC, Brasil.----------------------------------------10

Figura 2.2 Desenho esquemático das florestas de Baixio e de Terra Firme amostradas na estação chuvosa e seca no Vale do Rio Acre, AC.--------------------------12

Figura 2.3 Classes de tamanho de Euterpe precatoria . a e b - Plântulas; c e d - Jovem 1; e - Jovem 2; f-Adulto, com plântula e fruto. $-16$ 
Figura 2.4 Croqui dos transectos em áreas de Baixio e Terra Firme, AC (fora de escala). Transecto dividido em 20 parcelas de $500 \mathrm{~m}^{2}$ para contagem de adultos, 20 parcelas de $250 \mathrm{~m}^{2}$ para a contagem de jovens e 20 parcelas de $125 \mathrm{~m}^{2}$ para a contagem de plântulas.

Figura 2.5 Histogramas da estrutura populacional Euterpe precatoria amostradas nas Florestas de Baixio (1 ha) e de Terra Firme (1 ha) das Colocações Santa Maria (Seringal Porongaba, Município de Brasiléia) e Já Começa (Seringal Dois Irmãos, Município de Xapuri), AC. $-30$

Figura 2.6 Histogramas da estrutura populacional Euterpe precatoria amostradas nas Florestas de Baixio (1 ha) e de Terra Firme (1 ha) das Colocações São Pedro, Arraia, Limoeiro e Morada Nova (Seringal Caquetá - Município de Porto Acre), AC. 31

Figura 2.7 Densidade por hectare de indivíduos adultos de Euterpe precatoria amostrados nas colocações Santa Maria(SM), Arraia (AR), São Pedro (SP), Morada Nova (MN), Limoeiro (LI) e Já Começa (JC) no Vale do Rio Acre, AC. $-34$

Figura 2.8 Classes de diâmetro e Classes do número de folhas dos indivíduos Jovens 2 e Adultos de Euterpe precatoria na floresta de Baixio e de Terra Firme da Colocação S. Pedro - Seringal Caquetá, AC.

Figura 2.9 Distribuição espacial de Euterpe precatoria dividido em quatro classes de tamanho - Plântula, Jovem 1, Jovem 2 e Adulto - na floresta de Baixio e de Terra Firme da Colocação Já Começa - Seringal Dois Irmãos, AC.-------------41

Figura 2.10 Matriz de Transição (média na floresta de Baixio e de Terra Firme) feita a partir do gráfico do ciclo de vida de Euterpe precatoria no Seringal Caquetá, Colocação São Pedro, AC $-44$

Figura 2.11 Matriz de Transição (média da floresta de Baixio e de Terra Firme) feita a partir do gráfico do ciclo de vida de Euterpe precatoria do Seringal Dois Irmãos, Colocação Já Começa, AC. $-45$

Figura 2.12 Matriz de Transição feita a partir do gráfico do ciclo de vida de Euterpe precatoria na floresta de Baixio da Colocação São Pedro, Seringal Caquetá, AC. $-46$

Figura 2.13 Matriz de Transição feita a partir do gráfico do ciclo de vida de Euterpe precatoria na floresta de Terra Firme da Colocação São Pedro, Seringal Caquetá, AC 
Figura 2.14 Matriz de Transição média feita a partir do gráfico do ciclo de vida de Euterpe precatoria na floresta de Baixio do Colocação Já Começa, Seringal Dois Irmãos, AC.

Figura 2.15 Matriz de Transição feita a partir do gráfico do ciclo de vida de Euterpe precatoria na floresta de Terra Firme da Colocação Já Começa, Seringal Dois Irmãos, AC. $-49$

Figura 2.16 Resposta da taxa de crescimento populacional $(\lambda)$ de Euterpe precatoria para a redução do número de plântulas recrutadas anualmente. Floresta de Baixio, Floresta de Terra Firme e Média das duas florestas na Colocação São Pedro, Seringal Caquetá, AC. $-55$

Figura 2.17 Porcentagem média da abertura do dossel nas Florestas de Baixio e de Terra Firme das Colocações São Pedro (Seringal Caquetá) e Já Começa (Seringal Dois Irmãos), AC. $-58$

Figura 3.1 Colocações ativas do Seringal Caquetá, Município de Porto Acre, AC, habitadas por populações extrativistas (setembro de 1998). $-68$

Figura 3.2 Calendário anual da produção extrativista e dos roçados de subsistência no Seringal Caquetá, Município de Porto Acre, AC. ( $\mathrm{n}=10$ famílias). $-93$

Figura 4.1 Esquema do dossel sobre os indivíduos de Euterpe precatoria. (A) Açaí sob um dossel fechado (100 a 75\% de cobertura); (B) Açaí sob um dossel semi aberto (75 a 25\% de cobertura); (C) Açaí sob um dossel aberto (25 a 0\% de cobertura). 103

Figura 4.2 Diagrama do efeito da intensidade de colheita sobre a distribuição de classes de tamanho para ilustrar o processo de avaliações periódicas da regeneração.---110

\section{ÍNDICE DE TABELAS}

Tabela 2.1 Áreas de estudo e as localidades onde foi avaliado a estrutura das populações de Euterpe precatoria na floresta de Baixio e na floresta de Terra Firme no Vale do Rio Acre, AC. 15

Tabela 2.2 Áreas de estudo onde foram medidas a abertura do dossel nas florestas de Baixio e de Terra Firme, AC.

Tabela 2.3 Estatística descritiva do número de indivíduos por hectare de Euterpe precatoria divididos em 4 classes de tamanho nas florestas de Baixio e de Terra Firme amostrados na mesmas seis localidades no Vale do Rio Acre, AC, das figuras 1.5 e 1.6 . 
Tabela 2.4 Distância média encontrada entre os indivíduos de Euterpe precatoria na floresta de Baixio e de Terra Firme das Colocações Arraia, Limoeiro, São Pedro e Já Começa, AC.

Tabela 2.5 Proporção de plântulas : plântulas; Proporção de adultos : adultos; Proporção do total de indivíduos por hectare na Floresta de Baixio e de Terra Firme das colocações Santa Maria (Município de Brasiléia), Já Começa (Município de Xapuri), Arraia, Morada Nova, Limoeiro e São Pedro (Município de Porto Acre) no Vale do Rio Acre, AC. $-34$

Tabela 2.6 Distribuição espacial dos indivíduos de Euterpe precatoria em quatro classes de tamanho, calculada a partir do Índice de Morisitia (IdM) e do Índice de Morisitia padronizado (IdMp).

Tabela 2.7 Média de indivíduos/ha de Euterpe precatoria divididos em 4 classes de tamanho e as respectivas taxas de sobrevivência, mortalidade, recrutamento para a próxima classe de tamanho e número de novos recrutas por adulto na floresta da Colocação São Pedro, Seringal Caquetá, AC. 43

Tabela 2.8 Média de indivíduos/ha de Euterpe precatoria divididos em 4 classes de tamanho e as respectivas taxas de sobrevivência, mortalidade, transição para a próxima classe de tamanho e número de novos recrutas por adulto na floresta do Seringal Dois Irmãos, Colocação Já Começa, AC. $-44$

Tabela 2.9 Número de indivíduos/ha de Euterpe precatoria divididos em 4 classes de tamanho e as respectivas taxas de sobrevivência, mortalidade, transição para a próxima classe de tamanho e número de novos recrutas por adulto na floresta de Baixio da Colocação São Pedro, Seringal Caquetá, AC. $-46$

Tabela 2.10 Número de indivíduos/ha de Euterpe precatoria divididos em 4 classes e as respectivas taxas de sobrevivência, mortalidade, transição para a próxima classe de tamanho e número de novos recrutas por adulto na floresta de Terra Firme do Seringal Caquetá, Colocação São Pedro, AC.

Tabela 2.11 Número de indivíduos/ha de Euterpe precatoria divididos em 4 classes de tamanho e as respectivas taxas de sobrevivência, mortalidade, transição para a próxima classe de tamanho e número de novos recrutas por adulto na floresta de Baixio do Seringal Dois Irmãos, Colocação Já Começa, AC.------------------48

Tabela 2.12 Número de indivíduos/ha de Euterpe precatoria divididos em 4 classes de tamanho e as respectivas taxas de sobrevivência, mortalidade, transição para a próxima classe de tamanho e número de novos recrutas por adulto na floresta de Terra Firme do Seringal Dois Irmãos, Colocação Já Começa, AC. $-49$ 
Tabela 2.13 Taxa finita de crescimento $(\lambda)$ de algumas populações de palmeiras. $-50$

Tabela 2.14 Sensibilidade da taxa de crescimento populacional $(\lambda)$ em porcentagem às mudanças nas probabilidades de sobreviver e permanecer na mesma classe de plântulas $(\mathrm{P} 1,1)$, jovem $1(\mathrm{P} 2,2)$, jovem $2(\mathrm{P} 3,3)$ e adulto $(\mathrm{P} 4,4)$; sobreviver e passar para a classe de tamanho seguinte de plântulas (G1,2), jovem 1 (G2,3) e jovem $2(\mathrm{G} 3,4)$ e da fecundidade encontradas para E. precatoria nas Florestas de Baixio e de Terra Firme e uma média dos dois tipos florestais nas Colocações São Pedro (Seringal Caquetá) e Já Começa (Seringal Dois Irmãos), AC. $-53$

Tabela 2.15 Produção de Euterpe precatoria na Floresta de Terra Firme da Colocação São Pedro, AC. Junho de $1999(\mathrm{n}=15)$ $-60$

Tabela 2.16 Produção de frutos de Euterpe precatoria na Floresta de Terra Firme da Colocação S. Pedro, AC. Junho de $2000(n=10)$. $-60$

Tabela 2.17 Produção de frutos de Euterpe precatoria na Floresta de Baixio da Colocação S. Pedro, AC. Junho de $2000(\mathrm{n}=10)$.

Tabela 2.18 Estimativa do potencial produtivo de Euterpe precatoria das florestas de Baixio e de Terra Firme do Seringal Caquetá, AC.

Tabela 3.1 Questionário aplicado em 10 pessoas no Seringal Caquetá, AC, para a caracterização sócio-econômica dos sistemas de produção dos principais produtos florestais não madeireiros, castanha e borracha. Julho de 2000. 70

Tabela 3.2 Colocação onde mora, idade, número de pessoas na família, tempo que mora no local, área (ha) utilizada por família, número de pessoas na família que trabalham fora de casa, dos seringueiros entrevistados, AC. $-75$

Tabela 3.3 Caracterização econômica da produção borracha $(n=10)$ no Seringal Caquetá, AC. $-78$

Tabela 3.4 Caracterização econômica da produção de castanha $(n=10)$ no Seringal Caquetá, AC. $-79$

Tabela 3.5 Produção agrícola de subsistência de 1999 de 9 famílias Extrativistas do Seringal Caquetá, AC. Área plantada $\left(\mathrm{m}^{2}\right)$, quantidade colhida $(\mathrm{kg})$ e preço de venda (R\$) do Arroz, Feijão, Farinha e Milho, principais produtos de subsistência cultivados no estado do Acre. $-90$

Tabela 3.6 Questionário aplicado em representantes de 9 famílias do Seringal Caquetá, AC, para o levantamento de informações sobre a diária local de trabalho. $-92$ 
Tabela 3.7 Custo benefício da produção de açaí, castanha e borracha e do trabalho remunerado de 1 dia (8 horas) no Seringal Caquetá, AC, considerando os dados das tabelas 2.3, 2.4, 2.6 e os cálculos do potencial produtivo do Açaí. $-95$

Tabela 4.1 Nível de extração recomendada em termos de parâmetros demográficos; precaução (reserva para a fauna) e proposta por hectare de floresta de Baixio e de Terra Firme da Colocação São Pedro, Seringal Caquetá, AC. Julho de 2000.-

Tabela 4.2 Custo (R\$)de mão de obra e materiais por área de manejo por ano e durante o período de cinco anos para fazer o inventário e realizar o manejo de Açaí.---111

\section{ÍNDICE DE QUADROS}

Quadro 3.1 Questionário feito para a caracterização de 10 pessoas e das suas áreas no Seringal Caquetá, AC. Julho de 2000.

Quadro 3.2 Questionário feito com 10 pessoas para o levantamento da produção agrícola e pecuária de subsistência no Seringal Caquetá, AC 71

Quadro 3.3 Questionário da análise qualitativa da produção florestal de subsistência das famílias extrativistas do Seringal Caquetá, AC

Quadro 3.4 Questionário feito com 15 pessoas que representam 10 famílias para o levantamento da diária local de trabalho e de outras fontes de renda no Seringal Caquetá, AC. Julho de 2000. $-72$

\section{ÍNDICE DE FOTOS}

Foto 2.1 Euterpe precatoria Mart. $-14$

Foto 2.2 Cacho de frutos de Euterpe precatoria Mart. $-14$

Foto 2.3 Inventário Florestal na floresta de Baixio, Seringal Caquetá, AC.-------------------18

Foto 2.4 Inventário Florestal na floresta de Terra Firme, Seringal Caquetá, AC.------- -----18

Foto 3.1 Coletor de Açaí, Seringal Caquetá, AC, 1998.--------------------------------------85

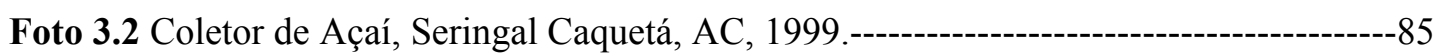

Foto 3.3 Debulhadores de frutos de Açaí, Seringal Caquetá, AC, 1998.------------------86

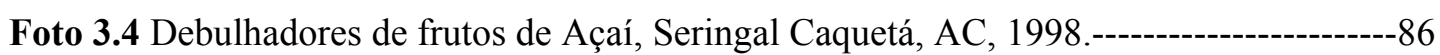

Foto 3.5 Transporte do Açaí da Floresta à casa, Seringal Caquetá, AC, 1999.----------------87

Foto 3.6 Transporte do Açaí do Seringal até os pontos de comercialização feito nas costas de boi, Seringal Caquetá, AC, 1999. $-87$ 


\section{Aspectos ecológicos e sócio-econômicos do manejo de Euterpe precatoria Mart. (Açaí) em áreas extrativistas no Acre, Brasil.}

Autora: Elektra Rocha

Orientador: Dr. Virgílio Maurício Viana

\section{RESUMO}

Os seringueiros localizados dentro de reservas e assentamentos extrativistas no Estado do Acre, Amazônia Ocidental, Brasil, possuem como meio econômico o extrativismo da borracha e da castanha e pretendem diversificar a produção com outros recursos florestais que complementem a renda a curto prazo, respeitando ao mesmo tempo os seus modos tradicionais de vida e a diversidade biológica. O conceito do manejo dos frutos de Euterpe precatoria (Açaí) engloba aspectos sociais, econômicos e ecológicos concernentes a floresta. Este estudo fez uma análise do potencial ecológico e sócio econômico da extração de frutos do Açaí em áreas da Reserva Extrativista Chico Mendes e do Seringal Caquetá, Acre, para responder: (1) E. precatoria possui características populacionais como grande produção de frutos, alta densidade e regeneração natural, estrutura e estabilidade populacional que podem favorecer o seu manejo sustentável? (2) Qual é a estimativa da colheita sustentável para áreas de florestas no Caquetá? (3) Qual a forma de organização comunitária para a produção de Açaí? (4) Qual é a rentabilidade do manejo dos frutos no Seringal Caquetá? (5) Quais as práticas necessárias para o bom manejo do recurso? No levantamento do potencial ecológico foram avaliados a densidade, estrutura populacional, potencial produtivo, dinâmica e estabilidade populacional em florestas inundadas e de Terra Firme. Através de um modelo de matriz foi feita a simulação da quantidade de frutos que podem ser retirados da floresta sem alterar a densidade atual da população. No levantamento sócio-econômico foram avaliados a forma de organização comunitária e a rentabilidade obtida com o manejo do Açaí, da castanha e da borracha e com a diária local de trabalho. E. precatoria apresentou um alto potencial de manejo devido a sua alta densidade, estrutura populacional em forma de $\mathrm{J}$ invertido, alta freqüência, alta produção de frutos e estabilidade populacional de crescente a estável. A simulação da colheita de frutos na floresta de Baixio mostrou que a manutenção de $50 \%$ do recrutamento inicial é necessária para manter a estabilidade da população, isto é, a cada duas palmeiras, coleta-se frutos em apenas uma. $\mathrm{Na}$ Terra Firme é necessário a manutenção de $25 \%$ do recrutamento inicial, ou a cada quatro palmeiras coleta-se frutos em três. A organização comunitária em mutirão ou estrutura familiar deve se adequar de acordo com a disponibilidade de recursos para a atividade produtiva das diferentes famílias, tais como, mão de obra, animais de carga e mercados. A remuneração que a comunidade do Caquetá pode conseguir com a comercialização do Açaí foi maior que a conseguida com a borracha ou com diária local. Com a castanha a renda do Açaí foi similar, mas poderia ser maior, caso tivesse o mesmo subsídio para o transporte.

Palavras-chave : Floresta Tropical; Amazônia Ocidental; Euterpe precatoria; Manejo; Reserva Extrativista; Seringueiros; Sustentabilidade. 


\title{
Ecological and socioeconomic aspects of the management of Euterpe precatoria Mart. (Açaí) in extractive areas in Acre, Brazil.
}

\begin{abstract}
Rubber tappers in extractive reserves and settlements in Acre State, Western Amazonia, Brazil, live from rubber and brazil nuts extraction and recently started to be interested in diversification of their production with other forest resources that could complement their annual income in the short term, while at the same time preserving their traditional way of life and also biodiversity. The concept of fruit management of Euterpe precatoria (Açaí) encompasses social, economic and ecological aspects related to the forest. This study analyzes the social, economic and ecological potential of fruit extraction of Açaí in areas of the Extractive Reserve Chico Mendes and the Seringal Caquetá, Acre State to answer some questions: (1) Does E. precatoria have populational characteristics such as great production of fruits, high natural density and regeneration, population structure and stability that allow its sustainable management? (2) What is the estimate for sustainable harvest in forested areas in Caquetá? (3) What is the community organization for Açaí production? (4) What is the fruit management profitability in Seringal Caquetá?(5) What are the right practice for a good resource management? For the inventory of ecological potential, we evaluated density, population structure, production potential, population dynamics and stability in seasonal flooded and upland forests. A matrix model was applied to simulate the amount of fruits that could be harvested from the forest without altering the current population density. In the social and economic inventory we evaluated the way the community is organized to work and the profitability achieved with the Açaí, rubber and Brazil nut management, and each product profit per year. E. precatoria showed a very high management potential due to its high density, population structure in a inverted $\mathrm{J}$ shaped, high frequency, high fruit production and a increasing to stable population stability. The simulation of fruit harvest in the seasonal flooded forest showed that the maintenance of $50 \%$ of the initial recruitment is necessary for the stability of the population, therefore from each two palms only one should be harvested for a sound sustainable management. In upland forest the initial recruitment must be $25 \%$, or from each four palms, three could be harvested. The community organization in a structural family must adapt to the productive system of each family, such as labor, animals for transportation and market availability. The profit that the Caquetá's community can achieve with the commercialization of Açaí was greater than the achieved with rubber and other economic activities. The Açai profit is similar to Brazil nuts extraction, but could be higher if it had the same transportation subsidies that the nut receives.
\end{abstract}

Keywords: Euterpe precatoria, tropical forest, Western Amazonia, management, extractive reserve, rubber tappers, sustainability. 


\section{CAPÍTULO 1}

\section{INTRODUÇÃO}

A ocupação do Acre foi determinada pelo extrativismo da borracha durante a segunda metade do século XIX, quando um acréscimo na sua produção foi necessário devido ao aumento da demanda do produto nos Estados Unidos e Europa. Para viabilizar a demanda da produção de borracha houve uma migração de pessoas do Nordeste para o Acre e também para outras partes da Amazônia (Sobrinho, 1992; Rueda, 1995).

O sistema de produção da borracha e sua organização social eram constituídos pelas casas aviadoras, diretamente ligadas ao capital externo, que tinham como objetivo comprar a borracha dos seringais ${ }^{1}$, e abastecê-los com alimentos e gêneros de consumo para o seringueiro ${ }^{2}$; pelos seringalistas - proprietários que exerciam controle geral da atividade extrativista da borracha, ditavam as leis, e aprisionavam o seringueiro devido à dívidas forjadas pelo sistema de aviamento ${ }^{3}$; pelos trabalhadores que prestavam serviços diretos aos seringalistas, como por exemplo: os jagunços, os gerentes dos armazens, os tratoristas e; pelos seringueiros, que sustentavam todo o sistema trabalhando na extração e preparo da borracha. (Sobrinho, 1992).

A partir de 1912 deu-se o primeiro colapso da borracha devido a concorrência com a Malásia, provocando a falência de casas aviadoras na Amazônia. A queda do preço da borracha incentivou a prática da agricultura de subsistência, proibida até então para as famílias de seringueiros que permaneceram nos seringais. Por outro lado, também provocou o êxodo rural de muitas famílias, iniciando o processo de urbanização de cidades como Rio Branco. O segundo colapso deu-se após a Segunda Guerra Mundial, quando a compra da borracha voltou-se novamente para os seringais de cultivos na Malásia e todos os contratos de comércio foram cancelados (Pinto, 1984; Sobrinho 1992). Atualmente os governos estadual e federal têm

\footnotetext{
${ }^{1}$ Seringal : Unidade de produção da borracha no Estado do Acre. Lugar onde há uma quantidade considerável de seringueiras dispostas proximamente entre si.

2 Índivíduo que dedica-se à extração do latex da seringueira e com ele prepara a borracha.

${ }^{3}$ Sistema econômico caracterizado pelo adiantamento ao cliente, o extrativista, de produtos manufaturados em troca de uma certa quantidade de produtos da floresta.
} 
mantido uma política de incentivos para a extração da borracha que passou por várias crises.

Nas décadas de 60-70 o governo federal criou programas que visavam a integração nacional da Amazônia e o Centro-Sul do país. Nesta ocasião, houve a construção de estradas e o assentamento de migrantes, em projetos de colonização, associada a uma política fiscal com incentivos para que grandes proprietários de terras ocupassem a Amazônia. Esta ocupação deu-se sem levar em consideração as populações humanas tradicionais da floresta que já ocupavam estas terras, acarretando em grandes lutas fundiárias entre os novos proprietários e os seringueiros que já residiam no local (Zee, 2001; Sobrinho, 1992).

Como alternativa econômica para a borracha, houve a implementação da extração predatória de madeira e da pecuária extensiva em grande escala, ocasionando a substituição dos antigos seringais por áreas de pastagens, modificando assim, grandemente o tipo de uso do solo. Como resistência a esta política no Acre houve a criação dos Sindicatos de Trabalhadores Rurais de Brasiléia e depois de Xapuri, que então articularam algumas estratégias de luta fundiária como por exemplo os empates ${ }^{4}$. A utilização do empate dos desmatamentos trouxe amadurecimento político e de organização social aos extrativistas, porque os seringueiros passaram a se organizar para a tomada de decisões. Isto acarretou no fortalecimento dos sindicados e o surgimento da concessão de uso coletivo da terra resultando na formação das Reservas Extrativistas (Allegretti, 1990).

O movimento para o estabelecimento de Reservas e Assentamentos extrativistas no Acre é uma das alternativas para o uso sustentável dos recursos naturais na Amazônia (Rueda, 1995; Fearnside, 1989 ). Estas áreas são administradas por famílias extrativistas que retém o direito de uso dos recursos em seus territórios tradicionais denominados colocações. Com exceção do desmatamento de pequenas áreas para a agricultura de subsistência, a terra não pode ser vendida ou transformada em usos não florestais(Governo do Brasil, 1994; Fearnside, 1989). São exemplos a

\footnotetext{
${ }^{4}$ Os seringueiros e suas famílias saíam em grandes grupos para a floresta para impedir que as máquinas e jagunços dos fazendeiros desmatassem as colocações. Colocação é o termo utilizado na região para designar a área dentro da floresta ocupada por uma família.
} 
Reserva Extrativista Chico Mendes em Xapuri e Brasiléia e o Assentamento Agroextrativista de Porto Alonso, Porto Acre.

Uma vez criadas as Reservas e Assentamentos Extrativistas, e portanto, feito a regularização fundiária, o desafio atual é aumentar a produtividade destas áreas obtendo a sustentabilidade dos sistemas de produção (Viana, et. al. 1998), respeitando ao mesmo tempo os modos tradicionais de vida das populações (Diegues, 2000) e a diversidade biológica.

O manejo de produtos florestais não madeireiros feito pelos moradores de áreas extrativistas pode ser uma forma de aumentar a produtividade destas áreas de florestas e um meio de melhorar a economia rural através da complementação da renda. Esta é uma forma de conter o desmatamento crescente nas florestas tropicais, e consequentemente, conservar a biodiversidade.

O extrativismo é uma atividade econômica histórica importante na Amazônia e os extrativistas sabem que as florestas são capazes de gerar mais renda e emprego que as mesmas áreas cortadas para pastagem ou técnicas de agricultura moderna. Desta forma, melhorar a eficiência e eqüidade social do extrativismo deveria ser um objetivo de desenvolvimento na região (i.e. Clay 1992, Clay \& Clement 1993, Fearnside 1989, Peters, et. al. 1989), apesar de haver muito debate sobre o assunto e idéias contrárias a esta (i.e. Homma 2000).

O valor relativo do extrativismo atual e melhorado ou do "bom manejo florestal" ${ }^{, 5}$ deve ser analisado no contexto dos custos econômicos a longo prazo dos vários tipos de degradação ambiental, associados com programas de desenvolvimento mais convencionais na Amazônia. Entre estas estão: a poluição da água, a diminuição da fertilidade do solo, o abandono eventual de áreas usadas para a agricultura e pastagens, o aumento em malária e outras doenças associadas com a mineração e colonização, a perda de biodiversidade, a emissão de carbono para atmosfera. Se estes impactos forem tratados como componentes do custo de produção, as alternativas de desenvolvimento convencionais devem ser vistas como anti-econômicas na Amazônia. O reconhecimento destes impactos ao longo prazo

\footnotetext{
5 “....as melhores práticas de gestão aplicáveis para uma determinada unidade de manejo florestal, considerandose suas características e condicionantes socio-culturais, ambientais e econômicas e o conhecimento técnico e científico existente"(Viana, comunicação pessoal 2001).
} 
reforçam o argumento a favor do extrativismo com manejo de florestas (Clay \& Clemet, 1993).

Em 1990 o valor de exportação de produtos florestais não madeireiros foi de U\$11 milhões para o Peru, U\$14 milhões para o Equador, U\$22 milhões para a Bolívia e U\$52 milhões para o Brasil (Broekhoven 1995, citado por Ros-Tonen, et al.,1995). Os frutos de Euterpe precatoria (Açaí) são um produto florestal não madeireiro que pode ser chave para fazer parte da diversificação da produção florestal de algumas comunidades extrativistas no Estado do Acre. Primeiro porque estes são coletados e utilizados pelos seringueiros desde a expansão da borracha, sendo portanto uma espécie conhecida; segundo, porque possuem grande potencial econômico (Kanh et al., 1993) e valores agregados nos mercados locais e regionais; e atualmente nacional (Alho, 1999).

Como na maioria das vezes os produtos extrativistas como por exemplo os frutos de Açaí, não são estimados adequadamente no modelo econômico, ou são ignorados, são poucos estudos que geram modelos práticos para o manejo e a comercialização destes produtos. Se a manutenção da floresta e das populações humanas no Acre depende da utilização desta floresta, através da diversificação da produção, deve haver uma preocupação com a produtividade presente e futura do recurso que estiver sendo extraído.

Considerando-se que o manejo dos frutos do Açaí engloba aspectos sociais, econômicos e ecológicos concernentes à floresta e este é um recurso chave para fazer parte da diversificação florestal de muitas famílias no estado, o presente trabalho se propõe a responder as seguintes questões:

1. Euterpe precatoria possui características populacionais como grande produção de frutos, alta densidade, alta regeneração natural, estrutura e estabilidade populacional que podem favorecer o seu manejo sustentável ${ }^{6}$ ?

2. Qual é a estimativa da colheita sustentável para áreas de florestas no Caquetá ?

3. Qual a forma de organização comunitária para a produção de Açaí adotada no Caquetá ?

4. Qual é a rentabilidade do manejo de frutos de Açaí no Seringal Caquetá?

\footnotetext{
${ }^{6}$ Manejo sustentável : aquele que garante a continuidade da produção e a manutenção das funções dos ecossistemas.
} 
Para responder estas questões este estudo fez uma análise do potencial ecológico e sócio econômico da extração de frutos de Euterpe precatoria em áreas da Reserva Extrativista Chico Mendes e do Seringal Caquetá, Acre.

No capítulo 2 foram avaliados os aspectos ecológicos para populações de $E$. precatoria tais como densidade, distribuição, estrutura e estabilidade populacionais, produção de frutos, em florestas de Baixio e de Terra Firme ${ }^{7}$. Estas informações são importantes para quantificar o recurso que pode ser extraído, a rentabilidade da produção e também a sua reposição. Além disso é possível, com estes dados, analisar se a intensidade da extração dos frutos é sustentável. A partir destas informações temos alguns parâmetros para avaliar o potencial ecológico de manejo (Peters,1996) e também para a elaboração de práticas de manejo da espécie.

No Capítulo 3 foram avaliados os aspectos sócio-econômicos tais como a organização comunitária e a rentabilidade do manejo de E. precatoria, e de outros produtos como a borracha e castanha na comunidade do Seringal Caquetá. A rentabilidade do manejo do Açaí foi comparada com a da castanha e borracha e com a diária local de trabalho. Assim foi possível ter uma indicação do investimento exigido para o manejo da espécie (Peters, 1996) e também saber se o manejo e comercialização dos frutos podem garantir um retorno sócio-econômico em relação aos investimentos efetuados.

No capítulo 4 foram feitas algumas recomendações ecológicas e socioeconômicas para o manejo das populações de E. precatoria no Seringal Caquetá. Estas recomendações visam ser úteis e servir como base de um modelo para alcançar a sustentabilidade do manejo do Açaí para as diferentes famílias no Seringal Caquetá. O manejo inclui a jardinagem e o monitoramento que têm como objetivo favorecer a produtividade e avaliar o aproveitamento em relação aos graus variados de extração (Peters; 1990; 1991; 1996) respectivamente de E. precatoria em áreas de florestas. As recomendações sócio-econômicas incluem a forma de organização comunitária, a rentabilidade e as demandas da comunidade do Seringal Caquetá para tornar o Açaí mais um produto a fazer parte da diversificação da produção florestal.

\footnotetext{
${ }^{7}$ As tipologias florestais Baixio e Terra firme serão definidas no item Material e Métodos.
} 


\section{CAPÍtULLO 2}

\section{ECOLOGIA POPULACIONAL DE Euterpe precatoria MART. (AÇAÍ)}

\subsection{INTRODUÇÃO}

O Estado do Acre possui atualmente 91\% de cobertura de vegetação nativa (INPE 2001), em sua maioria florestas, habitadas por populações tradicionais. Muitas famílias de seringueiros localizadas dentro de Reservas e Assentamentos Extrativistas no Estado possuem como meio econômico o extrativismo da borracha e castanha, e pretendem diversificar a produção com outros produtos florestais não madeireiros para a complementação da renda a curto prazo.

Euterpe precatoria (Açaí) fornece a polpa, extraída dos frutos, que pode ser um recurso chave para a diversificação florestal de algumas comunidades extrativistas. Primeiro porque os frutos são coletados e utilizados pelos seringueiros desde a expansão da borracha (Fearnside, 1992) e segundo porque possuem grande potencial econômico (Kahn et al., 1993), e valores econômicos agregados nos mercados locais e regionais; e mais recentemente nacional (Alho, 1999).

Além do potencial sócio-econômico, Euterpe precatoria possui características ecológicas favoráveis ao seu manejo sustentável? Qual é o potencial produtivo de florestas de Baixio e Terra firme? Qual a quantidade de frutos que pode ser retirada de uma população sem causar alteração na estrutura ou na estabilidade da população?

Considerando-se que o potencial de manejo de vários produtos florestais não madeireiros é baseado em suas características botânicas, ciclo de vida, produtividade e estrutura populacional, foi feito um levantamento da densidade, distribuição dos indivíduos em diferentes tipos florestais, estrutura populacional, dinâmica e produção de frutos de Euterpe precatoria.

O levantamento da densidade e produção foram feitos para conhecer a quantidade de recurso disponível nas áreas de florestas naturais das colocações ou o potencial produtivo destas áreas. Espécies de alta densidade e reprodução são mais facilmente manejadas que espécies de baixas densidades. 
Estes parâmetros, quando avaliados em tipos florestais distintos, podem informar em qual tipologia o recurso é mais abundante. Um recurso pode ser abundante em um tipo de floresta e estar ausente ou em menor quantidade em outro.

A estrutura populacional fornece informações sobre o comportamento da espécie, como por exemplo, se ela está regenerando in situ ou não, se o recrutamento é contínuo ou descontínuo e portanto fornece informações sobre a reposição do recurso. A realização deste estudo ao longo do tempo em áreas de extração permite o monitoramento do impacto da extração de alguns recursos não madeireiros (Peters,1996 e 1995). Práticas deste tipo são necessárias caso a preocupação ao manejar um recurso florestal não seja apenas com a colheita presente, mas também com a produtividade futura.

A análise da dinâmica populacional permite inferir se o produto florestal coletado vem de populações crescentes, estáveis ou decrescentes (Peters, 1995). Estas informações são importantes ferramentas na elaboração de boas práticas de manejo da espécie e também para avaliar o potencial ecológico de manejo.

Estas características ecológicas de Euterpe precatoria são indicativos do potencial ecológico de manejo e permitem avaliar se a espécie possui um potencial baixo, médio ou alto para o manejo sustentável (Peters, 1996).

O monitoramento e a avaliação destas características ao longo do tempo é uma forma de obter indicativos da dinâmica de população que sugiram a estabilidade da população da palmeira e continuidade de rendimento de frutos em relação aos impactos ecológicos pelo uso humano (Peters, 1991).

Os objetivos deste capítulo foram:

(1) Conhecer a densidade de Euterpe precatoria (Açaí) em florestas de Terra Firme e Baixio e em Colocações no Vale do Rio Acre;

(2) Determinar a distribuição da população em classes de tamanho em condições de Baixio e Terra Firme no Vale do Rio Acre;

(3) Estimar a estabilidade das populações de Euterpe precatoria nas áreas estudadas e simular a colheita sustentável de frutos;

(4) Estimar o potencial produtivo dos frutos do Açaí em florestas de Baixio e Terra Firme do Seringal Caquetá. 


\subsection{MATERIAL E MÉTODOS}

\subsection{1 ÁREAS DE ESTUDO}

Este estudo foi conduzido em duas regiões distintas do Vale do Rio Acre, na Reserva Extrativista Chico Mendes e no Seringal Caquetá, Acre.

2.2.1.1 Reserva Extrativista Chico Mendes - Seringal Dois Irmãos, Colocação Já Começa, Município de Xapuri; Seringal Porongaba, Colocação Santa Maria, Município de Brasiléia-AC (Figura 1A);

A Reserva Extrativista Chico Mendes, estabelecida em março de 1990, fica entre os paralelos $10^{\circ} 05^{\prime} 41^{\prime \prime} \mathrm{S}$ e os meridianos $67^{\circ} 56^{\prime} 10^{\prime \prime}$ WGR e $69^{\circ} 48^{\prime} 22^{\prime}$ " WGR; está localizada no estado do Acre entre os municípios de Assis Brasil, Brasiléia, Xapuri, Sena Madureira e Rio Branco, dentro de uma área de 971 mil hectares. O acesso é através da estrada BR-317 que passa praticamente ao redor da área da Reserva a sudeste, ou através do Rio Acre e Rio Xapuri e seus afluentes no período chuvoso. Outro possível acesso é pelo rio Iaco e Macau e os seus afluentes na parte oriental da Reserva, no município de Sena Madureira, (Feitosa, 1995).

$\mathrm{O}$ clima é quente e úmido, com uma temperatura média anual de $26^{\circ} \mathrm{C}$. $\mathrm{O}$ período mais quente acontece em setembro, outubro e novembro, com médias máximas, de $38^{\circ} \mathrm{C}$, e o período mais frio é em junho, julho e agosto, com médias mínimas de $20^{\circ} \mathrm{C}$. A pluviosidade média anual é $2.200 \mathrm{~mm}$. O período mais chuvoso são os meses de janeiro, fevereiro e março, somando $800 \mathrm{~mm}$. O período mais seco é registrado em junho, julho e agosto, com uma média cumulativa de até $150 \mathrm{~mm}$ (Feitosa, 1995). 
O relevo da área é do tipo planalto baixo amazônico ocidental com a depressão do Rio Acre caracterizando uma plataforma regular sem formações de rochas como montanhas ou colinas. A altitude varia entre 100 e $200 \mathrm{~m}$ (Feitosa, 1995).

Os tipos principais de solos que acorrem no estado do Acre são: Eutrófico Podzolico Amarelo Vermelho, Álico Podzolico Vermelho, Cambissolo Eutrófico, Cambissolo Distrófico, Gley Hidromórfico Distrófico, Gley Hidromórfico Eutrófico, Latossolo Distrófico Amarelo Vermelho (Radam Brasil, 1976).

2.2.1.2 Seringal Caquetá - Assentamento Agroextrativista de Porto Alonso nas Colocações São Pedro, Arraia, Limoeiro e Morada Nova, Município de Porto Acre AC (Figura $1 \mathrm{~B})$.

O Seringal Caquetá fica entre os paralelos $09^{\circ} 33^{\prime} 50^{\prime}$ S e os meridianos $67^{\circ}$ 19' 40" WGR e 67 32' 20" WGR no estado do Acre no município de Porto Acre, dentro de uma área de 28.686 hectares. O acesso é através da estrada BR-317, rodovia AC 22 e através do rio Acre e seus afluentes, no período chuvoso (INCRA, 1997).

O clima é quente e úmido, com uma temperatura anual que varia de 22 a $26^{\circ} \mathrm{C}$. O período mais quente acontece entre os meses de Agosto a Outubro, com médias máximas, de $31^{\circ} \mathrm{C}$, e o período mais frio é em junho, julho e agosto, com médias mínimas de $20^{\circ} \mathrm{C}$. A pluviosidade média anual é $1973 \mathrm{~mm}$. O período mais chuvoso são os meses de janeiro, fevereiro e março. O período mais seco é registrado de junho a agosto (Estação meteorológica da UFAC, citado pelo INCRA, 1996).

O relevo da área é do tipo planalto baixo amazônico ocidental com a depressão do Rio Acre caracterizando uma plataforma regular sem formações de rochas como montanhas ou colinas. A altitude varia entre 100 e $200 \mathrm{~m}$. Os tipos de solos existentes no Seringal Caquetá são Gley Humico Hidromórfico Eutrófico, Podzólico Vermelho Amarelo Álico-Plintico, Cambissolo Álico, Podzólico Vermelho Amarelo Álico e Podzólico Vermelho Amarelo Álico Abriptico (Radam Brasil, 1976). 


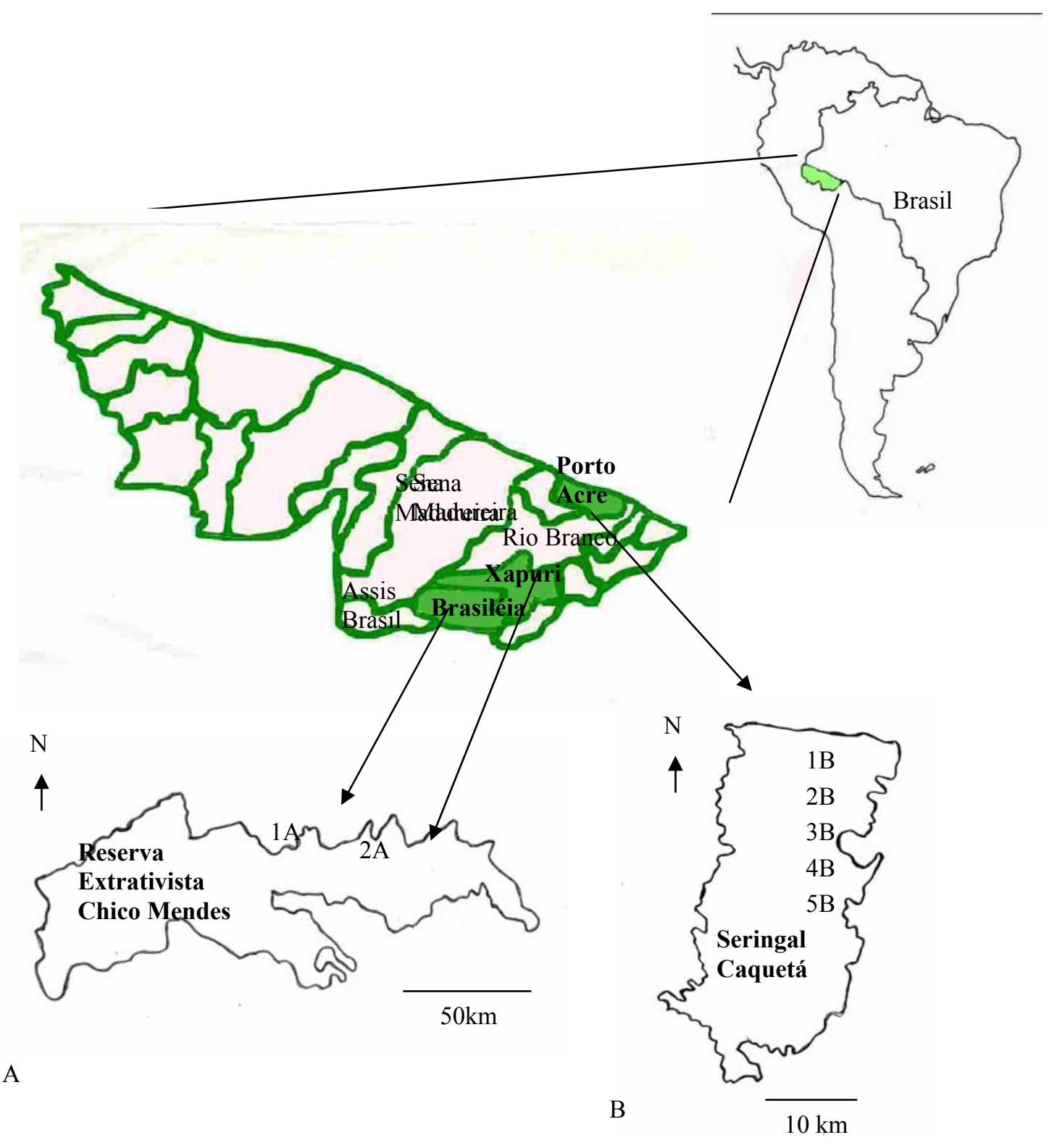

Figura 2.1 Localização das áreas de estudo, Acre, Brasil. 1A Seringal Porongaba, Colocação Santa Maria; 2A Seringal Dois Irmãos, Colocação Já Começa na Reserva Extrativista Chico Mendes. Seringal Caquetá, 1B Colocação Floresta; 2B Colocação Morada Nova; 3B Colocação Arraia; 4B Colocação São Pedro; 5B Colocação Limoeiro. 
A vegetação que recobre as áreas de estudo é a floresta Ombrófila Aberta das Terras Baixas com Cipó, Bambu ou Palmeira, enserida dentro de um bioclima de 30 a 90 dias secos (Veloso et. al.,1991; IBGE, 1998). Em todas as colocações deste estudo pode-se reconhecer tipologias florestais distintas, entre elas, as florestas chamadas de Baixio e de Terra Firme.

Os Baixios são definidos aqui como florestas que inundam sazonalmente no período de Novembro - Março e/ou que sofrem influência direta dos igarapés. Estas florestas, devido a topografia possuem um lençol freático mais superficial, que em épocas chuvosas, aflora e inunda estas áreas. Apresentam um dossel mais aberto, em relação as florestas de Terra Firme (Lamotte, 1990), pela predominância de palmeiras arborescentes tais como Mauritia flexuosa, (Goulding, 1985), Oenocarpus bataua e uma grande abundância de palmeiras de subosque. O período de inundação das florestas de Baixio nas áreas de estudo duram de 4 a 5 meses por ano.

As florestas de Terra Firme cobrem planaltos e rampas de vale e são áreas com dossel mais fechado, subosque "limpo", com solos bem drenados em qualquer época do ano, e que não inundam através dos rios e fluxos pequenos de água (Figura 2.2). Estas florestas são dominadas por árvores grandes e caracterizam-se por uma estrutura vertical bem desenvolvida e uma diversidade de espécies arbóreas muito alta (Prance et. al., 1976) em relação às florestas sazonalmente inundadas (Kahn \& de Granville, 1992). As palmeiras são um componente estrutural importante dos ecossistemas de floresta, dominando o subosque da maioria das florestas de Terra Firme, como também o dossel de florestas inundadas periodicamente (Kanh \& De Granville, 1992).

Todas as áreas estudadas estão localizadas na Bacia do Vale do Rio Acre (Tabela 2.1). 


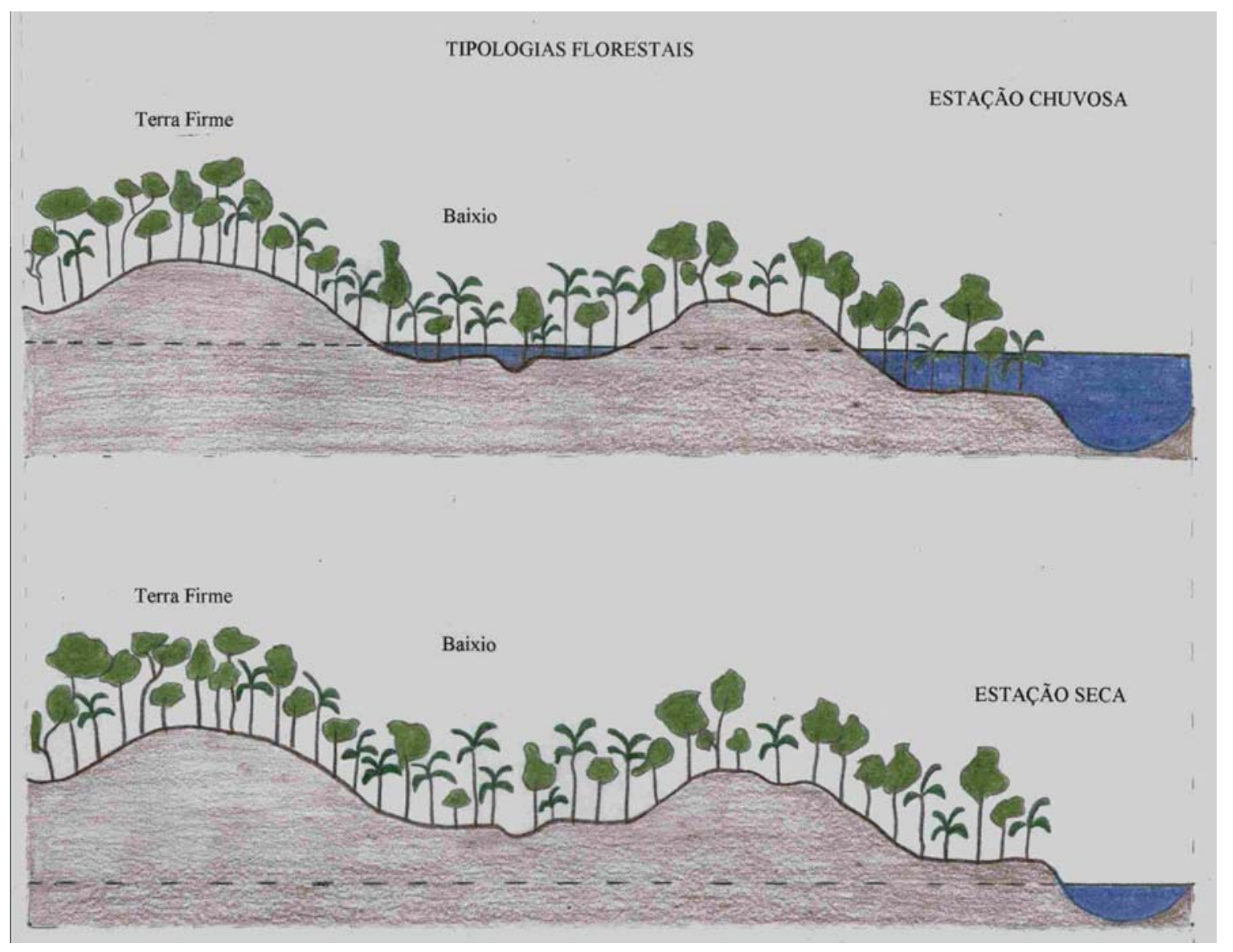

Figura 2.2. Desenho esquemático das florestas de Baixio e de Terra Firme na estação chuvosa e seca no Vale do Rio Acre, AC.

\subsubsection{DESCRIÇÃO DA ESPÉCIE}

Euterpe precatoria Mart. é uma palmeira neotropical de sub-dossel que possui um estipe único, cinza claro (Foto 2.1). A espécie é distribuída na América Central (Belize, Guatemala, Honduras, Nicaragua, Costa Rica e Panamá) e norte da América do Sul (Colômbia, Venezuela, Trinidad, Guianas, Equador, Peru, Brasil e Bolívia). No Brasil a palmeira ocorre nos estados amazônicos do Acre, Amazonas, Rondônia, Pará (Henderson et. al. 1995).

Euterpe precatoria ocorre em vários habitats, em terrenos alagados e também em terras não alagadas. Ela pode ser comum na várzea, mas também ocorre em rampas andinas íngremes a $2000 \mathrm{~m}$ de altitude (Kahn \&.Henderson, 1999). Na Bolívia a espécie é encontrada em florestas inundadas sazonalmente, em ilhas de 
floresta, em áreas de savana e floresta de Terra Firme (Moraes 1996; Pena-Claros \& Zuidema, 1999 citado por Zuidema \& Boot 2000).

Henderson et. al. (1995) e Kuchmeister et. al. (1997) trabalhando na Amazônia encontraram uma altura média de aproximadamente $20 \mathrm{~m}$ para $E$. precatoria.

O sistema radicular é muito grande e bastante superficial, podendo ser encontrado $80 \%$ do volume da raiz total nos primeiros $20 \mathrm{~cm}$ de solo. Euterpe precatoria forma raízes adventícias continuamente na base do estipe, nas quais formam um anel espesso, de raízes aéreas $(1.5 \mathrm{~cm})$ purpúreas que pode alcançar 80 $\mathrm{cm}$ do nível do solo. A presença de pneumatóforos na planta, que ajudam o sistema radicular a respirar em solos inundados, sugere que ela é bem adaptada a terrenos periodicamente inundados (Castro \& Bovi, 1993).

As inflorescências se desenvolvem da axila das folhas, depois da senescência da folha mais velha e são protegidas por envolturas denominadas ferófilos. São compostas de um raquis duro central aproximadamente com $56 \mathrm{~cm}$ de comprimento, com uma média de 54 ráquilas (Castro \& Bovi, 1993). As inflorescências são bissexuais e tem flores tríades estaminadas e pistiladas que produzem néctar. Euterpe precatoria parece ser uma palmeira geralmente entomófila com um predominância de besouros e abelhas como polinizadores potenciais (Kuchmeister et. al., 1997)

Os frutos de Euterpe precatoria são globosos (Foto 2.2), medem de 0.9 a 1.3 centímetros em diâmetro, púrpura escuro quando amadurecidos, com um mesocarpo suculento. Há uma semente por fruto, com um endosperma sólido e homogêneo (Henderson et al., 1995). 


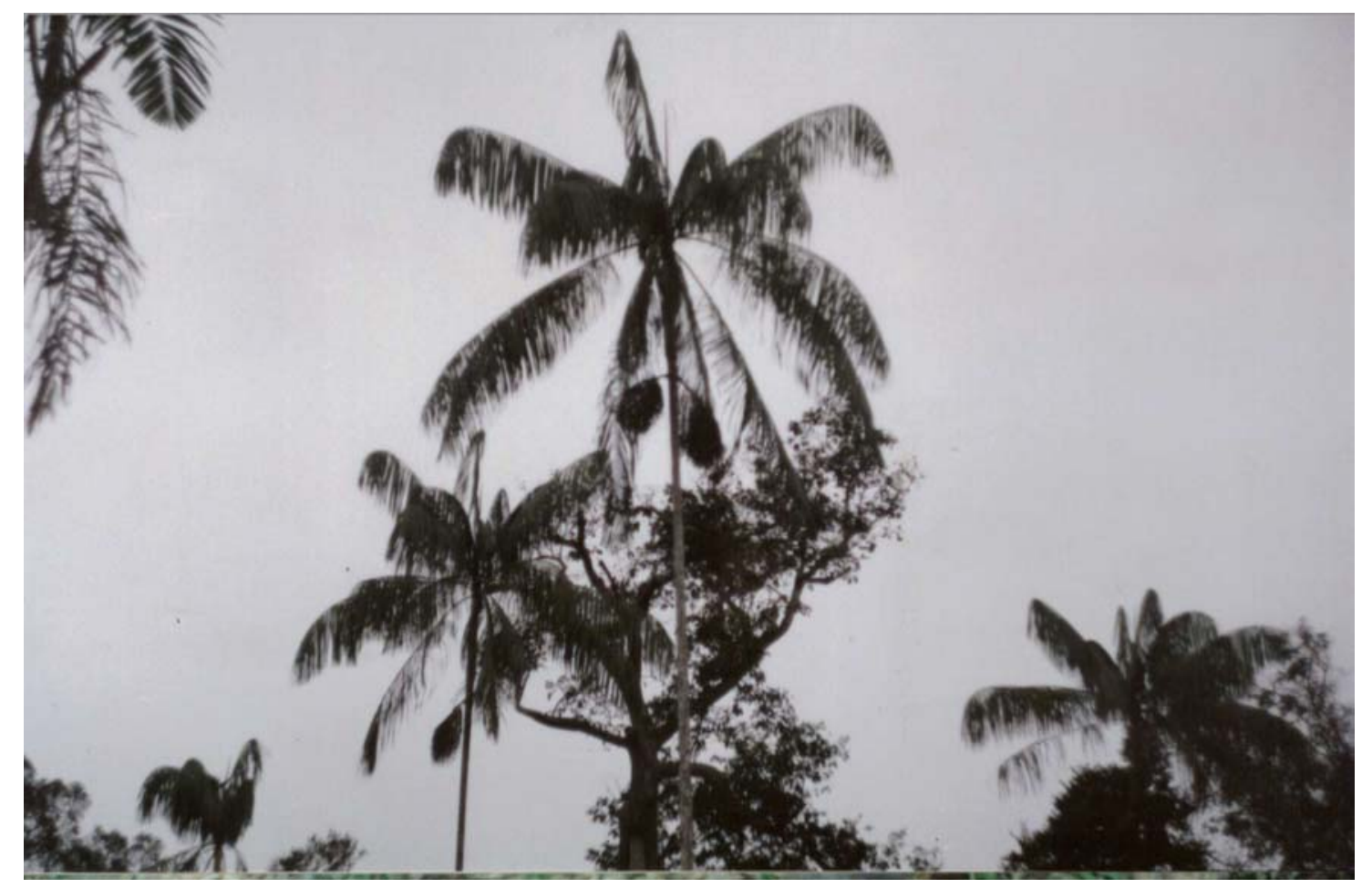

Foto 2.1 - Euterpe precatoria Mart.

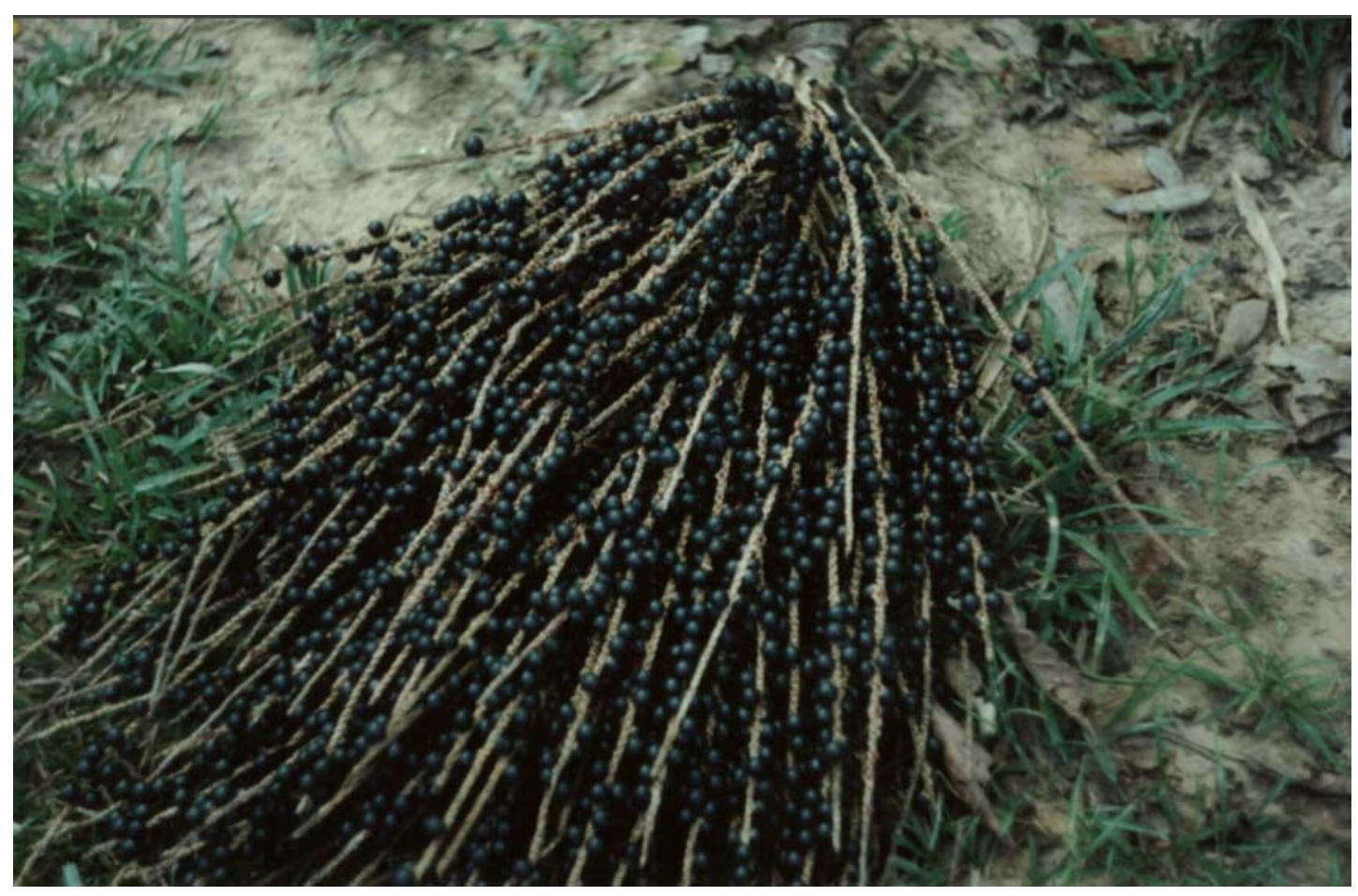

Foto 2.2 - Cacho de frutos de Euterpe precatoria Mart. 


\subsubsection{ESTRUTURA POPULACIONAL E DENSIDADE}

A compreensão de aspectos dinâmicos de uma população de plantas necessita do conhecimento de sua estrutura de tamanho. Para estudar a dinâmica de Euterpe precatoria os indivíduos foram divididos em quatro estágios do desenvolvimento segundo o tamanho e caracteres vegetativos (Figura 2.3) a saber :

(1) Plântulas: indivíduos abaixo de $50 \mathrm{~cm}$ de altura;

(2) Jovem 1: indivíduos acima de 50cm de altura, sem estipe;

(3) Jovem2: indivíduos com estipe aparente (desprovida de bainha), nãoreprodutivos;

(4) Adultos: indivíduos reprodutivos (aqueles que possuem ferófilos aparentes, cachos novos e/ou restos de cachos velhos, na planta ou no solo debaixo do indivíduo).

Estas classes de tamanho foram elaboradas juntamente com os seringueiros que reconhecem as quatro classes no campo.

A Tabela 2.1 mostra as áreas de estudo e suas localidades, onde a estrutura da população de Euterpe precatoria foi avaliada

Tabela 2.1 Áreas de estudo e as localidades onde foi avaliado a estrutura populacional de Euterpe precatoria na floresta de Baixio e na floresta de Terra Firme no Vale do Rio Acre, AC.

\begin{tabular}{llll}
\hline Áreas de estudo & Área & Seringal & Colocação \\
\hline $\begin{array}{l}\text { Município de Xapuri - Reserva Extrativista Chico } \\
\text { Mendes }\end{array}$ & Dois Irmãos & Já Começa \\
$\begin{array}{l}\text { Município de Brasiléia - Reserva Extrativista Chico } \\
\text { Mendes }\end{array}$ & Porongaba & Santa Maria \\
$\begin{array}{l}\text { Município de Porto Acre - Assentamento } \\
\text { Agroextrativista de Porto Alonso. }\end{array}$ & Caquetá & São Pedro \\
& 4 & & Arraia \\
& 5 & & Limoeiro \\
& 6 & & Morada Nova \\
\hline
\end{tabular}



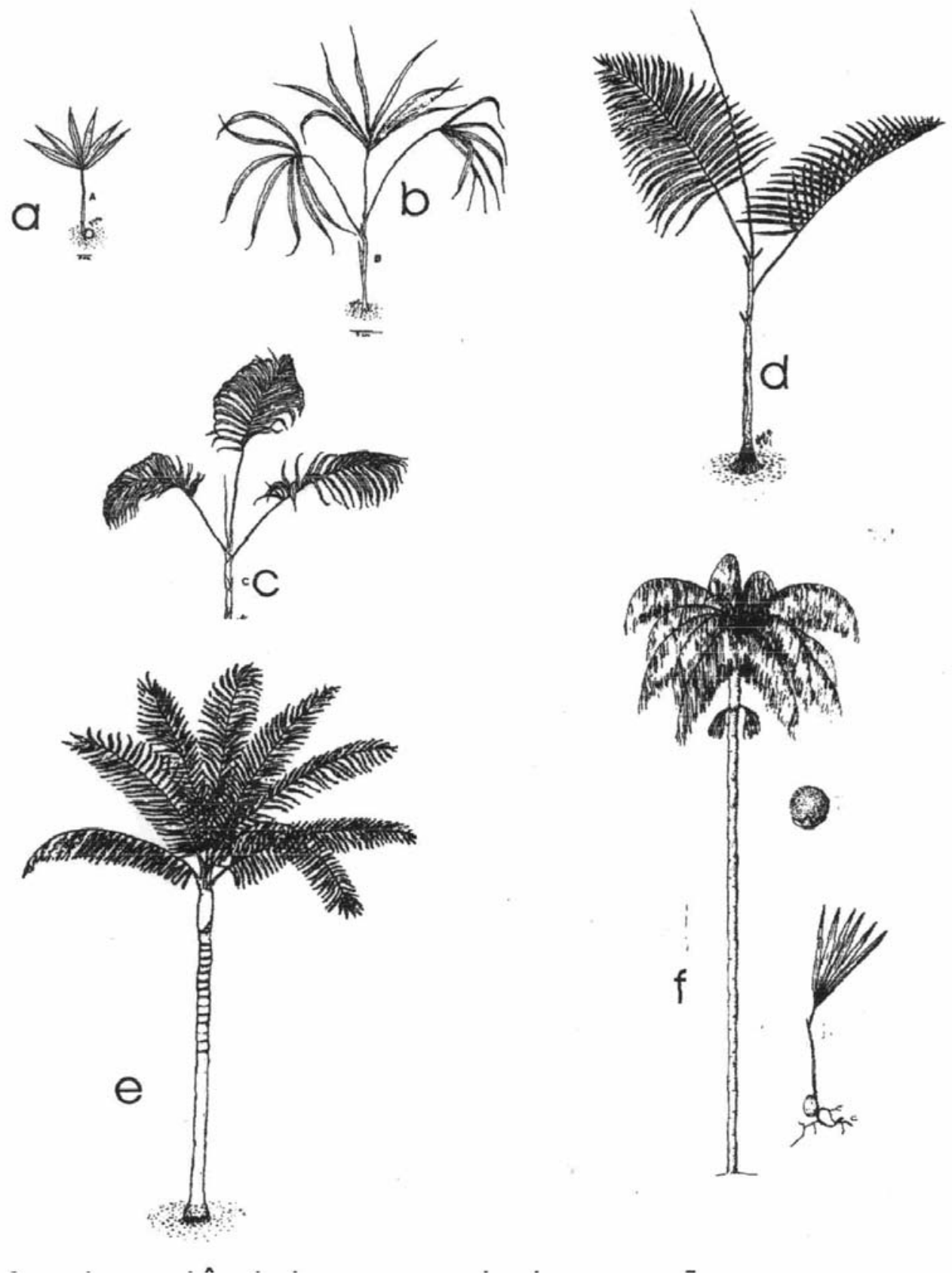

Figura 2.3. Classes de tamanho de Euterpe precatoria . a e b - Plântulas; c e d - Jovem 1; e Jovem 2; f - Adulto, com plântula e fruto. (Sem escala). a, b, c, d, e - classes de tamanho de Euterpe edulis, fonte: Reis, 1995 * ; f - classe de tamanho de Euterpe precatoria, fonte: Henderson, 1995.

* O esquema das classes de tamanho a, b, c, d, e de Euterpe edulis foi utilizado para Euterpe precatoria pela semelhança vegetativa das espécies.

Em cada localidade (Tabela 1) foram realizados 2 transectos de 500 x 20 metros, um na floresta de Baixio, outro na floresta de Terra Firme, utilizando o 
método de transecto, com localização restrita-aleatória (Matteucci-Colma, 1982). Os transectos foram divididos em 20 parcelas de $500 \mathrm{~m}^{2}$ para a contagem de indivíduos adultos, 20 parcelas de $250 \mathrm{~m}^{2}$ para a contagem de jovens 1 e 2 e 20 parcelas de 125 $\mathrm{m}^{2}$ para a contagem de plântulas, totalizando $1,0.5$ e 0.25 ha respectivamente para cada floresta de Baixio e de Terra Firme conforme mostra a Figura 2.4.
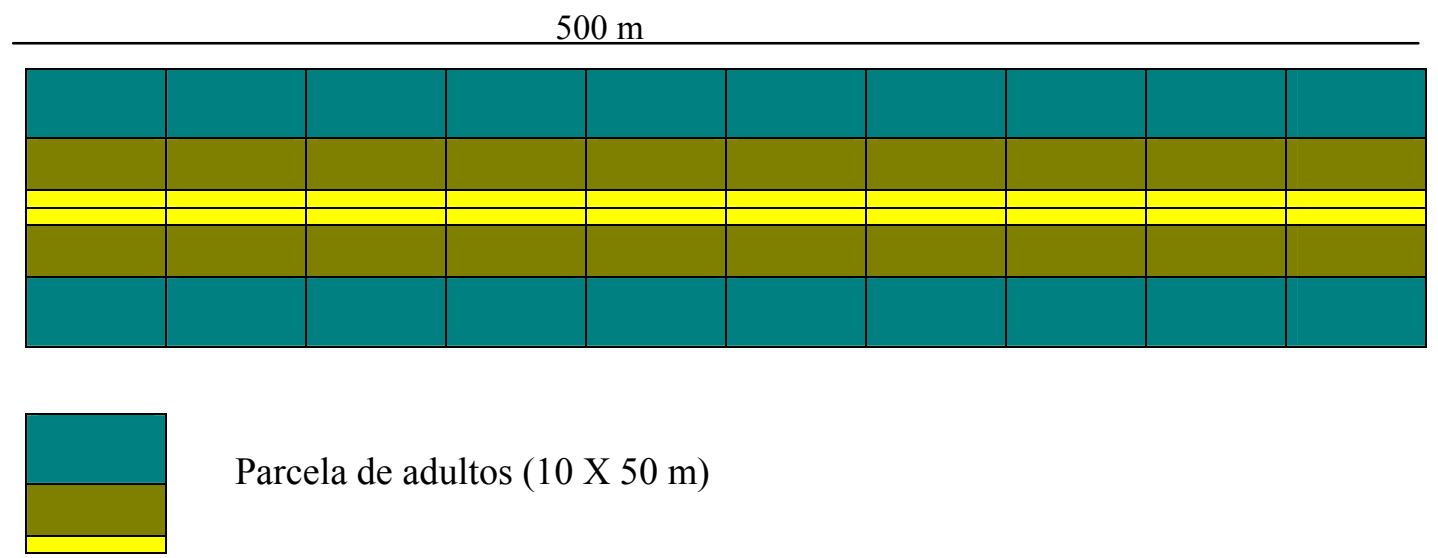

Parcela de adultos $(10$ X $50 \mathrm{~m})$

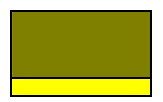

Parcela de jovens 1 e $2(5$ X $50 \mathrm{~m})$

$\square \quad$ Parcela de plântulas $(2,5$ X 50 m)

Figura 2.4 Croqui dos transectos em áreas de Baixio e Terra Firme, AC (sem escala). Transecto dividido em 20 parcelas de $500 \mathrm{~m}^{2}$ para contagem de adultos, 20 parcelas de $250 \mathrm{~m}^{2}$ para a contagem de jovens e 20 parcelas de $125 \mathrm{~m}^{2}$ para a contagem de plântulas.

Para estimar a densidade média de Euterpe precatoria no Vale do Rio Acre foram utilizados um total de 6 hectares para a amostragem de adultos, 3 hectares para jovens 1,2 e 1.5 hectares para plântulas.

Vários autores têm utilizado parcelas de 1 a 3 hectares (Campbell et. al., 1986; Anderson et. al. 1985) para amostrar comunidades vegetais na Amazônia. Neste estudo o método foi aplicado em treinamentos com os seringueiros do Seringal Caquetá (fotos 2.3 e 2.4) para avaliar a disponibilidade de frutos de Açaí em suas áreas de florestas, e para estimar a rentabilidade do recurso. 


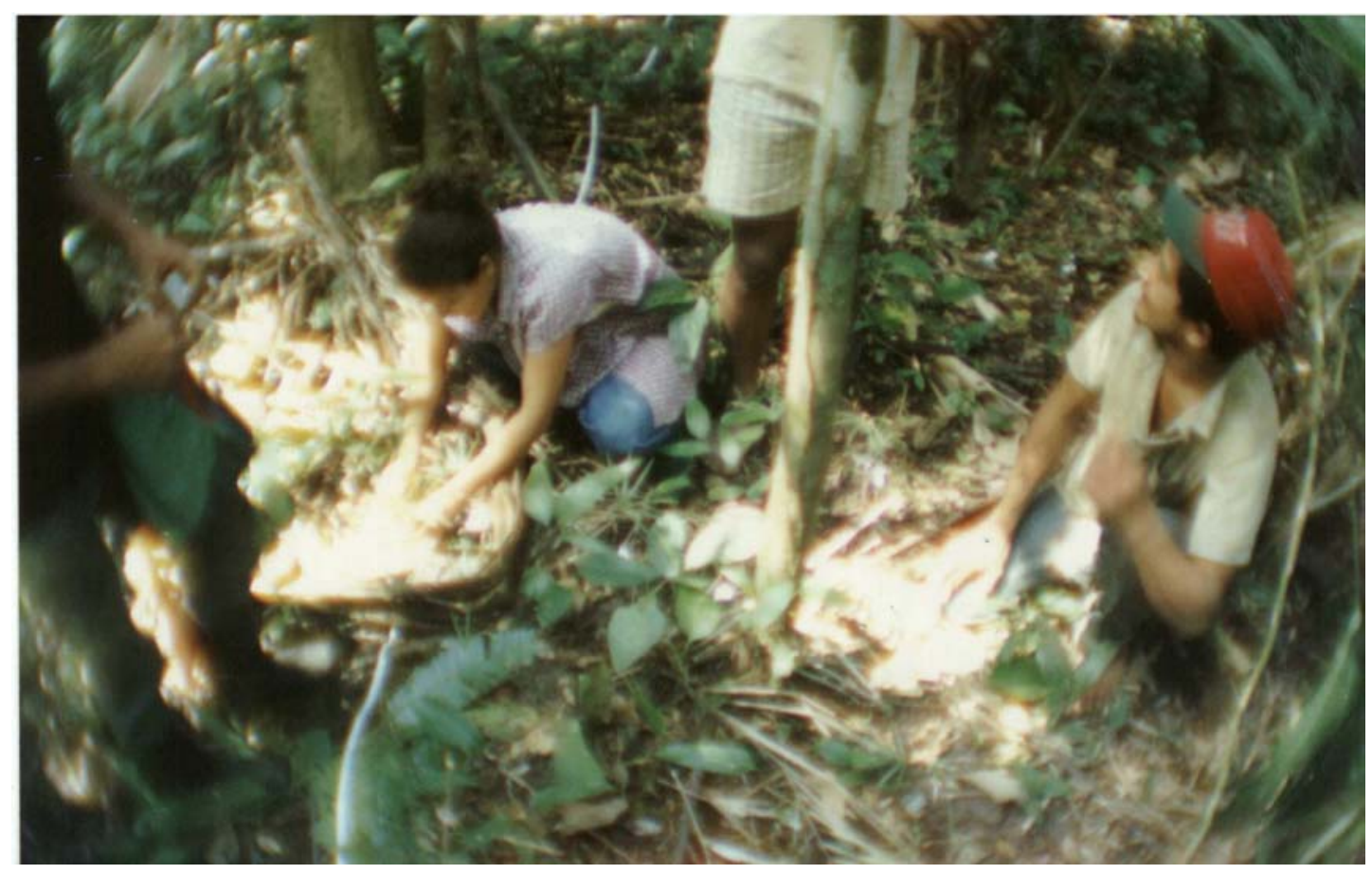

Foto 2.3 - Inventário Florestal na floresta de Baixio, Seringal Caquetá, AC.

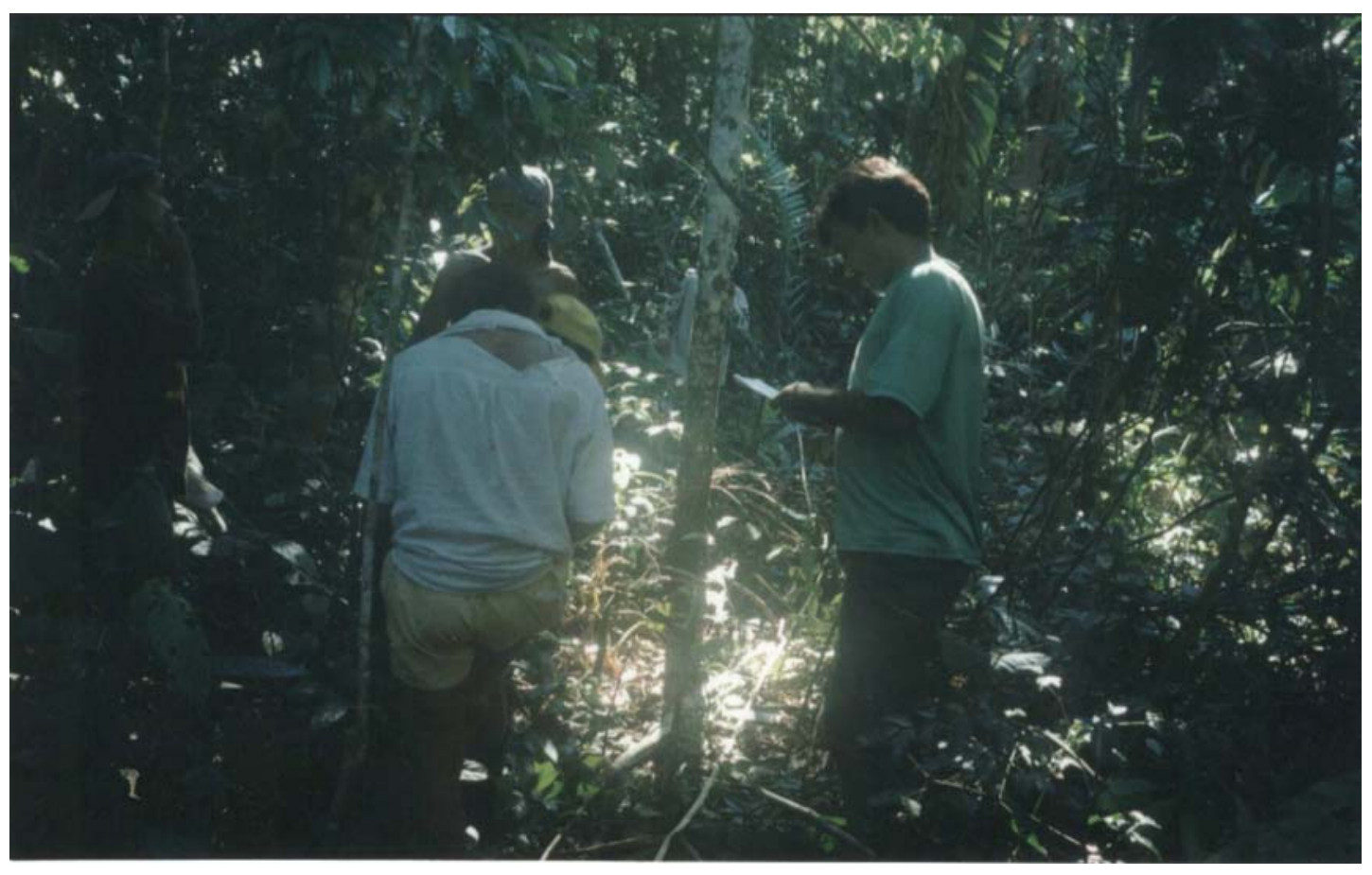

Foto 2.4 - Inventário Florestal na floresta de Terra Firme, Seringal Caquetá, AC. 
O método de transecto foi utilizado neste estudo basicamente por três motivos: (1) diminuição do tempo e dinheiro empregados no estudo, levando em consideração que as áreas são de difícil acesso; (2) facilidade para delimitar os diferentes tipos florestais através da informação dos moradores locais, fisionomia e ondulação do terreno, visto que a heterogeneidade das áreas é alta e não existem mapas ou fotos aéreas que delimitam os tipos florestais; (3) como a amostragem foi feita junto com os moradores locais, este método, cujo desenho experimental é simples e mais barato (gasta menos tempo) é fundamental para que os moradores sejam capazes de fazer a avaliação da densidade de Euterpe precatoria e outros recursos florestais não madeireiros em suas áreas de florestas, mesmo considerando as limitações estatísticas do método (Hubbel, 1984; Mateucci-Colma, 1982).

Dentro dos transectos nas florestas de Baixio e de Terra Firme foram calculadas as distâncias médias entre os indivíduos de uma mesma classe de tamanho.

Para calcular a distância entre indivíduos, consideramos que sua distribuição seja uniforme na área. Desta forma, a área total dividida pelo número de indivíduos é igual a área parcial ocupada por cada indivíduo. Representando-se matematicamente esta área parcial como uma circunferência, temos que a distância entre dois indivíduos é a soma dos dois raios, que é igual ao diâmetro da circunferência.

Daí podemos calcular a distância através da seguinte forma:

Sendo: $\mathrm{A}=\pi \mathrm{r}^{2}$

$\mathrm{D}=2 \mathrm{r}$

Onde: A é a área parcial de cada indivíduo

r é o raio da circunferência

D é o diâmetro e também (para este fim) a distância entre dois indivíduos

Substituindo r por D:

$\mathrm{A}=\pi(\mathrm{D} / 2)^{2}$

$\mathrm{A}=\pi \mathrm{D}^{2} / 4$

$\mathrm{D}=\sqrt{ }(\mathrm{A} * 4 / \pi)$ 


\subsubsection{DESENVOLVIMENTO DOS INDIVÍDUOS DE Euterpe precatoria}

O porte dos indivíduos foi comparado entre Baixio e Terra Firme. Para isto, na Colocação S. Pedro (Tabela 2.1) foi contado o número de folhas e medido o diâmetro do caule a 1,3 m de altura (DAP) de todos os indivíduos adultos $(\mathrm{n}=60)$ e Jovens $2(\mathrm{n}=57)$ do transecto do Baixio e todos os indivíduos adultos $(\mathrm{n}=29)$ e jovens $2(n=4)$ do transecto da Terra Firme. Na Colocação Já Começa foi medido o DAP e estimada a altura de todos os adultos dos transectos nas florestas de Baixio $(\mathrm{n}=46)$ e de Terra Firme $(\mathrm{n}=45)$.

\subsubsection{DISTRIBUIÇÃO ESPACIAL}

Para uma caracterização do padrão de distribuição espacial das palmeiras foram calculadas as freqüências de distribuição usando dois índices de distribuição nas localidades identificadas na Tabela 2.1, exceto na Colocação Morada Nova. Na Colocação Já Começa cada indivíduo ao longo dos transectos nas florestas de Baixio e de Terra Firme foi mapeado, usando coordenadas cartesianas (x y).

As propriedades desejáveis de uma medida do padrão espacial de plantas incluem o grau de não casualidade que pode ser medido, a medida ser insensível ao tamanho da unidade da amostra, a medida ser fácil de calcular e prontamente aplicada em modelos teóricos e a medida não ser função da densidade da planta (Crawley, 1986). A distribuição espacial dos indivíduos foi avaliada usando o índice de dispersão de Morisita e o índice de dispersão de Morisita padronizado (Krebs, 1989). Apesar do índice de Morisitia ser relativamente independente da densidade, pode ser afetado através do tamanho da amostra (Krebs, 1989). O índice de Morisitia padronizado não é afetado porém pelo tamanho da amostra ou densidade (Myers, 1986 citado por Matos-Silva, 1995). Foi feito o cálculo da distribuição espacial utilizando o índice de Morisita (Krebs, 1989) a partir da seguinte fórmula: $\mathrm{Id}=\mathrm{n} \sum \mathrm{x}^{2}-\sum \mathrm{x} /\left(\sum \mathrm{x}\right)^{2}-\sum \mathrm{x}$ 
Onde:

Id = índice de dispersão de Morisitia

$\mathrm{n}=$ Número de parcelas

$\sum \mathrm{x}=$ Somatório do número de palmeiras presentes nas parcelas estudadas

$\sum \mathrm{x}^{2}=$ Somatório do quadrado do número de palmeiras por parcela

Aceitando-se como critério para a caracterização da distribuição espacial os valores do índice de Morisita obtidos, sendo:

$\mathrm{Id}=1$ - distribuição aleatória

Id $>1$ - distribuição agrupada

Id $<1$ - distribuição regular.

O índice de dispersão de Morisitia padronizado baseado no índice de dispersão de Morisitia foi calculado usando o procedimento seguinte:

A) Índice Uniforme

$\mathrm{M}_{\mathrm{u}}=\chi_{0.975}^{2}-\mathrm{n}+\Sigma \mathrm{x}_{\mathrm{i}} /\left(\Sigma \mathrm{x}_{\mathrm{i}}\right)-1$

B) Índice agrupado

$\mathrm{M}_{\mathrm{c}}=\chi_{0.025}^{2}-\mathrm{n}+\sum \mathrm{x}_{\mathrm{i}} /\left(\Sigma \mathrm{x}_{\mathrm{i}}\right)-1$

Onde:

$\chi_{0.975}^{2}=0$ valor de $\chi^{2}$ com $n-1$ graus de liberdade que tem $97.5 \%$ de área à direita;

$\chi_{0.025}^{2}=0$ valor de $\chi^{2}$ com n-1 grau de liberdade que tem $25 \%$ de área à direita;

$\mathrm{x}_{\mathrm{i}}=\mathrm{o}$ número de plantas na parcela

$\mathrm{n}=\mathrm{o}$ número de parcelas

O índice padronizado de Morisitia (Ip) é obtido de uma das equações seguintes:

A) Se $I_{d} \geq M_{c}>1.0$ :

$\mathrm{I}_{\mathrm{p}}=0.5+0.5\left(\mathrm{I}_{\mathrm{d}}-\mathrm{M}_{\mathrm{c}} / \mathrm{n}-\mathrm{M}_{\mathrm{c}}\right)$

B) $\mathrm{Se}_{\mathrm{c}}>\mathrm{I}_{\mathrm{d}}>1.0$ :

$\mathrm{I}_{\mathrm{p}}=0.5\left(\mathrm{I}_{\mathrm{d}}-1 / \mathrm{M}_{\mathrm{c}}-1\right)$

A) Se $1.0>I_{d}>M_{u}$ :

$\mathrm{I}_{\mathrm{p}}=-0.5\left(\mathrm{I}_{\mathrm{d}}-1 / \mathrm{M}_{\mathrm{u}}-1\right)$

B) Se $1.0>M_{u}>I_{d}$ :

$I_{p}=-0.5+0.5\left(I_{d}-M_{u} / M_{u}\right)$ 
O Índice de Morisitia padronizado (Ip) tem o valor aproximado de 0 para uma distribuição aleatória. Valores acima de 0 indicam agrupamento e valores abaixo de 0 indicam um padrão uniforme. O índice varia de -1 a 1 , com limite de confiança de $95 \%$ de -0.5 e 0.5 (Krebs, 1989).

\subsubsection{DINÂMICA POPULACIONAL}

Os dados sobre a dinâmica da população foram coletados durante o período de um ano nas Colocações Já Começa e São Pedro (Tabela 2.1) em florestas de Baixio e de Terra Firme utilizando o desenho experimental e a amostragem descritos acima (Figura 2.4).

Todos os indivíduos de Euterpe precatoria separados em classes de tamanho (Figura 2.3) foram marcados com plaquetas de alumínio para o posterior recenseamento.

Após o período de 1 ano foi feito o recenseamento na área 1 (Novembro de 1997 a novembro de 1998) e na Área 3 (junho 1999 a junho de 2000), onde foram levantados dados demográficos de sobrevivência, mortalidade, transição e fecundidade na floresta de Baixio e de Terra Firme.

A taxa anual de sobrevivência $\left(\sigma_{\mathrm{i}}\right)$ de palmeiras na classe de tamanho i foi calculada como o número de palmeiras que sobreviveram durante aquele ano $\left(\mathrm{S}_{\mathrm{i}}\right)$ dividido pelo número de palmeiras vivas no começo do ano. $\left(\mathrm{n}_{\mathrm{i}}\right)$.

$$
\sigma_{\mathrm{i}}=\mathrm{S}_{\mathrm{i}} / \mathrm{n}_{\mathrm{i}}
$$

A mortalidade calculada como:

$$
1-\sigma_{\mathrm{i}}
$$

A taxa de transição $\left(\mathrm{y}_{\mathrm{i}}\right)$ de indivíduos de uma classe de tamanho para a próxima foi obtida considerando o número de indivíduos que passaram de uma classe para a próxima durante o ano. Para todas as classes de tamanho as taxas de transição foram calculadas como o número de novas palmeiras que deixaram a classe de tamanho i e apareceram anualmente na próxima classe de tamanho $\left(\mathrm{r}_{\mathrm{i}}\right)$, dividido pelo número de palmeiras que permaneceram vivas na classe de tamanho i no começo do ano e tinha sobrevivido para o próximo ano $\left(\mathrm{S}_{\mathrm{i}}\right)$.

$$
\gamma_{\mathrm{i}}=\mathrm{r}_{\mathrm{i}} / \mathrm{S}_{\mathrm{i}}
$$


O número de plântulas produzidas por palmeira reprodutiva por ano (taxa de fecundidade - F) foi expressa em termos da média do número de plantas na classe de tamanho 1 (plântulas) produzidas por plantas da classe de tamanho 4 (adultos); como sugerido por Caswell (1989) para espécies cujas sementes germinam em menos que um ano. $\mathrm{Na}$ análise da fecundidade apresentada aqui não foi levado em consideração a influência do tamanho da palmeira na quantidade de cachos e sementes produzidas, desta forma, todos os adultos foram considerados com igual chance de serem a árvore progenitora de uma plântula recrutada.

Um modelo determinístico para populações estruturadas em classes de idade, chamado modelo de matrizes de Leslie foi desenvolvido em 1945, quando o autor mostrou como os dados de idade específica, da mortalidade e fecundidade podem ser combinados nos modelos de matriz para estudar a dinâmica e estrutura das populações (Viana,1986).

Como a idade não é muitas vezes um bom parâmetro para predizer o comportamento de palmeiras, visto que o crescimento, sobrevivência e fecundidade podem variar grandemente entre indivíduos de idades idênticas (Pinard \& Putz, 1992), Lefkovich (1965) sugeriu o modelo estruturado por classes de tamanho. Estes modelos de matrizes podem ser utilizados para estudar, por exemplo, a dinâmica de comunidades (Martinez-Ramos et al., 1988; Pinero et al., 1984), a variação no crescimento e reprodução (Enright, 1992) e a sustentabilidade da colheita (Pinard 1993; Zuidema, 2000).

Neste estudo o modelo de matriz de transição estruturado por classes de tamanho (Lefkovich, 1965) foi aplicado para a análise do crescimento populacional de Euterpe precatoria das áreas estudas e para examinar as conseqüências das mudanças demográficas que são o resultado da sua extração (Pinard \& Putz 1992) por serem uma ferramenta relativamente simples e direta (Silvertown et al., 1993).

Caswell (1989) fez uma revisão do modelo de matriz estruturado pelo tamanho (Lefkovich, 1965) e apresentou o modelo básico assim:

$$
\mathrm{n}_{\mathrm{t}+1}=\mathrm{M} \mathrm{n}_{\mathrm{t}}
$$

Onde $\mathrm{n}_{\mathrm{t}+1}$ é a distribuição de classes de tamanho no tempo $\mathrm{t}+1$; $\mathrm{M}$ é a matriz quadrada, com linha e colunas, descrevendo as probabilidades de transição entre as classes de tamanho de um período a outro e $n_{t}$ é o vetor das classes de tamanho no 
tempo t. A matriz $\mathrm{M}$ foi feita neste estudo a partir do ciclo de vida apresentado abaixo:

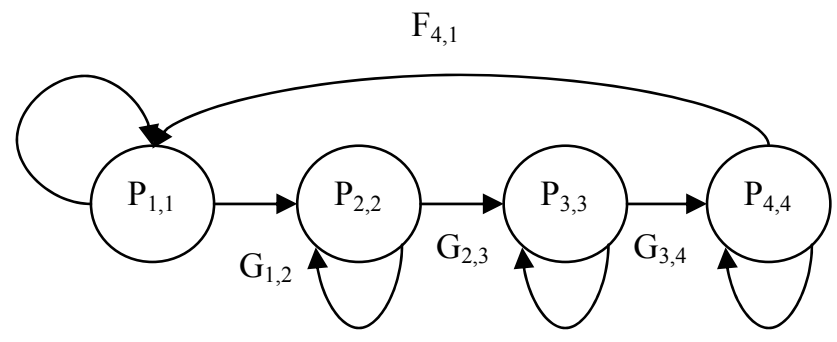

Onde cada círculo representa uma classe de tamanho, sendo que a classe de menor tamanho (plântulas) se encontra no extremo esquerdo, as classes intermediárias (jovem 1 e 2) no centro e a maior classe de tamanho no extremo direito. As setas que apontam para os mesmos círculos indicam a probabilidade de sobreviver e permanecer na mesma classe de tamanho, as setas que apontam de um círculo a outro indicam a probabilidade de passar para a próxima classe de tamanho e a seta que liga a maior classe de tamanho (adultos) com o círculo de menor classe (plântulas) representa a fecundidade.

A matriz possui os valores de fecundidade (F) de adultos no canto superior direito, os valores de $(\mathrm{P})$ na diagonal principal, que representam as probabilidades dos indivíduos permanecerem em uma dada classe e os valores de (G) na subdiagonal que representam as probabilidades dos indivíduos de sobreviverem e passarem para a próxima classe de tamanho. Os valores zero na matriz representam transições não estudadas (Caswell, 1989).

$$
\mathrm{N}=\left|\begin{array}{llll|l}
\mathrm{P}_{1,1} & 0 & 0 & \mathrm{~F}_{4,1} \\
\mathrm{G}_{1,2} & \mathrm{P}_{2,2} & 0 & 0 & \mathrm{X} \\
0 & \mathrm{G}_{2,3} & \mathrm{P}_{3,3} & 0 & \\
0 & 0 & \mathrm{G}_{3,4} & \mathrm{P}_{4,4} &
\end{array}\right| \begin{aligned}
& \mathrm{nt}_{1} \\
& \mathrm{nt}_{3} \\
& \mathrm{nt}_{4}
\end{aligned}
$$

Onde $\mathrm{nt}_{1}, \mathrm{nt}_{2}, \mathrm{nt}_{3} \mathrm{e} \mathrm{nt}_{4}$ representam o número de plântulas, jovens 1 , jovens $2 \mathrm{e}$ adultos encontrados no censo no tempo $t$.

Os elementos da matriz de transição foram calculados seguindo Caswell (1989): 
a) A probabilidade de sobreviver e permanecer na mesma classe de tamanho $\left(\mathrm{P}_{\mathrm{i}}\right)$ é definida como o produto da probabilidade de sobrevivência $\left(\sigma_{\mathrm{i}}\right)$ e a probabilidade de permanecer na mesma classe de tamanho (igual a 1 menos a probabilidade de mover-se para a próxima classe de tamanho).

$$
P_{i}=\sigma_{i}\left(1-\gamma_{i}\right)
$$

onde $\gamma_{\mathrm{i}}$ é a probabilidade de sobreviver e passar para a próxima classe de tamanho.

b) A probabilidade de sobreviver e crescer para a próxima classe de tamanho $\left(G_{i}\right)$ foi obtida pela multiplicação da probabilidade de sobrevivência $\left(\sigma_{\mathrm{i}}\right)$ pela probabilidade de transição de indivíduos sobreviventes $\left(\gamma_{\mathrm{i}}\right)$.

$$
\mathrm{G}_{\mathrm{i}}=\sigma_{\mathrm{i}} \gamma_{\mathrm{i}}
$$

c) O número de prole produzida por palmeira reprodutiva por ano (F) foi expressa em termos da média do número de plântulas produzidas por adultos.

A multiplicação da matriz de transição pelo vetor coluna fornece o tamanho e a estrutura de classes de tamanho da população em um intervalo de tempo no futuro. Uma propriedade deste tipo de matriz de transição (M) é que quando é multiplicada várias vezes pela estrutura de classes inicial $\left(\mathrm{n}_{\mathrm{t}}\right)$, cada classe de tamanho tende a aumentar em uma taxa constante que é a raiz latente dominante da matriz $(\lambda)$ Caswell(1989).

Este número $\lambda$ é chamado de "taxa finita de aumento populacional"8 e é uma medida do balanço entre sobrevivência e reprodução. $\mathrm{O}$ mesmo processo pode ser descrito como :

$\mathrm{N}_{\mathrm{t}+1}=\lambda \mathrm{n}_{\mathrm{t}}$

A população em equilíbrio cresce em uma taxa constante $(\lambda)$ (Caswell, 1989) sem alterar sua estrutura. Um $\lambda$ maior que 1.0 indica que o população está aumentando em tamanho, um $\lambda$ menor que 1.0 que a população está diminuindo em tamanho. Um $\lambda$ igual a 1.0 indica que as taxas de nascimento e de morte são equilibradas de forma que a população permanece estável (Caswell, 1989; Pinard \& Putz, 1992).

A aplicação do modelo matricial depende de sua sensibilidade para as alterações na estimativa dos parâmetros demográficos da população (taxas de

\footnotetext{
${ }^{8}$ Número de indivíduos adicionados à população em um intervalo de tempo determinado por indivíduo
} 
sobrevivência, fecundidade e transição) (Silva Matos, 1995; Fisch, 1998) Assim, a análise de sensibilidade fornece a importância relativa de cada parâmetro para $\mathrm{o} \lambda \mathrm{em}$ cada classe de tamanho (Kroon; et.al. 1986). A análise de sensibilidade é o produto dos autovetores direito (distribuição estádio-estável ${ }^{9} \mathrm{~W}$ ) e esquerdo (valor estávelreprodutivo ${ }^{10} \mathrm{~V}$ ) e é dada pela fórmula segundo Caswell (1989):

$\mathrm{S}_{\mathrm{ij}}=\mathrm{V}_{\mathrm{i}} \mathrm{W}_{\mathrm{j}}(\mathrm{V}, \mathrm{W})$

Onde : $\mathrm{S}_{\mathrm{ij}}$ é a sensibilidade do $\lambda$ para mudanças nos elementos $\mathrm{a}_{\mathrm{ij}}$ da matriz

V é a estrutura estádio-estável de classes de tamanho (vetor eigen esquerdo)

W é valor estável-reprodutivo de cada classe (vetor eigen direito).

Assim a sensibilidade do $\lambda$ para mudanças no $\mathrm{a}_{\mathrm{ij}}$ é proporcional ao produto do inézimo elemento do vetor de valor reprodutivo e o jnésimo elemento da distribuição de estádio estável (Caswell, 1989).

A estrutura de estádio estável e o valor estável reprodutivo são válidos somente para um conjunto de valores de fecundidade, transição e sobrevivência para um intervalo de tempo específico(Viana, 1986).

Conhecendo-se a estabilidade do recurso nas áreas de florestas para as populações de Açaí, foram feitas simulações para calcular a quantidade de frutos que podem ser colhidos da floresta sem danificar a regeneração da espécie a longo prazo através da variação do coeficiente de fecundidade no modelo de matriz (Peters, 1990).

A fecundidade foi diminuída de 90 a 10\% do seu valor inicial e para cada matriz foi verificado a mudança no valor de $\lambda$ calculado, em outras palavras, a estabilidade da população foi avaliada simulando uma diminuição do número de sementes que podem estar disponíveis para germinação a cada ano de extração de frutos, para inferir-se sobre a quantidade máxima de frutos que podem ser retirados da população estudada sem causar uma diminuição desta estabilidade (Peters, 1990). Todos os cálculos dos parâmetros populacionais foram feitos no programa POPTOOLS for Windows, 1999.

\footnotetext{
${ }^{9}$ Distribuição de tamanho de uma população cujas taxas de sobrevivência e reprodução são constantes para cada classe de tamanho, de modo que esta distribuição torna-se constante no tempo.

${ }^{10}$ Número relativo esperado de plantas reprodutivas produzidas por cada uma das plantas reprodutivas de tamanho x de uma população.
} 
O modelo utilizado aqui possui algumas limitações: (1) de elaboração e de aplicação do modelo; (2) os modelos de matrizes assumem que a dinâmica populacional não muda no tempo, isto pode ser pouco realista, devido à variação temporal nas condições ambientais; (3) os modelos assumem que as taxas demográficas dos indivíduos são descritas adequadamente pelo seu valor médio (Zuidema \& Boot, 2000) e (4) a coleta de dados ter sido realizada no período de apenas 1 ano.

\subsubsection{ESTIMATIVA DA ABERTURA DO DOSSEL NA FLORESTA DE BAIXIO E DE TERRA FIRME}

As palmeiras são um componente estrutural importante dos ecossistemas de floresta, sendo dominantes no subosque da maioria das florestas de Terra Firme, como também no dossel de florestas de pântano (Kanh \& De Granville, 1992). A arquitetura das copas das palmeiras arborescentes na floresta de Baixio proporciona visualmente uma maior penetração de luz, e como estas são dominantes neste habitat, espera-se uma maior abertura do dossel nas florestas de Baixio em relação as de Terra Firme.

Com o objetivo de conhecer melhor as características físicas das florestas de Baixio e de Terra Firme estudadas com relação à penetração de luz no subosque, foram feitas 63 e 21 medidas da porcentagem de abertura do dossel nos dois tipos de floresta das Colocações São Pedro e Já Começa (Tabela 2.2) respectivamente, na mesma época do ano (estação seca - Julho). As medidas foram feitas com um densiômetro esférico de copa Forest Densiometers Modelo-C.

Tabela 2.2 Áreas de estudo onde foram medidas a abertura do dossel nas florestas de Baixio e de Terra Firme, AC.

\begin{tabular}{lll}
\hline Áreas de estudo & Localidade & \\
\hline & Seringal & Colocação \\
Município de Xapuri - Reserva Extrativista Chico Mendes & Dois Irmãos & Já Começa
\end{tabular}

Município de Porto Acre - Assentamento Agroextrativista Caquetá

São Pedro de Porto Alonso. 
Cada medida foi tirada com o aparelho a $1 \mathrm{~m}$ de altura do solo. Na Colocação Já Começa foram distribuídos 21 pontos ao longo dos transectos de Baixio e Terra Firme, de 24 em 24 metros, e 21 pontos em cada lado dos transectos, em duas linhas imaginárias, paralelas e distando $10 \mathrm{~m}$ destes. Na Colocação São Pedro foram feitos 21 pontos de 24 em 24 metros ao longo da linha principal dos transectos.

\subsubsection{PRODUÇÃO DE FRUTOS E POTENCIAL PRODUTIVO}

A análise da produção de frutos foi feita nas florestas de Baixio e de Terra Firme da Colocação S. Pedro, Seringal Caquetá.

Para a análise da produção de frutos por palmeira por ano foram avaliados 35 indivíduos adultos amostrados aleatoriamente, 10 na floresta de Baixio e 25 na floresta Terra Firme. De todos os 35 indivíduos foram extraídos os seus cachos. Para escalar cada palmeira, o escalador utilizou uma peconha ${ }^{11}$ e um cinto de segurança.

Para cada indivíduo adulto foram avaliados: (1) o número de cachos; (2) peso (kg) dos cachos, utilizando uma balança com capacidade de $20 \mathrm{~kg}$ e graduação $0,5 \mathrm{~kg}$; (3) peso ( $\mathrm{kg}$ ) médio dos frutos sem o cacho; (4) peso ( $\mathrm{kg}$ ) médio de frutos por cacho, com uma balança digital Pocket Pro 250-B, capacidade $250 \mathrm{~g}$ e graduação $0,1 \mathrm{~g}$. O peso $(\mathrm{kg})$ médio de frutos foi calculado a partir de 20 frutos por cacho. Estas medidas foram realizadas em julho de 1999 em 15 indivíduos na Floresta de Terra Firme; em junho de 2000 em 20 indivíduos, sendo 10 no Baixio e 10 na Terra Firme.

A estimativa da produção de frutos de Euterpe precatoria por hectare de floresta foi calculada a partir do número médio de palmeiras adultas/hectare $(\mathrm{N})$ multiplicado pelo peso médio de frutos $(\mathrm{kg}) /$ palmeira $(\mathrm{P})$. O desvio padrão do potencial produtivo foi calculado multiplicando-se o desvio padrão da produção de frutos $(\mathrm{kg})$ por palmeira $(\mathrm{S})$ pelo número de palmeiras por hectare $(\mathrm{N})$ dividido pela raiz quadrada do número de palmeiras avaliadas (n).

Potencial produtivo/ ha $=\mathrm{N} \times \mathrm{P}$

Desvio padrão do potencial produtivo $=\mathrm{S} \times \mathrm{N} / \hat{\imath}(\mathrm{n})$

\footnotetext{
${ }^{11}$ saco de estopa amarrado e colocado ao redor dos pés
} 
As estimativas de potencial produtivo total são altamente conservativas já que elas estão baseadas na "produção extrativa" e excluem aquela parte da produção que: 1) não é colhida pelos extratores da palmeira; 2) poderia ter sido consumida por animais antes da colheita e 3 ) poderia ter caído no solo antes da colheita.

\subsection{RESULTADOS E DISCUSSÃO}

\subsubsection{ESTRUTURA POPULACIONAL E DENSIDADE}

A variação das distribuições de tamanho nas populações de Euterpe precatoria amostradas no Vale do Rio Acre é demonstrada nos histogramas das Figuras 2.5 e 2.6. Das 12 amostras coletadas no Vale do Rio Acre 100\% apresentaram número maior de plântulas e jovens 1 , em relação aos jovens 2 e adultos. Destas, 50\% apresentaram uma distribuição de tamanho dos indivíduos tendendo a uma exponencial e isto reflete uma população com mais jovens do que adultos nestas áreas. Esta distribuição é encontrada em populações naturais que possuem alta regeneração e que provavelmente são estáveis na densidade. (Hall \& Bawa, 1993; Peters, 1996; Meyer, 1952, citado por Pinard \& Putz, 1992).

Várias espécies vegetais apresentam tal estrutura, tais como: espécie amgazônica Phithecelobium rancemosum, Leite et al. (1982); Anadenanthera falcata no Cerrado (Lobo, 1993); Talauma ovata por De Steven (1994); Euterpe edulis (Fisch, 1998; Silva Matos, 1995; Reis, 1995); Astrocaryum mexicanum (Van Valen, 1975; Sarukhan, 1980, citados por Fisch, 1998), Iriartea deltoidea (Pinard, 1993) e Phytelephas seemanii (Bernal, 1998).

Este padrão no número de indivíduos das áreas estudadas é devido, principalmente à mortalidade causada por injúrias mecânicas pela queda de galhos, árvores e folhas (Pineiro et.al., 1984). Em classes de tamanho maiores estas injúrias dificilmente causam a morte, mas podem retardar o desenvolvimento como observado em outras palmeiras, como Pococcus barteri (Bullock 1980) Astrocaryum mexicanum (Sarukhan et. al. 1984). 

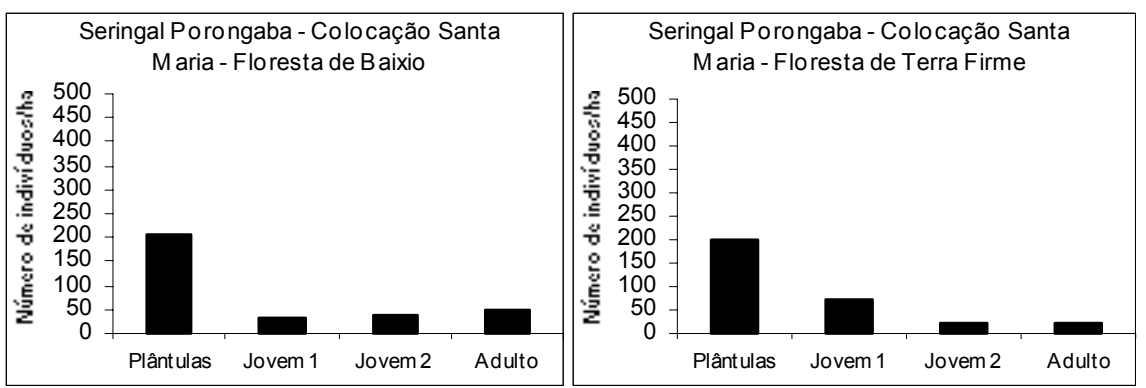

A
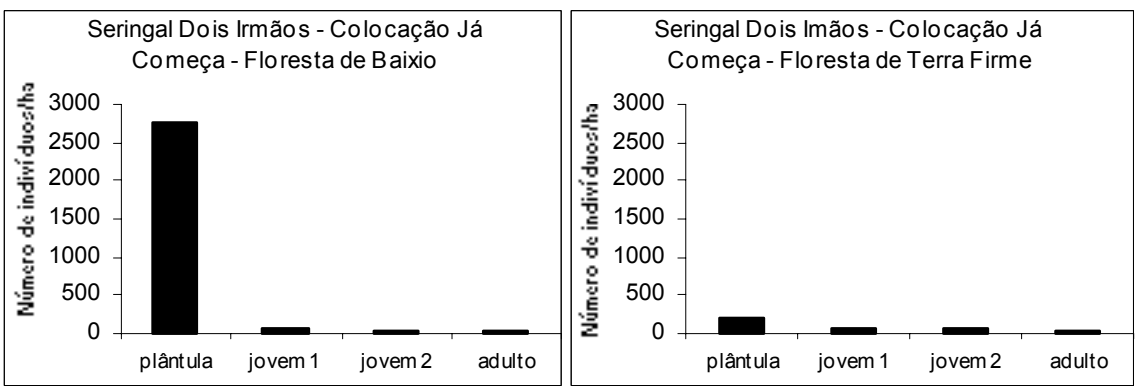

$\mathrm{B}$

Figura 2.5 Histogramas da estrutura populacional de Euterpe precatoria amostradas nas Florestas de Baixio (1 ha) e de Terra Firme (1 ha) das Colocações (A) Santa Maria (Seringal Porongaba, Município de Brasiléia) e (B) Já Começa (Seringal Dois Irmãos, Município de Xapuri), AC.

Outras causas de mortalidade nas fases iniciais de desenvolvimento podem ser a herbivoria (Howe \& Smallwood 1982 citado por Zuidema \& Boot, 2000), a competição por recursos como água, nutrientes e luz (Swaine, et. al. 1987). Na área de estudo não foi observado a herbivoria, como causa da mortalidade das plântulas. 

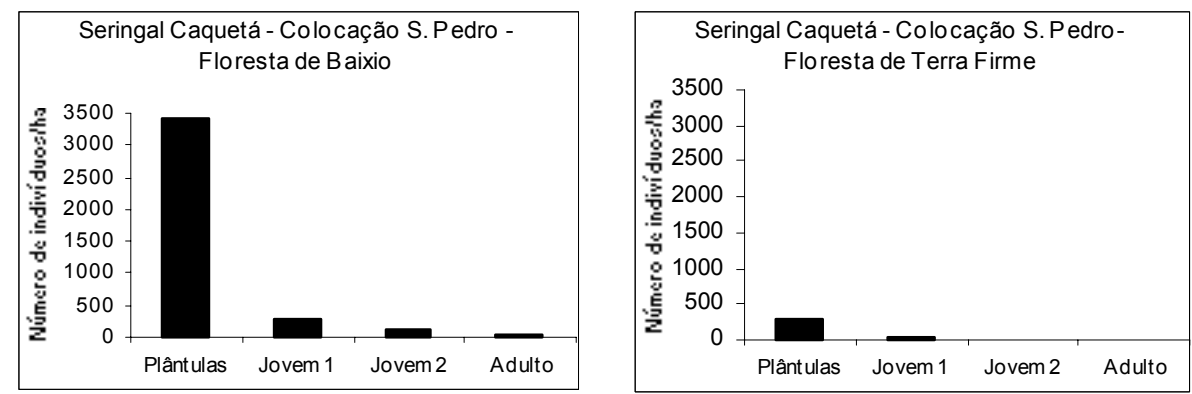

A
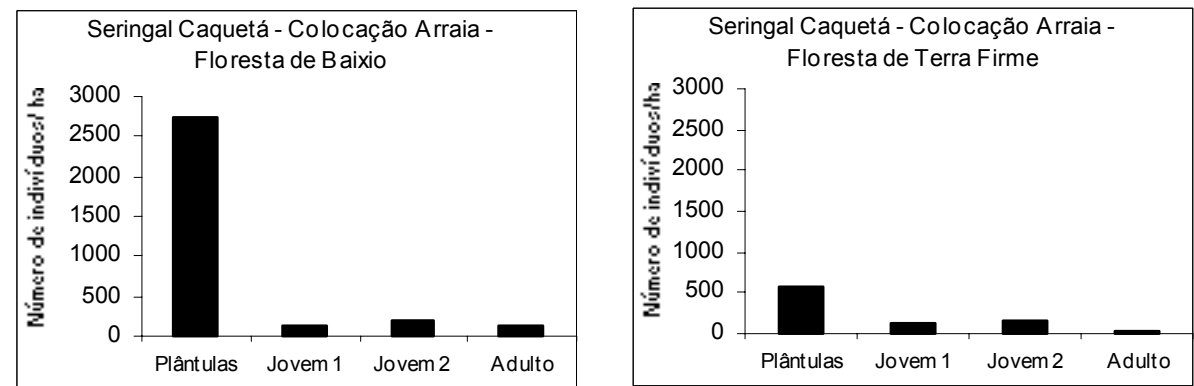

B
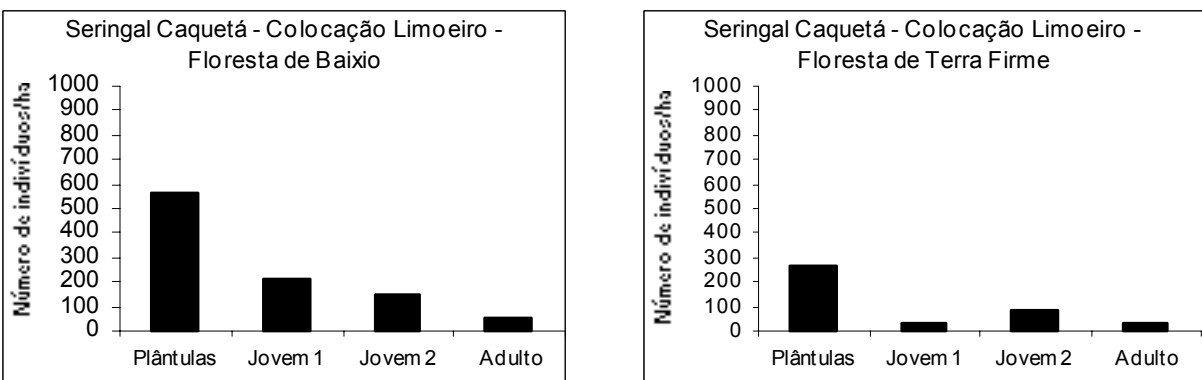

$\mathrm{C}$
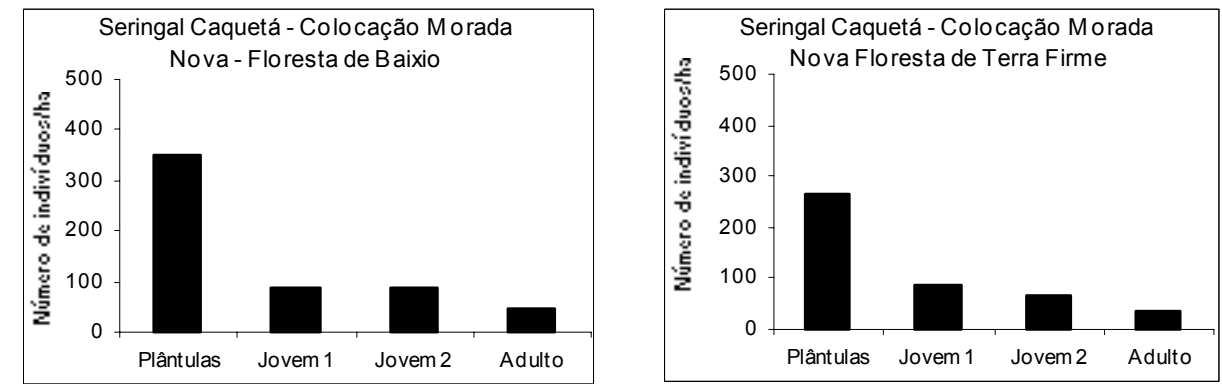

D

Figura 2.6 Histogramas da estrutura populacional de Euterpe precatoria amostradas nas Florestas de Baixio (1 ha) e de Terra Firme (1 ha) das Colocações (A) São Pedro, (B) Arraia, (C) Limoeiro e (D) Morada Nova no Seringal Caquetá - Município de Porto Acre, AC. 
A média do número de indivíduos adultos/ha no Vale do Rio Acre encontrada na floresta de Baixio foi de $60 \pm 19$ e na floresta de Terra Firme foi de $28 \pm 9$ (Tabela 2.3). Zuidema \& Boot (2000) encontraram 25 palmeiras por hectare na floresta de terras baixas na Bolívia.

Apesar da média por hectare do número de indivíduos neste estudo ter sido maior na floresta de Baixio que na floresta de Terra Firme no Vale do Rio Acre, a variância do número de plântulas, jovem 1, jovem 2 e adultos foi 103, 8,1 e 6 vezes maior no Baixio do que na Terra Firme. Isto pode sugerir que no primeiro tipo de floresta, os indivíduos estão mais heterogeneamente distribuídos que na Terra Firme. Para a classe de tamanho adultos a variância da densidade no Baixio foi mais alta que na Terra Firme devido a uma única amostra de 1 ha que conteve 118 indivíduos. A Figura 2.7 mostra a diferença de densidade de indivíduos reprodutivos (adultos) entre colocações.

Tabela 2.3 Estatística descritiva do número de indivíduos por hectare de Euterpe precatoria divididos em 4 classes de tamanho nas florestas de Baixio e de Terra Firme amostrados na mesmas seis localidades no Vale do Rio Acre, AC das Figuras 2.5 e 2. 6.

\begin{tabular}{|c|c|c|c|c|c|}
\hline Floresta de Baixio & Estatística Descritiva & & & & \\
\hline Classes de Tamanho & Densidade média $\mathrm{n}^{\mathrm{o}} / \mathrm{ha}$ & $\begin{array}{l}\text { Desvio pad } \\
\text { da média }\end{array}$ & Mínimo & Máximo & Variância \\
\hline Plântula & 1.633 & 1.260 & 208 & 3.432 & 2.010 .979 \\
\hline Jovem 1 & 136 & 77 & 34 & 290 & 9.622 \\
\hline Jovem 2 & 110 & 54 & 40 & 196 & 4.128 \\
\hline Adulto & 60 & 19 & 45 & 118 & 822 \\
\hline \multicolumn{6}{|c|}{ Floresta de Terra Firme Estatística Descritiva } \\
\hline Classes de Tamanho & Densidade média $\mathrm{n}^{\mathrm{o}} / \mathrm{ha}$ & $\begin{array}{l}\text { Desvio pad } \\
\text { da média }\end{array}$ & Mínimo & Máximo & Variância \\
\hline Plântula & 306 & 92 & 200 & 580 & 19.525 \\
\hline Jovem 1 & 72 & 26 & 28 & 130 & 1.237 \\
\hline Jovem 2 & 77 & 37 & 4 & 164 & 3.089 \\
\hline Adulto & 28 & 9 & 11 & 45 & 137 \\
\hline
\end{tabular}

Observações de campo em todas as áreas de Baixio e de Terra Firme amostradas do Seringal Caquetá evidenciaram que dentro do primeiro tipo de floresta, formam-se agrupamentos densos de indivíduos muito próximos uns dos outros, enquanto que na Terra Firme, os indivíduos se encontram mais esparsos. Isto 
também foi demostrado pela distância média encontrada entre os indivíduos no Baixio e na Terra Firme das Colocações, Tabela 2.4.

Independentemente da classe de tamanho e também da Colocação amostradas, a distância média entre os indivíduos de Euterpe precatoria foi menor na floresta de Baixio, que na floresta de Terra Firme.

Tabela 2.4 Distância média entre os indivíduos de Euterpe precatoria na floresta de Baixio e de Terra Firme das Colocações Arraia, Limoeiro, São Pedro e Já Começa, AC.

\begin{tabular}{lllll}
\hline Floresta de Baixio & \multicolumn{4}{l}{ Distância entre os indivíduos } \\
\hline Colocação & Plântula & Jovem 1 & Jovem 2 & Adulto \\
Arraia & 2,2 & 9,3 & 7,7 & 9,9 \\
Limoeiro & 4,8 & 7,7 & 9,0 & 16,3 \\
São Pedro & 1,9 & 6,6 & 9,5 & 16,0 \\
Já Começa & 2,1 & 16,3 & 17,8 & 16,8 \\
Média & 2,7 & 10,0 & 11,0 & 14,7 \\
Desvio padrão da média & 1,3 & 4,3 & 4,6 & 3,2 \\
\hline Floresta de Terra Firme & Distância entre os indivíduos \\
\hline Colocação & Plântula & Jovem 1 & Jovem 2 & Adulto \\
Arraia & 4,7 & 9,9 & 8,8 & 20,3 \\
Limoeiro & 6,9 & 21,3 & 12,6 & 21,7 \\
São Pedro & 6,4 & 16,0 & 56,4 & 34,0 \\
Já Começa & 7,7 & 14,6 & 15,1 & 17,0 \\
Média & 6,4 & 15,4 & 23,2 & 23,2 \\
Desvio padrão da média & 1,3 & 4,7 & 22,3 & 7,4 \\
\hline
\end{tabular}

O teste estatístico de Kruskal-Wallis foi aplicado nas médias do número de indivíduos adultos por hectare de Euterpe precatoria nas florestas de Baixio $(\mathrm{n}=6)$ e de Terra Firme $(\mathrm{n}=6)$ amostradas no Vale do Rio Acre (Tabela 2.1). Como resultado obteve-se uma diferença significativa $(\mathrm{p}<0,01)$ da densidade de adultos ser maior no Baixio que na Terra Firme. 

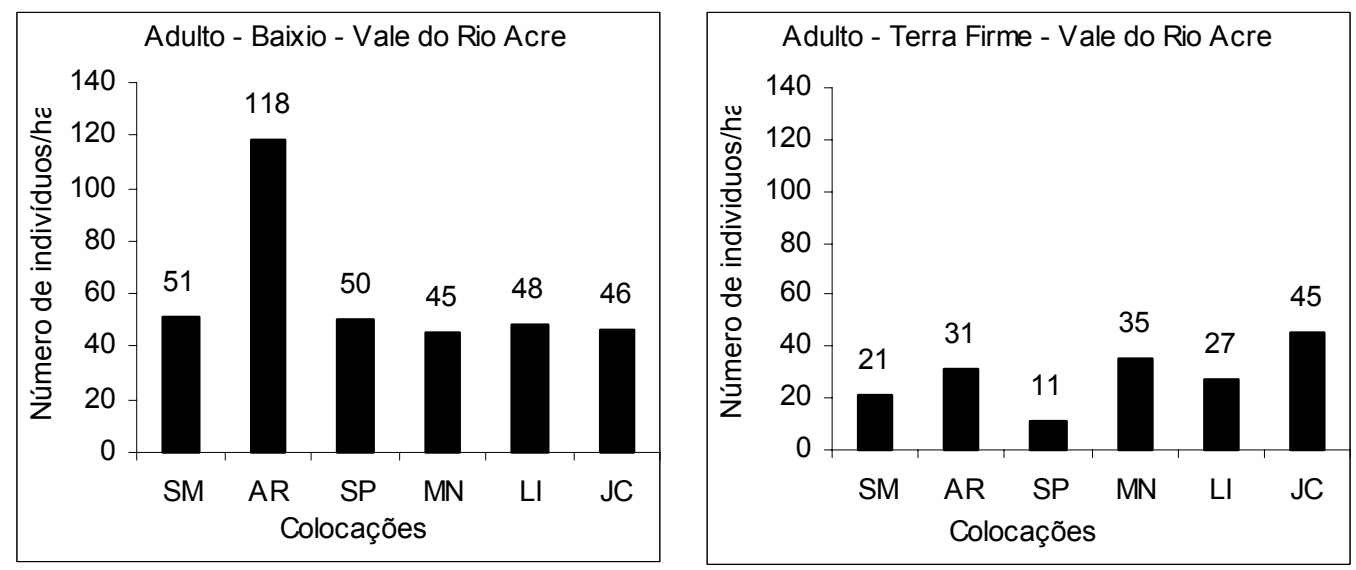

Figura 2.7 Densidade por hectare de indivíduos adultos de Euterpe precatoria amostrados nas colocações Santa Maria (SM), Arraia (AR), São Pedro (SP), Morada Nova (MN), Limoeiro (LI) e Já Começa (JC) no Vale do Rio Acre, AC.

Um estudo realizado pela SEFE (não publicado) utilizando dois transectos de 20 x 500 m em cada tipo de floresta amostraram 19 hectares de floresta de Baixio e 22 hectares de Terra Firme de indivíduos adultos de Euterpe precatoria no Seringal S. Cristovão, município de Brasiléia. Como resultado obtiveram que o número de indivíduos adultos não foi significativamente diferente $(\mathrm{p}=0,165)$ entre Baixio e Terra Firme e nem dentro de um mesmo tipo de floresta na mesma Colocação, (n = 2) para as áreas de Baixio e de Terra Firme amostradas.

A Tabela 2.5 também mostra diferenças da densidade de indivíduos de Euterpe precatoria entre florestas de Baixio e Terra Firme.

Tabela 2.5 Proporção de plântulas : plântulas; Proporção de adultos : adultos; Proporção do total de indivíduos por hectare na Floresta de Baixio e de Terra Firme das colocações Santa Maria (Município de Brasiléia), Já Começa (Município de Xapuri), Arraia, Morada Nova, Limoeiro e São Pedro (Município de Porto Acre) no Vale do Rio Acre, AC. BA = Baixio; TF $=$ Terra Firme.

\begin{tabular}{llllll}
\hline Município & Colocação & $\begin{array}{l}\text { Proporção plântula } \\
\text { TF : BA }\end{array}$ & $\begin{array}{l}\text { Proporção adultos } \\
\text { TF : BA }\end{array}$ & $\begin{array}{l}\text { Proporção de indivíduos } \\
\text { TF: BA }\end{array}$ \\
\hline Brasiléia & Santa Maria & $1: 1$ & $1: 2$ & $1: 1$ \\
Xapuri & Já Começa & $1: 13$ & $1: 1$ & $1: 8$ & \\
Porto Acre & Arraia & $1: 5$ & $1: 4$ & $1: 3$ & \\
Porto Acre & Morada Nova $1: 1$ & $1: 1$ & $1: 1$ & \\
Porto Acre & Limoeiro & $1: 2$ & $1: 2$ & $1: 2$ & \\
Porto Acre & São Pedro & $1: 11$ & $1: 4$ & $1: 10$ \\
\hline
\end{tabular}


Quando se compara a proporção de plântulas, adultos e indivíduos por hectare entre os dois tipos de florestas das 6 localidades amostradas no Vale do Rio Acre (Tabela 2.5), uma proporção menor de plântulas ocorreu na floresta de Terra Firme em relação ao Baixio, com exceção das colocações Santa Maria e Morada Nova. Comparando-se o número de adultos por hectare entre os dois tipos florestais, este também foi maior nas florestas de Baixio que nas de Terra Firme, com exceção da Colocação Já Começa e Morada Nova. A proporção do número total de indivíduos de E. precatoria foi maior nas florestas de Baixio que nas de Terra Firme. Exceto nas colocações Santa Maria e Morada Nova onde $84,2 \%$ e $64,7 \%$ do número de indivíduos, são plântulas no Baixio e Terra Firme respectivamente. Nestas Colocações a proporção de plântulas foi a mesma em ambos tipos florestais.

A diferença de densidade entre Baixio e Terra Firme pode ser devido ao maior número de amostras coletadas em Brasiléia, como apresentado acima, ou ainda estar relacionado com variações topográficas e de solos existentes nos Baixios amostrados.

A ocorrência de Euterpe precatoria em habitats alagados e também em terras não alagadas encontrado neste estudo corrobora o encontrado por Kahn \& Henderson (1999).

$\mathrm{Na}$ Amazônia peruana foi encontrado que a densidade da população de $E$. precatoria varia de 50 a 250 plantas/ha nos ecossistemas de floresta (Kahn, 1988 citado por De Castro \& Bovi, 1993). Os valores médios da densidade encontrados para as florestas de Baixio foram maiores e para as florestas de Terra Firme (Tabela 2.3) menores que a densidade mínima encontrada por Kahn (1988). Emperaire (2000) trabalhando em Manaquiri, Amazonas (100 km de Manaus) encontrou 116 indivíduos férteis em uma parcela de 0,5 ha em uma floresta secundária com o dossel acima de 30m. Esta densidade foi muito maior que a densidade máxima encontrada em 1 ha de floresta no Vale do Rio Acre.

Na Bolívia E. precatoria é encontrada também em florestas inundadas sazonalmente e de Terra Firme, além de áreas de savana (Moraes 1996, Pena-Claros \& Zuidema, 1999). A densidade de indivíduos reprodutivos varia amplamente entre os tipos de habitat. A densidade encontrada nas florestas inundadas e ilhas de florestas em áreas de savana foi de 260 indivíduos por hectare (Pena-Claros \& 
Zuidema, 1999, citado por Zuidema, 2000), enquanto que em florestas de Terra Firme foi de 23 indivíduos/ha. Comparando com o presente estudo as densidades nas florestas inundada e de Terra Firme apresentaram-se 4 vezes menor e aproximadamente a mesma respectivamente. Peres (1994) trabalhando no Amazonas, próximo ao Rio Urucu com a comunidade de palmeiras também encontrou uma maior densidade de Euterpe precatoria em florestas inundadas sazonalmente que em florestas de Terra Firme.

Euterpe precatoria ocorreu em 100\% dos hectares de florestas amostrados neste estudo com máximo de 118 indivíduos/hectare e o mínimo de 11 indivíduos/hectare (Tabela 2.3). A variação da freqüência de Euterpe precatoria medida em 4 hectares de Terra Firme e 4 hectares de Baixio no Vale do Rio Acre foi de $70 \%$ a $90 \%$ e de $80 \%$ a $100 \%$ respectivamente. Boom (1986) trabalhando na Amazônia boliviana inventariou todas as árvores maiores que $10 \mathrm{~cm}$ de DAP em um transecto de um 1ha na floresta tropical de Terra Firme ao longo do Rio Ivon, e encontrou Euterpe precatoria como uma das espécies mais freqüentes.

A regra na floresta tropical é a alta diversidade de espécies vegetais e a distribuição não igualitária de indivíduos entre estas espécies (Peters, 1996 Chapman \& Hall, 1992). Desta forma, existem espécies que se apresentam com alta densidade de indivíduos, ou as espécies comuns, e espécies com baixa densidade que são as espécies raras. Por convenção, espécies raras são aquelas com menos de 1 indivíduo adulto por hectare, e espécies comuns aquelas acima dessa densidade (Kageyama, 1996).

Considerando esta definição operacional e um gradiente nas comunidades desde as espécies muito raras até as muito comuns, Euterpe precatoria pode ser considerada uma espécie comum nas áreas de estudo. Evidências deste fato foram (1) a pequena distância média entre os indivíduos nas florestas de Baixio e de Terra Firme amostradas (Tabela 2.4), (2) a alta freqüência, (3) a curva populacional na forma de J invertido e (4) as observações de campo de que não se pode andar 3 minutos nas áreas amostradas do Seringal Caquetá sem avistar 1 indivíduo adulto e de outras classes de tamanho de Euterpe precatoria.

A curva de freqüência de tamanho ( $\mathrm{J}$ invertido), as altas densidade e freqüência encontradas para Euterpe precatoria nas áreas amostradas podem ser 
explicadas pelo fato desta espécie ser classificada ecologicamente como tolerante (Denslow, 1980) ou clímax (Budowski, 1965) ou seja, a sua germinação, crescimento e alcance da maturidade reprodutiva ocorre sob as condições da floresta madura e com muita sombra.

Esta tolerância à sombra (Denslow,1980) de Euterpe precatoria, implica na formação de bancos de plântulas, o que sugere uma taxa de germinação proporcionalmente alta para a espécie já que o banco de sementes é muito passageiro no solo, assim como o encontrado para Euterpe edulis (Reis, 1992, citado por Reis, 1995; Fisch, 1998).

A competição interespecífica pode ser uma possível causa da (1) diferença de densidade de Euterpe precatoria entre Baixio e Terra Firme, (2) de uma maior heterogeneidade da distribuição dos indivíduos no primeiro tipo de floresta e (3) das taxas de transição maiores e constantes, de Jovens 1 a adultos. É possível que a falta de competição com outras espécies devido ao alagamento seja uma causa responsável pelas maiores densidades de Açaí nestes locais alagados, ou seja, apesar de Euterpe precatoria crescer em florestas de Terra Firme existem outras espécies que podem também crescer em áreas que não alagam em uma taxa muito mais rápida. Estas espécies porém, podem ter problemas com habitats inundados (Peters, comunicação pessoal).

A alta densidade e freqüência e um número maior de plântulas e jovens $1 \mathrm{em}$ relação aos jovens 2 e adultos, sugerem que Euterpe precatoria tem um alto potencial de manejo. 


\subsubsection{DESENVOLVIMENTO DOS INDIVÍDUOS DE Euterpe precatoria}

Na Floresta de Baixio da Colocação São Pedro houve um maior número de indivíduos adultos com DAP entre 14 a $16 \mathrm{~cm}$ e número de folhas de 12 a 14 e indivíduos jovens 2 com DAP entre 6 e 14cm e número de folhas entre 6 e 8 . O DAP médio dos indivíduos adultos foi de $15,3 \mathrm{~cm} \pm 1,4$. Na Floresta de Terra Firme houve a predominância de adultos com DAP entre 18 e $20 \mathrm{~cm}$ e número de folhas entre $16 \mathrm{a}$ 18 e jovens 2 com DAP de 14 a $18 \mathrm{~cm}$ e número de folhas de 12 a 14 . O DAP médio dos adultos foi de $17,4 \mathrm{~cm} \pm 1,7$ (Figura 2.8).

Na Colocação Já Começa foi estimada visualmente a altura das palmeiras adultas de E. precatoria. A maioria dos indivíduos no Baixio apresentaram uma classe de altura menor que na Terra Firme. A altura média foi de 15,0m $\pm 1,8$ e 15,5m $\pm 1,2$ respectivamente. O DAP médio foi de $17,8 \mathrm{~cm} \pm 3,2$ e $19,8 \mathrm{~cm} \pm 2,8$ e o DAP da maioria dos indivíduos adultos foi menor no Baixio que na Terra Firme.

Estes dados sugerem que o porte dos indivíduos de E. precatoria apresentouse menor na floresta de Baixio que na de Terra Firme independentemente da Colocação e ano amostrados. 

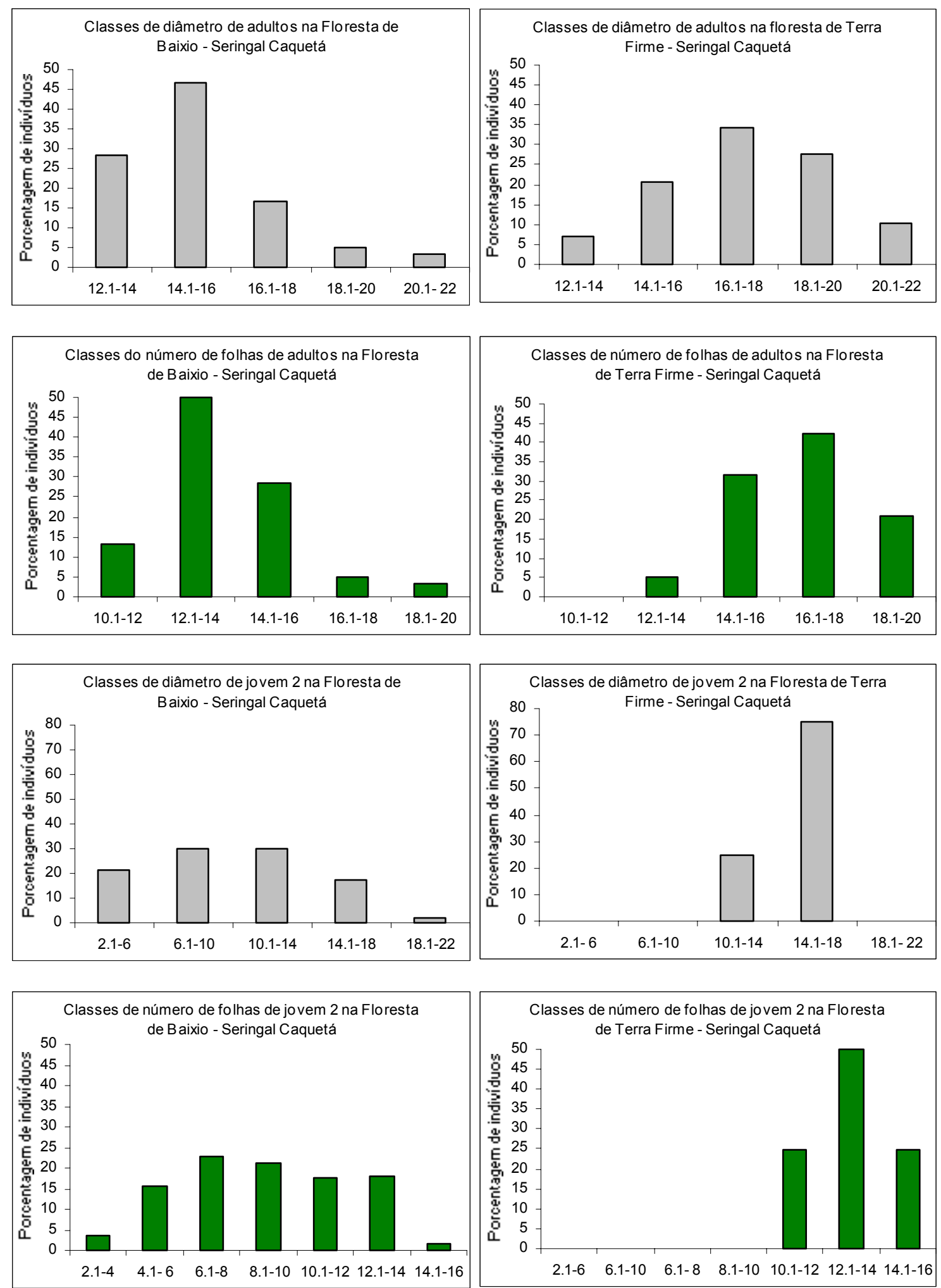

Figura 2.8 Classes de diâmetro e classes do número de folhas dos indivíduos Jovens 2 e Adultos de Euterpe precatoria na floresta de Baixio e de Terra Firme da Colocação S. Pedro, Seringal Caquetá, AC. 


\subsubsection{DISTRIBUIÇÃO ESPACIAL}

De acordo com os valores do índice de Morisita calculados (IdM) e os valores do Índice de Morisitia padronizados (IdMp) (Tabela 2.6), as plântulas enquadraramse na categoria de distribuição espacial agrupada e os estágios Jovem1, Jovem 2 e Adultos na categoria aleatória, tanto na floresta de Baixio quanto na floresta de Terra Firme.

Tabela 2.6 Distribuição espacial dos indivíduos de Euterpe precatoria em quatro classes de tamanho, calculada a partir do Índice de Morisitia (IdM) e do Índice de Morisitia padronizado (IdMp).

\begin{tabular}{llll}
\hline Floresta de Baixio & & & \\
\hline Classes de tamanho & $\mathrm{IdM}$ & $\mathrm{IdMp}$ & Distribuição \\
Plântula & 3,5 & 1,2 & Agrupada \\
Jovem 1 & 1,6 & 0,2 & Aleatória \\
Jovem 2 & 1,6 & 0,2 & Aleatória \\
Adulto & 1,5 & 0,2 & Aleatória \\
\hline Floresta de Terra Firme & & & \\
\hline Classes de tamanho & $\mathrm{IdM}$ & $\mathrm{IdMp}$ & Distribuição \\
Plântula & 3,9 & 1,4 & Agrupada \\
ovem 1 & 1,5 & 0,2 & Aleatória \\
Jovem 2 & 1,4 & 0,2 & Aleatória \\
Adulto & 1,6 & 0,2 & Aleatória \\
\hline
\end{tabular}

Ocorreu um padrão de distribuição espacial menos agrupado quanto maior o desenvolvimento dos indivíduos de Euterpe precatoria assim como o encontrado para Euterpe edulis, em Campinas, SP (Silva, 1991; Alves, 1994 e Silva Matos, 1995; citados por Fisch, 1998). Reis (1995) estudando uma população de Euterpe edulis na floresta Ombrófila Densa na região de Blumenau, SC observou uma distribuição agrupada para o banco de plântulas e jovens, e uma distribuição aleatória para os estágios imaturo e adultos. A Figura 2.9 é ilustrativa dos valores da Tabela 2.6 .

O padrão de distribuição de agrupado a aleatório mostra a importância da competição intraespecífica na determinação do padrão espacial dos adultos como o encontrado por Yeaton (1979) citado por Cassilas (1984) para Socratea durissima. Segundo o autor a competição intraespecífica ocorre principalmente por água e nutrientes resultando em um espaçamento aleatório nas palmeiras adultas. 

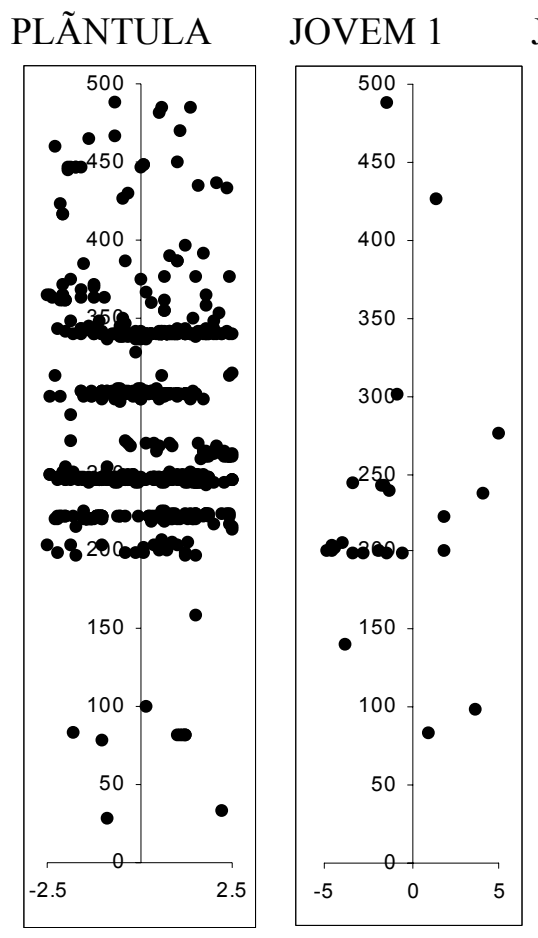

JOVEM 2 ADULTO

PLÂNTULA

\section{JOVEM 1}
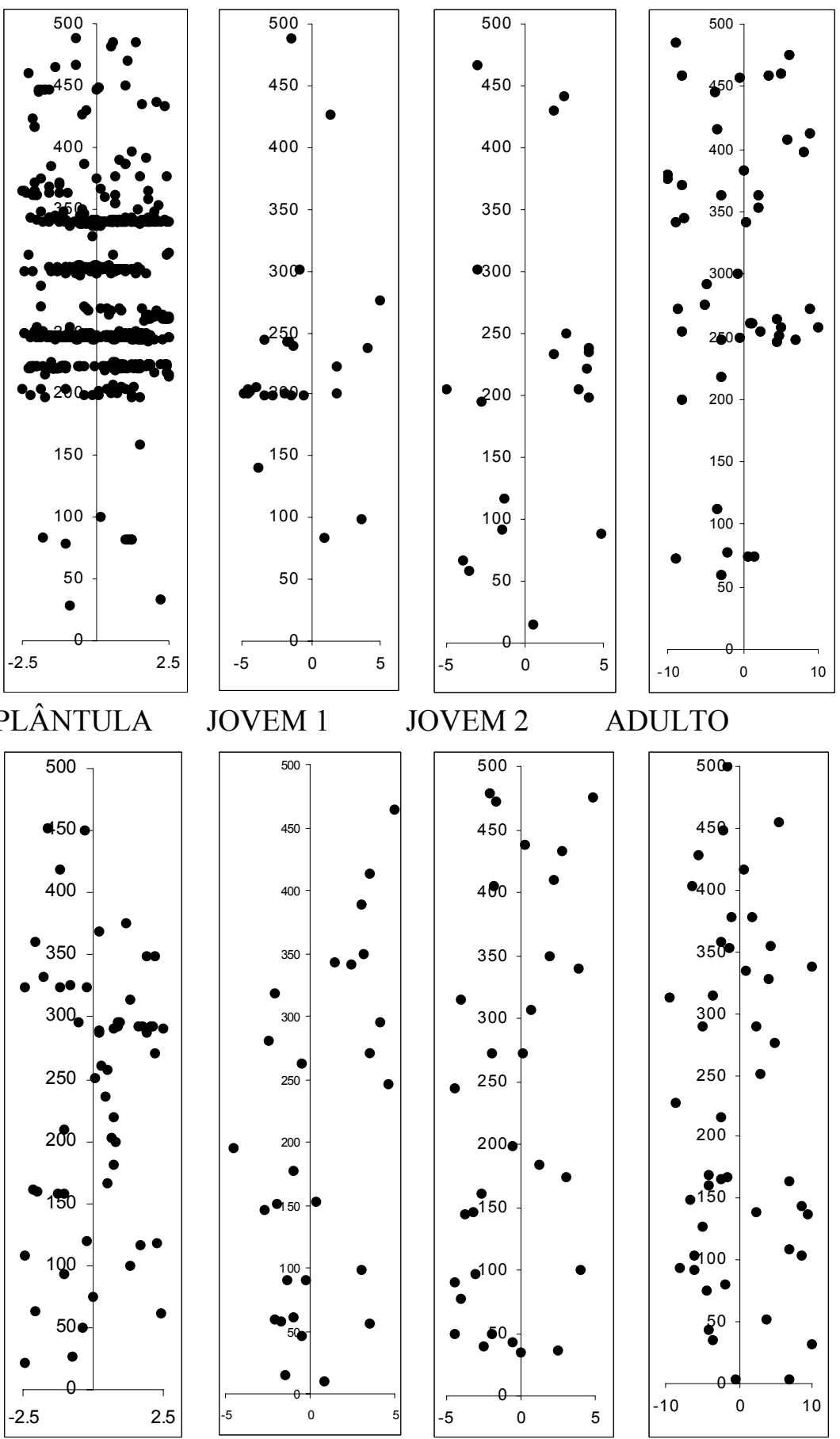

ADULTO

Figura 2.9 Distribuição espacial de Euterpe precatoria dividido em quatro classes de tamanho - Plântula, Jovem 1, Jovem 2 e Adulto respectivamente na floresta de Baixio (4 Figuras acima) e de Terra Firme (4 Figuras abaixo) da Colocação Já Começa - Seringal Dois Irmãos, AC. 
Janzen (1970) assume que devido à alta chuva de sementes logo abaixo das árvores progenitoras a densidade de predadores e patógenos tende a se concentrar perto das árvores mães onde a mortalidade de sementes e plântulas é mais alta que a uma certa distância destas. Os propágulos dispersados longe da planta mãe, então, são os mais prováveis para escapar a predação e de ter uma sobrevivência mais alta.

Considerando-se que o estabelecimento de uma plântula depende da chance dela chegar em um local específico, porque neste local são providas as condições para a germinação da semente e de ausência de predadores, competidores e patógenos (Harper 1977), a influência destes fatores no estabelecimento de plântulas pode ser uma função da distância entre as plântulas e /ou sua árvore mãe ou uma função da densidade de plântulas (Augspurger 1983). Como conseqüência, o padrão de distribuição espacial encontrado para Euterpe precatoria neste estudo - onde uma menor agregação aconteceu com o maior desenvolvimento dos indivíduos (Tabela 2.6) - pode ser o resultado do padrão de sobrevivência e do crescimento, mas também do padrão de distribuição de sítios favoráveis ao desenvolvimento.

Segundo Reis \& Kageyama (2000) Euterpe edulis, palmeira da Mata Atlântica, se caracteriza por uma curva de distribuição de sementes do tipo leptocúrtica, com alta densidade de sementes próximo a planta-mãe e uma grande redução numérica a partir do aumento da distância da fonte de sementes, corroborando Janzen (1970) para espécies tropicais. Clark \& Clark (1984) e Augspurger (1983) constataram o mesmo comportamento para outras espécies.

Apesar desta interpretação, trabalhos como de Hubbel (1980) detectaram padrões agregados na distribuição das populações de 70\% das espécies estudadas em grandes extensões de florestas tropicais (inclusão DAP $\geq 2 \mathrm{~cm}$ ). $\mathrm{O}$ autor encontrou que a densidade de sementes é muito alta próximo ao adulto, e mesmo que haja uma grande mortalidade neste local, a baixa porcentagem que sobrevive ainda é maior que as sobreviventes que foram dispersadas a distâncias maiores. 


\subsubsection{DINÂMICA POPULACIONAL}

Independente da Colocação e tipo de floresta amostradas, a taxa de sobrevivência foi maior para jovens 2 e adultos que para plântulas e jovens 1 (Tabelas 2.9, 2.10, 2.11, 2.12). O padrão de sobrevivência em relação ao tamanho da planta foi similar ao encontrado para outras espécies de palmeiras (Enright \& Watson, 1992 citado por Zuidema \& Boot, 2000). A probabilidade de sobrevivência aumentou de plântulas para jovens independente da Colocação e do tipo florestal (Tabelas 2.9, 2.10, 2.11 e 2.12), como encontrado por Zuidema \& Boot (2000) para Euterpe precatoria em florestas de terras baixas na Bolívia.

Bovi \& De Castro (1992) encontraram uma sobrevivência de plântulas de Euterpe precatoria baixa, especialmente na fase de folha única até as plantas terem aproximadamente $50 \mathrm{~cm}$ de altura. Fatores como a disponibilidade de água, nutrientes e luz, (Swaine, et. al., 1987), herbivoria, danos físicos pela queda de árvores e/ou galhos comumente afetam a mortalidade da população de várias espécies de palmeiras (Zuidema \& Boot, 2000).

Tabela 2.7 Média de indivíduos/ha de Euterpe precatoria divididos em 4 classes de tamanho e as respectivas taxas de sobrevivência, mortalidade, recrutamento para a próxima classe de tamanho e número de novos recrutas por adulto na floresta da Colocação São Pedro, Seringal Caquetá, AC.

\begin{tabular}{lllll}
\hline Classe de tamanho & Plântula & Jovem 1 & Jovem 2 & Adulto \\
\hline Palmeiras ha $^{-1}$ & 1793 & 157 & 73 & 27,7 \\
Taxa de sobrevivência $(\sigma)$ & $0,43(43 \%)$ & $0,77(77 \%)$ & $0,97(97 \%)$ & $0,95(95 \%)$ \\
Taxa de mortalidade & $0,57(57 \%)$ & $0,23(23 \%)$ & $0,03(3 \%)$ & $0,05(5 \%)$ \\
Taxa de transição $(\gamma)$ & $0,13(13 \%)$ & $0,09(9 \%)$ & $0,03(3 \%)$ & 0 \\
Recrutas palmeira $^{-1}$ & 0 & 0 & 0 & 8,95 \\
\hline
\end{tabular}




\begin{tabular}{|llll}
0,374791 & 0 & 0 & 8,95 \\
0,054657 & 0,700637 & 0 & 0 \\
0 & 0,066879 & 0,945205 & 0 \\
0 & 0 & 0,027397 & 0,954955
\end{tabular} \mid

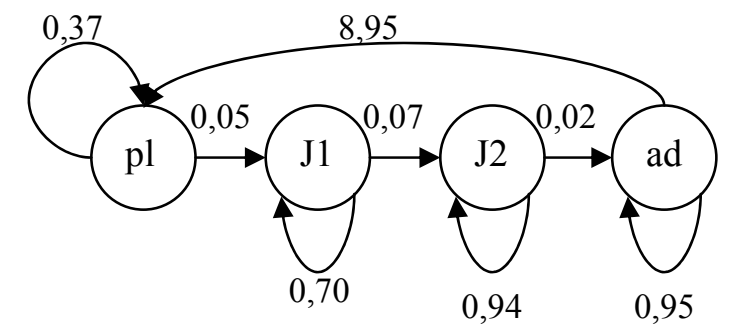

Figura 2.10 Matriz de Transição (média na floresta de Baixio e de Terra Firme) feita a partir do gráfico do ciclo de vida de Euterpe precatoria no Seringal Caquetá, Colocação São Pedro, AC. No gráfico do ciclo de vida $\mathrm{pl}=$ plântulas, $\mathrm{j} 1=$ jovem $1, \mathrm{j} 2=$ jovem 2 e ad $=$ adulto.

Comparando a dinâmica de plântula, jovem 1 e jovem 2 entre colocações, a taxa de sobrevivência média foi similar, menor e maior e o número total de indivíduos que sobreviveram após um ano foi 2; 3,5 e 2,5 vezes maior na Colocação São Pedro que na Já Começa respectivamente.

Para adultos, a taxa de sobrevivência foi $1 \%$ maior e o número de indivíduos após um ano foi 1,2 vezes maior na Colocação Já Começa que na São Pedro (Tabelas 2.7 e 2.8; Figuras 2.10 e 2.11).

Tabela 2.8 Média de indivíduos/ha de Euterpe precatoria divididos em 4 classes de tamanho e as respectivas taxas de sobrevivência, mortalidade, transição para a próxima classe de tamanho e número de novos recrutas por adulto na floresta do Seringal Dois Irmãos, Colocação Já Começa, AC.

\begin{tabular}{lllll}
\hline Classe de tamanho & Plântula & Jovem 1 & Jovem 2 & Adulto \\
\hline Média de Palmeiras ha $^{-1}$ & 797 & 42.5 & 38 & 32.5 \\
Taxa de sobrevivência $(\sigma)$ & $0,43(43 \%)$ & $0,8(80 \%)$ & $0,75(75 \%)$ & $0,96(96 \%)$ \\
Taxa de mortalidade & $0,57(57 \%)$ & $0,2(20 \%)$ & $0,25(25 \%)$ & $0,04(4 \%)$ \\
Taxa de transição $(\gamma)$ & $0,02(2 \%)$ & $0,01(1 \%)$ & $0,18(18 \%)$ & 0 \\
Recrutas palmeira $^{-1}$ & 0 & 0 & 0 & 7,44 \\
\hline
\end{tabular}




$\left|\begin{array}{llll}0,422836 & 0 & 0 & 7,44 \\ 0,007528 & 0,788235 & 0 & 0 \\ 0 & 0,011765 & 0,618421 & 0 \\ 0 & 0 & 0,131579 & 0,961538\end{array}\right|$

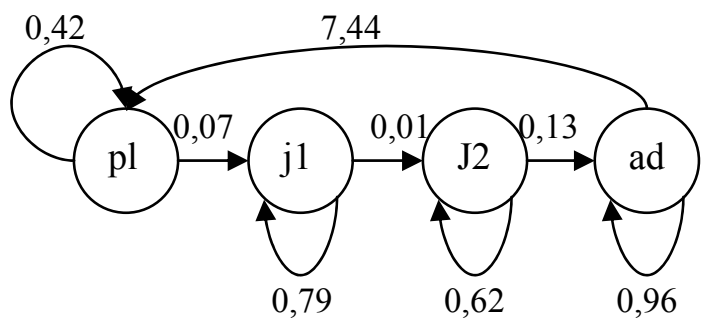

Figura 2.11 Matriz de Transição (média da floresta de Baixio e de Terra Firme) feita a partir do gráfico do ciclo de vida de Euterpe precatoria no Seringal Dois Irmãos, Colocação Já Começa, AC. No gráfico do ciclo de vida $\mathrm{pl}=$ plântulas, $\mathrm{j} 1=$ jovem $1, \mathrm{j} 2=$ jovem $2 \mathrm{e}$ ad $=$ adulto.

Com exceção da taxa de transição média da classe jovens 2 que foi menor, todas as outras classes de tamanho apresentaram taxas de transição média maiores na Colocação São Pedro que na Já Começa. A fecundidade foi 1,6 vezes maior na Colocação São Pedro que na Já Começa (Tabelas 2.7 e 2.8). As diferenças nas taxas de fecundidade e transição observadas entre colocações para Euterpe precatoria podem ser devido a diferenças naturais na distribuição do Açaí no Vale do Rio Acre, ocasionadas pelas diferenças edáficas, de declividade das áreas, diferenças de dispersão e predação de sementes, ou ainda devido a diferenças climáticas de precipitação e temperatura ocorridas entre os anos amostrados.

$\mathrm{Na}$ Colocação São Pedro o número de indivíduos de todas as classes de tamanho na floresta de Baixio foi maior que na floresta de Terra Firme. As taxas de sobrevivência de plântulas e jovens 2 foram mais baixas e as de jovem 1 e adultos mais altas no primeiro tipo florestal que no segundo. $\mathrm{O}$ número aproximado de indivíduos sobreviventes no Baixio após um ano foi 10; 7; 17 e 5 vezes maior que na Terra Firme, para plântulas, jovem 1, jovem 2 e adultos respectivamente (Tabelas 2.9 e 2.10). 
Tabela 2.9 Número de indivíduos/ha de Euterpe precatoria divididos em 4 classes de tamanho e as respectivas taxas de sobrevivência, mortalidade, transição para a próxima classe de tamanho e número de novos recrutas por adulto na floresta de Baixio da Colocação São Pedro, Seringal Caquetá, AC.

\begin{tabular}{lllll}
\hline Classe de tamanho & Plântula & Jovem 1 & Jovem 2 & Adulto \\
\hline Palmeiras há $^{-1}$ & 3432 & 290 & 142 & 50 \\
Taxa de sobrevivência $(\sigma)$ & $0,43(43 \%)$ & $0,78(78 \%)$ & $0,97(97 \%)$ & $0,96(96 \%)$ \\
Taxa de mortalidade & $0,57(57 \%)$ & $0,22(22 \%)$ & $0,03(3 \%)$ & $0,04(4 \%)$ \\
Taxa de transição $(\gamma)$ & $0,12(12 \%)$ & $0,09(9 \%)$ & $0,03(3 \%)$ & 0 \\
Recrutas palmeira $^{-1}$ & 0 & 0 & 0 & 9,34 \\
\hline
\end{tabular}

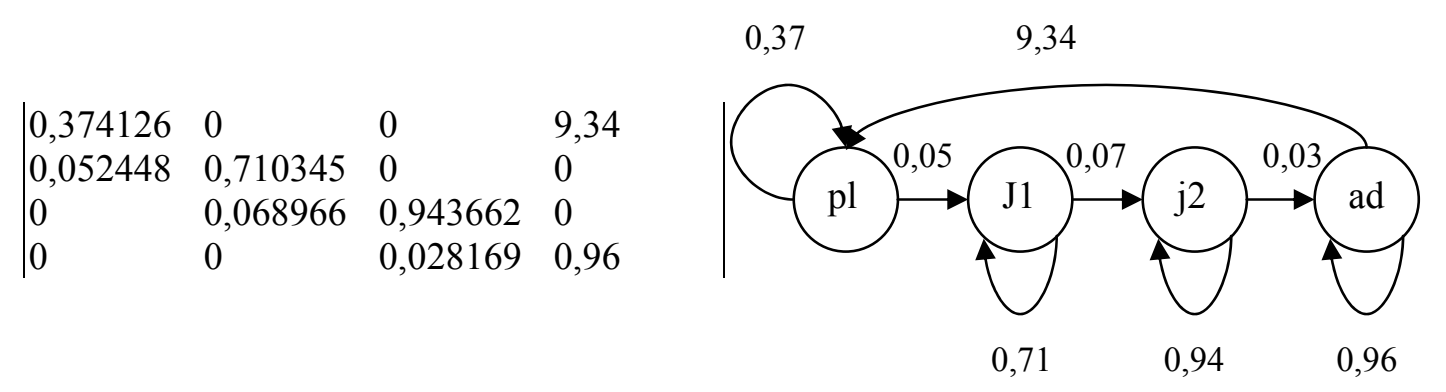

Figura 2.12 Matriz de Transição feita a partir do gráfico do ciclo de vida de Euterpe precatoria na floresta de Baixio da Colocação São Pedro, Seringal Caquetá, AC.

No gráfico do ciclo de vida $\mathrm{pl}=$ plântulas, $\mathrm{j} 1=$ jovem $1, \mathrm{j} 2=$ jovem $2 \mathrm{e}$ ad $=$ adulto.

Na Colocação São Pedro a menor taxa de transição de plântulas no Baixio pode estar relacionada com uma maior mortalidade desta classe neste tipo de floresta quando comparado com a Terra Firme. Mesmo assim, a taxa de transição de 12\% no Baixio representou um maior número de indivíduos que passaram de plântulas para jovem 1, que o número de plântulas encontrado no censo inicial da densidade na Terra Firme. Além disso a fecundidade durante o período de 1 ano foi aproximadamente 3,5 vezes maior no Baixio que na Terra Firme (Tabelas 2.9 e 2.10).

O gráfico do ciclo de vida na Terra Firme desta Colocação (Figura 2.13) mostra uma taxa de transição zero para jovens 2 no período estudado. A transição zero pode ser devido ao período de tempo de apenas 1 ano de avaliação ou devido ao número pequeno de indivíduos amostrados na Terra Firme desta área. 
Tabela 2.10 Número de indivíduos/ha de Euterpe precatoria divididos em 4 classes de tamanho e as respectivas taxas de sobrevivência, mortalidade, transição para a próxima classe de tamanho e número de novos recrutas por adulto na floresta de Terra Firme do Seringal Caquetá, Colocação São Pedro, AC.

\begin{tabular}{lllll}
\hline Classe de tamanho & Plântula & Jovem 1 & Jovem 2 & Adulto \\
\hline Palmeiras ha ${ }^{-1}$ & 308 & 48 & 8 & 11 \\
Taxa de & $0,49(49 \%)$ & $0,63(63 \%)$ & $1(100 \%)$ & $0,91(91 \%)$ \\
Sobrevivência $(\sigma)$ & & & & \\
Taxa de mortalidade & $0,51(51 \%)$ & $0,38(38 \%)$ & 0 & $0,09(9 \%)$ \\
Taxa de transição $(\gamma)$ & $0,21(21 \%)$ & $0,07(7 \%)$ & 0 & 0 \\
Recrutas palmeira $^{-1}$ & 0 & 0 & 0 & 2,72 \\
\hline
\end{tabular}

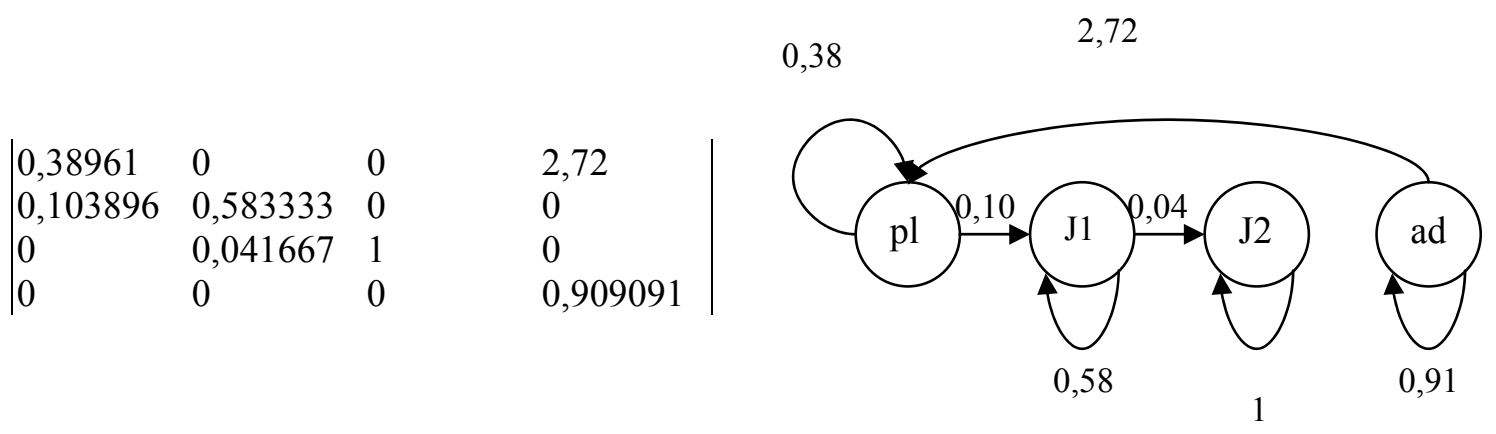

Figura 2.13 Matriz de Transição feita a partir do gráfico do ciclo de vida de Euterpe precatoria na floresta de Terra Firme da Colocação São Pedro, Seringal Caquetá, AC.

No gráfico do ciclo de vida $\mathrm{pl}=$ plântulas, $\mathrm{j} 1=$ jovem $1, \mathrm{j} 2=$ jovem $2 \mathrm{e}$ ad $=$ adulto. A ausência de flecha de uma classe de tamanho a outra no gráfico significa taxa transição zero no período estudado.

Na Colocação Já Começa apenas o número de plântulas foi maior no Baixio que na Terra Firme. $\mathrm{O}$ número de jovens 1 e jovens 2 foi menor e o de adultos aproximadamente o mesmo. Ao final de um ano o número total de plântulas foi 10 vezes maior no Baixio que na Terra Firme e o de adultos o mesmo. Para jovens 1 e 2 o número de sobreviventes após um ano, foi maior na Terra Firme que no Baixio (Tabelas 2.11 e 2.12). 
Tabela 2.11 Número de indivíduos/ha de Euterpe precatoria divididos em 4 classes de tamanho e as respectivas taxas de sobrevivência, mortalidade, transição para a próxima classe de tamanho e número de novos recrutas por adulto na floresta de Baixio do Seringal Dois Irmãos, Colocação Já Começa, AC.

\begin{tabular}{lllll}
\hline Classe de tamanho & Plântula & Jovem 1 & Jovem 2 & Adulto \\
\hline Palmeiras ha $^{-1}$ & 2.756 & 48 & 40 & 44 \\
Taxa de sobrevivência $(\sigma)$ & $0,41(41 \%)$ & $0,75(75 \%)$ & $0,85(85 \%)$ & $0,98(98 \%)$ \\
Taxa de mortalidade & $0,59(59 \%)$ & $0,25(25 \%)$ & $0,15(15 \%)$ & $0,02(2 \%)$ \\
Taxa de transição $(\gamma)$ & 0 & $0,06(6 \%)$ & $0,12(12 \%)$ & 0 \\
Recrutas palmeira $^{-1}$ & 0 & 0 & 0 & 4,52 \\
\hline
\end{tabular}

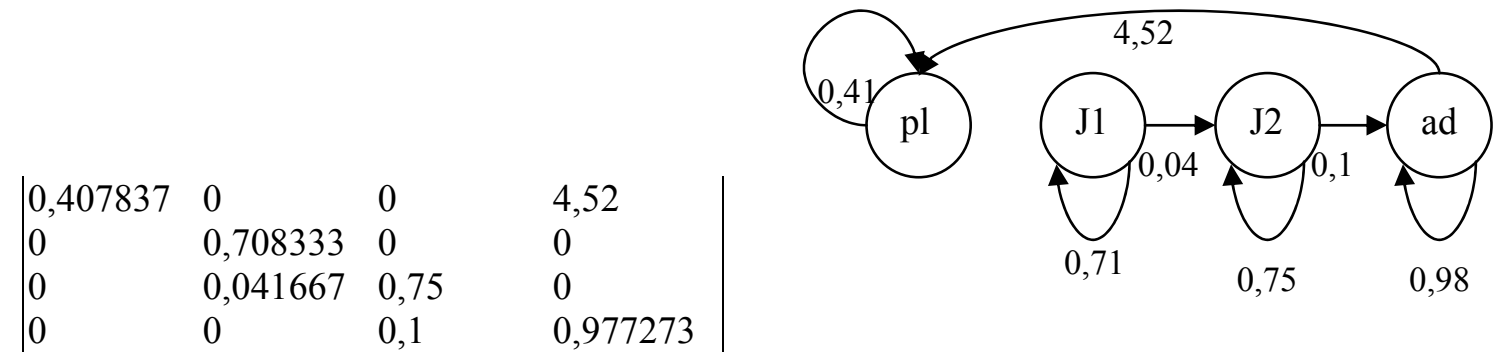

Figura 2.14 Matriz de Transição média feita a partir do gráfico do ciclo de vida de Euterpe precatoria na floresta de Baixio da Colocação Já Começa, Seringal Dois Irmãos, AC.

No gráfico do ciclo de vida $\mathrm{pl}=$ plântulas, $\mathrm{j} 1=$ jovem $1, \mathrm{j} 2=$ jovem 2 e ad $=$ adulto. A ausência de flecha de uma classe de tamanho a outra no gráfico significa taxa de transição zero no período estudado.

Na Colocação Já Começa não houve transição de plântulas no Baixio e de jovem 1 na Terra Firme no período de tempo estudado. A taxa de transição total das classes menores para a classe de tamanho adultos foi $1 \%$ maior na Terra Firme que no Baixio. Isto foi refletido na densidade de adultos semelhante (Baixio com $44 \mathrm{e}$ Terra Firme com 43 indivíduos) entre os dois tipos florestais nesta Colocação. Provavelmente o número de plântulas maior no Baixio que na Terra Firme para a Colocação Já começa está ligado a fecundidade aproximadamente 4.5 vezes maior no Baixio (Tabelas 2.11 e 2.12). Sabe-se que bancos de plântulas maiores, teoricamente, sugerem uma taxa de germinação proporcionalmente alta para a espécie, como o encontrado para Euterpe edulis. (Reis, M. S. 1992, citado por Reis, 1995; Fisch, 1998). 
Tabela 2.12 Número de indivíduos/ha de Euterpe precatoria divididos em 4 classes de tamanho e as respectivas taxas de sobrevivência, mortalidade, transição para a próxima classe de tamanho e número de novos recrutas por adulto na floresta de Terra Firme do Seringal Dois Irmãos, Colocação Já Começa, AC.

\begin{tabular}{lllll}
\hline Classe de tamanho & Plântula & Jovem 1 & Jovem 2 & Adulto \\
\hline Palmeiras ha $^{-1}$ & 216 & 60 & 56 & 43 \\
Taxa de sobrevivência $(\sigma)$ & $0,57(57 \%)$ & $0,83(83 \%)$ & $0,71(71 \%)$ & $0,95(95 \%)$ \\
Taxa de mortalidade & $0,43(43 \%)$ & $0,17(17 \%)$ & $0,29(29 \%)$ & $0,05(5 \%)$ \\
Taxa de transição $(\gamma)$ & $0,01(1 \%)$ & 0 & $0,2(20 \%)$ & 0 \\
Recrutas palmeira $^{-1}$ & 0 & 0 & 0 & 1 \\
\hline
\end{tabular}

\begin{tabular}{|llll}
0,518519 & 0 & 0 & 1 \\
0,055556 & 0,83 & 0 & 0 \\
0 & 0 & 0,571429 & 0 \\
0 & 0 & 0,142857 & 0,953488
\end{tabular} \mid

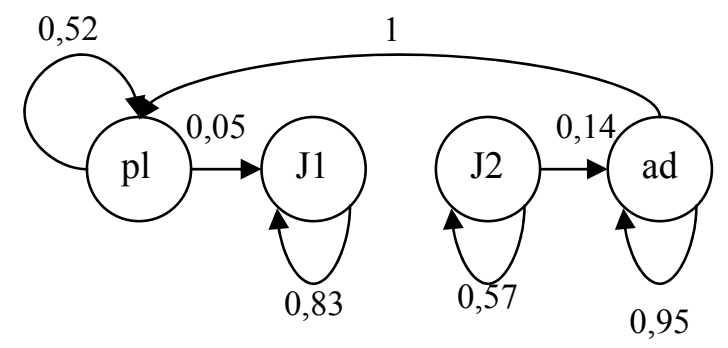

Figura 2.15 Matriz de Transição feita a partir do gráfico do ciclo de vida de Euterpe precatoria na floresta de Terra Firme da Colocação Já Começa, Seringal Dois Irmãos, AC. No gráfico do ciclo de vida $\mathrm{pl}=$ plântulas, $\mathrm{j} 1=$ jovem $1, \mathrm{j} 2=$ jovem 2 e ad $=$ adulto. A ausência de flecha de uma classe de tamanho a outra no gráfico significa taxa de transição zero no período estudado.

Os gráficos do ciclo de vida no Baixio e na Terra Firme desta Colocação (Figuras 2.14 e 2.15) mostram taxas de transição zero para plântulas e jovens 1 respectivamente no período estudado.

As matrizes de transição das Colocações São Pedro e Já Começa obtidas a partir dos ciclos de vida de E. precatoria encontram-se representadas pelas Figuras $2.10,2.11,2.12,2.13,2.14,2.15$. As matrizes de transição foram feitas a partir do gráfico do ciclo de vida que as acompanham em cada figura utilizando os valores dos parâmetros da sobrevivência, transição e fecundidade apresentados nas Tabelas 2.7, 2.8, 2.9, 2.10, 2.11,2.12. Os valores médios foram calculados do Baixio e Terra Firme de cada Colocação (Tabelas 2.7 e 2.8; Figuras 2.10 e 2.11). 
A estimativa da taxa média de aumento populacional $(\lambda)$ para Euterpe precatoria na Colocação S. Pedro, foi de 1,016 e para a Colocação Já Começa de 0,964 .

Estes valores sugerem que a população de Euterpe precatoria estudada na Colocação São Pedro está aumentando, ou seja, a taxa de natalidade é maior que a taxa de mortalidade e na Colocação Já Começa o tamanho da população está decrescendo, ou seja, a mortalidade é maior que a natalidade. De acordo com os cálculos dos valores de $\lambda$ feitos separadamente nos Baixios e Terra Firmes e Colocações (Tabela 2.13) pode-se perceber que o valor médio crescente do $\lambda$ na Colocação São Pedro foi devido a estabilidade crescente $(>1)$ da população na floresta de Baixio. Na Floresta de Terra Firme da mesma Colocação foi encontrado o valor de 1 para a taxa de crescimento populacional, que representa uma população estável na densidade. Desta forma, a dinâmica populacional do Açaí no Baixio e na Terra Firme é distinta na Colocação São Pedro (Tabela 2.13).

Na Colocação Já Começa o valor de $\lambda$ médio do Baixio e Terra Firme foi decrescente $(\lambda=0,964)$. Na Tabela 2.13 são apresentados taxas de crescimento populacional de outras populações de palmeiras.

Tabela 2.13 Taxa finita de crescimento $(\lambda)$ de algumas populações de palmeiras.

\begin{tabular}{|c|c|c|c|}
\hline Espécie & $\lambda$ & & Fonte \\
\hline \multirow[t]{3}{*}{ Euterpe precatoria } & $\mathrm{JC}$ & Floresta & Este estudo \\
\hline & $0,977-1,021$ & Baixio & \\
\hline & $0,953-1,000$ & Terra Firme & \\
\hline Euterpe precatoria & $0,96-0,97$ & & Zuidema \& Boot (1999) \\
\hline Podoccocus bartieri & 1,01 & & Bullock (1980) \\
\hline Astrocaryum mexicanum & $0,99-1,03$ & & Pinero et. al. (1984) \\
\hline Euterpe edulis & 1,24 & & Matos, et. al. (1995) \\
\hline Euterpe edulis & 1,16 & & Fisch (1998) \\
\hline Phytelephas seemanii & 1,05 & & Bernal (1998) \\
\hline Iriartea deltoidea & $0,98-1,01$ & & Pinard (1993) \\
\hline
\end{tabular}

JC = Colocação Já Começa, Seringal Dois Irmãos ; SP = Colocação São Pedro, Seringal Caquetá. 
Independentemente da área amostrada os valores da taxa de crescimento populacional são maiores na floresta de Baixio que na de Terra Firme, mas os valores encontrados na Colocação Já Começa apresentaram-se menores que aqueles encontrados na Colocação São Pedro. Isto pode ser devido a diferenças naturais na distribuição de Açaí no Vale do Rio Acre ocasionadas pelas diferenças edáficas, de declividade das áreas, diferenças de dispersão e predação de sementes, ou ainda devido a diferenças climáticas de precipitação e temperatura ocorridas entre os anos amostrados.

Zuidema \& Boot, (2000), estudando Euterpe precatoria na Bolívia encontraram um $\lambda$ igual a 0,97 . Este valor decrescente de lambda parece estar relacionado com a intensa colheita de indivíduos adultos para a extração de palmito na área, já que a classe dos indivíduos reprodutivos contribuem muito para o valor de $\lambda$.

A taxa de crescimento $(\lambda)$ de uma população de Euterpe precatoria na floresta de terras baixas da Bolívia durante o ano normal foi 0,977 , e durante o ano seco um pouco mais baixa, 0,960. A diferença entre estes valores pode ser explicada pelas taxas de crescimento mais baixas em categorias de tamanho intermediárias a grandes, durante o ano seco, e também pelo recrutamento e sobrevivência muito reduzidos que segue o ano seco (Zuidema \& Boot, 2000).

Para populações de outras espécies de palmeira foram encontrados valores de $\lambda$ como 1,16 para Euterpe edulis (Fisch, 1998), 1,05 para Phytelephas seemanii (Bernal, 1998) e 0,98 a 1,01 para Iriartea deltoidea (Pinard 1993).

A sensibilidade dos parâmetros demográficos para a taxa de crescimento populacional seguiu a ordem: Fecundidade $(\mathrm{F})<$ Probabilidade de sobreviver e permanecer na mesma classe $(\mathrm{P})<$ Probabilidade de sobreviver e passar para a próxima classe de Tamanho $(\mathrm{G})$ na floresta de Baixio da Colocação São Pedro para plântulas (1) jovens 1 (2) e jovens 2 (3). Na classe de tamanho adultos (4) a maior sensibilidade para o valor de $\lambda$ foi a de sobreviver e permanecer na mesma classe de tamanho e a menor foi atribuída ao parâmetro G (Tabela 2.14). Na floresta de Terra Firme da mesma Colocação a sensibilidade dos parâmetros demográficos para a taxa de crescimento populacional seguiu a ordem:

$(\mathrm{F})<(\mathrm{G})<(\mathrm{P})$. 
As análises de sensibilidade feitas no Baixio desta Colocação (Tabela 2.14) mostraram o mesmo padrão para as plântulas, jovens 1 e 2 encontrado para a média dos dois tipos florestais (Tabela 2.14). Na Terra Firme a probabilidade dos indivíduos jovens 2 permanecerem na mesma classe de tamanho foi maior que de crescerem para a classe seguinte (Tabela 2.14). Este fato pode estar relacionado com a taxa de transição que foi zero para esta classe no período estudado (Figura 2.12). A taxa de transição zero atribuída para os jovens 2 na Terra Firme da Colocação São Pedro provavelmente está relacionada com o baixo número de indivíduos amostrados desta classe, ou ainda pode ser devido ao período curto estudado.

O valor reprodutivo aumentou de plântulas para adultos nas duas colocações amostradas e independente do tipo de floresta, apresentando certamente valores máximos na classe de tamanho adultos.

No Baixio da Colocação São Pedro a probabilidade de um indivíduo de Euterpe precatoria passar para a próxima classe de tamanho $(\mathrm{G})$ contribuiu mais para o valor de $\lambda$ que a probabilidade de sobreviver e permanecer na mesma classe (P). Isto está diretamente relacionado com as condições ambientais do Baixio analisado que possui maior penetração de luz no subosque e maior disponibilidade de água em relação a Terra Firme. As menores luminosidade e umidade da Terra Firme fazem com que a probabilidade de permanecer na mesma classe de tamanho $(\mathrm{P})$ de um ano a outro contribua mais para o valor de lambda que a probabilidade de passar para a próxima classe de tamanho. A maior diversidade encontrada em florestas de Terra Firme em relação as florestas de inundação sugere que no primeiro tipo florestal exista uma maior variedade de espécies na competição interespecífica com Euterpe precatoria por luz, nutrientes etc.

Tanto os indivíduos do Baixio quanto os da Terra Firme da Colocação Já Começa contribuíram mais para o valor de $\lambda$ com a probabilidade de permanecer na mesma classe de tamanho $(\mathrm{P})$ que a probabilidade de passar para a próxima classe de tamanho $(\mathrm{G})$.

A análise da sensibilidade para os elementos da matriz mostraram que para as plântulas e os jovens 1 a maior contribuição do valor de $\lambda$ é a do parâmetro $\mathrm{G}$, e para os jovens 2 e adultos a maior contribuição é a do parâmetro P (Figura 2.11). 
Tabela 2.14 Sensibilidade da taxa de crescimento populacional $(\lambda)$ em porcentagem $(\%)$ às mudanças nas probabilidades de sobreviver e permanecer na mesma classe de plântulas $(\mathrm{P} 1,1)$, jovem $1(\mathrm{P} 2,2)$, jovem $2(\mathrm{P} 3,3)$ e adulto $(\mathrm{P} 4,4)$; sobreviver e passar para a classe de tamanho seguinte de plântulas $(\mathrm{G} 1,2)$, jovem $1(\mathrm{G} 2,3)$ e jovem $2(\mathrm{G} 3,4)$ e da fecundidade $(\mathrm{F} 4,1)$ encontradas para E. precatoria na Floresta de Baixio e na de Terra Firme e uma média dos dois tipos florestais nas Colocações São Pedro (Seringal Caquetá) e na Colocação Já Começa (Seringal Dois Irmãos), AC.

\begin{tabular}{|c|c|c|c|c|c|c|}
\hline \multicolumn{7}{|c|}{ SENSIBILIDADE } \\
\hline & \multicolumn{3}{|c|}{ Seringal Caquetá, Colocação São Pedro } & \multicolumn{3}{|c|}{ Seringal Dois Irmãos, Colocação Já Começa } \\
\hline & Baixio & Terra Firme & Média & Baixio & Terra Firme & Média \\
\hline$\overline{\mathrm{P} 1,1}$ & 1,5 & $6,1 \mathrm{E}-27$ & 1,5 & $4,5 \mathrm{E}-34$ & $5,1 \mathrm{E}-33$ & 0,3 \\
\hline G1,2 & 18,5 & $3,6 \mathrm{E}-26$ & 17,5 & 0 & $2,6 \mathrm{E}-32$ & 21,6 \\
\hline $\mathrm{P} 2,2$ & 3,1 & 9E-27 & 3,0 & $6 \mathrm{E}-23$ & $1,2 \mathrm{E}-32$ & 0,9 \\
\hline $\mathrm{G} 2,3$ & 14,1 & 9E-26 & 14,3 & $3,9 \mathrm{E}-22$ & 0 & 13,8 \\
\hline P3,3 & 12,5 & 100 & 13,4 & $6,9 \mathrm{E}-22$ & $4,2 \mathrm{E}-34$ & 0,5 \\
\hline $\mathrm{G} 3,4$ & 34,4 & 0 & 34,9 & $1,6 \mathrm{E}-21$ & $1,1 \mathrm{E}-33$ & 1,2 \\
\hline $\mathrm{P} 4,4$ & 15,9 & $4,2 \mathrm{E}-32$ & 15,5 & 100 & 100 & 61,7 \\
\hline $\mathrm{F} 4,1$ & 0,1 & $1,4 \mathrm{E}-33$ & 0,1 & $5,7 \mathrm{E}-35$ & $2,2 \mathrm{E}-33$ & 0,02 \\
\hline
\end{tabular}

P1,1 = Probabilidade de plântulas sobreviverem e permanecerem na mesma classe de tamanho; P2,2 $=$ Probabilidade de jovens 1 sobreviverem e permanecerem na mesma classe de tamanho; P3,3 = Probabilidade de jovens 2 sobreviverem e permanecerem na mesma classe de tamanho; P4,4 = Probabilidade de adultos sobreviverem e permanecerem na mesma classe de tamanho; P1,2 = Probabilidade de plântulas sobreviverem a passarem para jovem 1; P2,3 = Probabilidade de jovens 1 sobreviverem e passarem para jovens 2; P3,4 = Probabilidade de jovens 2 sobreviverem e passarem para adultos. O período considerado é de 1 ano.

A sensibilidade dos parâmetros para o lambda da matriz seguiu a seguinte ordem: $\mathrm{F}<\mathrm{P}<\mathrm{G}$ na Colocação Já Começa para jovens 1 e 2. Para plântulas a taxa de transição foi zero e portanto o parâmetro que mais contribuiu para o valor do $\lambda$ foi o P(probabilidade de permanecer na mesma classe de tamanho). Para adultos o parâmetro que menos contribuiu para o valor de $\lambda$ foi o $G$ (probabilidade de passar para a próxima classe de tamanho) e o que mais contribuiu foi o P. A análise da sensibilidade para os elementos da matriz mostraram que para as classes de tamanho 2 e 3 a maior contribuição do valor de $\lambda$ é a do parâmetro $G$ e para a classe 1 e 4 a maior contribuição é a do parâmetro $\mathrm{P}$ (Tabela 2.14).

As análises de sensibilidade feitas no Baixio e Terra Firme desta Colocação (Tabela 2.14) mostraram o mesmo padrão para as plântulas, jovens 1 e 2 encontrado para a média dos dois tipos de floresta (Tabela 2.14). A diferença entre permanecer na mesma classe e crescer para a classe seguinte foi muito maior no Baixio que na 
Terra Firme para a classe de tamanho jovem 2, apesar da maior contribuição do parâmetro $\mathrm{G}$ para esta classe independente do tipo florestal (Tabela 2.14).

A probabilidade de sobrevivência foi a taxa vital mais importante para determinar o $\lambda$, seguido pelo crescimento e reprodução, assim como o encontrado por Zuidema \& Boot (2000) estudando Euterpe precatoria na Bolívia.

Pineiro et. al. (1984) consideraram que para espécies arbóreas a importância relativa (sensibilidade) dos parâmetros para o lambda da matriz segue a seguinte ordem: $\mathrm{F}<\mathrm{P}<\mathrm{G}$. Porém, discutem que são as condições ambientais onde a população está crescendo que determinam os padrões de sensibilidade encontrados.

Os valores de $\lambda$ calculados neste estudo (Tabela 2.13) sugerem que os frutos de Euterpe precatoria, podem ser coletados sustentavelmente na floresta de Baixio da Colocação São Pedro, porque o valor de $\lambda$ foi crescente. Na Floresta de Terra Firme desta Colocação o crescimento populacional demonstrou-se constante $(\lambda=1)$. Apesar disso, as limitações deste estudo, pelo tempo amostrado (1 ano) e pelas próprias limitações de elaboração e aplicação do modelo devem ser considerados. Desta forma, sugere-se que sejam feitos novos recenseamentos com as mesmas populações para verificar se este padrão permanece ao longo dos anos. Zuidema \& Boot (2000) estudando a dinâmica de Euterpe precatoria na Bolívia encontraram uma variação do valor de $\lambda$ de ano para ano.

Considerando-se a estabilidade da população de Euterpe precatoria estudada nos diferentes tipos florestais da Colocação São Pedro foi feita uma simulação para calcular a quantidade de frutos que pode ser colhida da floresta sem danificar a estabilidade das populações a longo prazo, através da variação do coeficiente de fecundidade no modelo de matriz (Peters, 1990). Esta alteração simulou a diminuição do número de plântulas que estão disponíveis a cada ano, e a partir de então, tornouse possível inferir sobre a quantidade mínima de recrutamento necessário para que a população de Açaí seja mantida, sem causar uma diminuição na estabilidade populacional devido a colheita. 


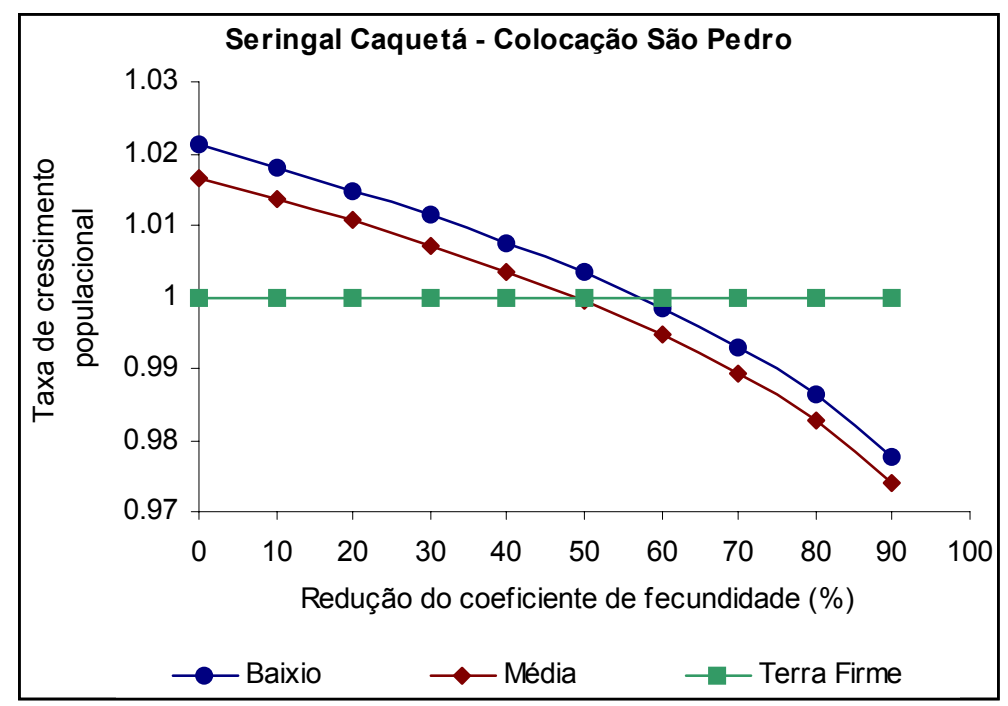

Figura 2.16 Resposta da taxa de crescimento populacional $(\lambda)$ de Euterpe precatoria para a redução do número de plântulas recrutadas anualmente. Valor igual a 1 no eixo y indica que o $\lambda$ é estável; valores menores que 1 indicam população decrescendo e valores acima de 1 indicam que a população está aumentando. Floresta de Baixio, Floresta de Terra Firme e Média das duas florestas, Colocação São Pedro, Seringal Caquetá, AC.

Sabe-se que a colheita intensiva de frutos ao longo do tempo pode causar uma alteração na estrutura da população e isto será percebido primeiro no estágio de plântulas. Desta forma, a simulação da colheita de frutos foi feita através da redução do coeficiente de fecundidade da matriz de transição. Foi calculado então o $\lambda$ para cada nova matriz para determinar o nível da redução da fecundidade necessário para diminuir o valor de $\lambda$ abaixo de 1 . O resultado desta análise na floresta de Baixio mostra que o valor de $\lambda$ torna-se igual a 1 (população estável) quando o nível de fecundidade diminui 55\% do nível inicial. Caso a colheita de frutos seja mantida de modo a reduzir $60 \%$ do recrutamento inicial, o valor de $\lambda$ será menor que 1 indicando que o nível de regeneração é insuficiente para balancear a taxa de mortalidade natural. Desta forma, a matriz de transição sugere que pelo menos 55\% do recrutamento inicial medido no Seringal Caquetá é necessário para manter a estabilidade da população estudada. Em outras palavras, a Intensidade Máxima de Colheita Sustentável (Viana, 1986) de Açaí na floresta de Baixio da Colocação S. 
Pedro é aquela que reduza a fecundidade em não mais que $55 \%$ do recrutamento inicialmente medido.

$\mathrm{Na}$ floresta de Terra Firme da Colocação São Pedro também foi feita a simulação da colheita de frutos pela diminuição do recrutamento de 10 a $90 \%$. Como resultado, a estabilidade da população de Euterpe precatoria manteve-se estável ( $\lambda$ =1) e constante independentemente da redução do recrutamento de plântulas. Este dado pode sugerir que apesar da densidade de Euterpe precatoria ser maior no Baixio que na Terra Firme, no segundo tipo florestal a população parece ser mais resistente $^{12}$. Por outro lado provavelmente esta redução está relacionada com a taxa de transição zero de jovens 2 nesta área que pode ter provocado um artefato de modelagem (Figura 2.16). Caso mais que $80 \%$ dos frutos produzidos a cada ano por Grias peruviana (Peters, 1990 a) e 98\% de frutos produzidos a cada ano por Brosimum alicastrum (Peters, 1990 b) forem coletados, os valores da taxa de crescimento populacional para estas espécies poderão diminuir abaixo de 1 indicando um nível de regeneração insuficiente para balancear a taxa de mortalidade natural.

Do ponto de vista demográfico, a manutenção de 55\% do recrutamento inicial pode ser favorável para manter a estabilidade da população na floresta de Baixio estudada, porém, deve ser enfatizado que este resultado é baseado na suposição de que as plântulas que permanecerem em determinado local da floresta, encontrem condições apropriadas para crescer e se reproduzir (Peters, 1990).

Estudos realizados na América do Sul e Central mostram que mais de 90\% das árvores de dossel produzem frutos adaptados para o consumo e subsequente dispersão por animais (Peters, 1996). Um dos itens mais comuns da dieta dos cervídeos são os frutos de Euterpe precatoria e de Iriartea sp. Estes frutos ocorreram na dieta de $80 \%$ dos veados cinzentos e na dieta de $59 \%$ dos veados vermelhos amostrados. [Bodmer, (1989) citado por Bodmer et. al.. (1999)]. Segundo o depoimento de moradores dos Seringais Dois Irmãos e Caquetá, os principais animais consumidores dispersores de frutos de Euterpe precatoria no pico da frutificação são pássaros das famílias Psitacidae (papagaios, araras); Rhamphastidae (tucanos); Crasinae (jacus). Assim como o encontrado por Reis (1995), estudando a dispersão de Euterpe edulis na Floresta Ombrófila Densa em Santa Catarina, os 
frutos de Euterpe precatoria são consumidos e dispersados por um grande número de animais. Kuchmeister et. al. (1997) no Estado do Amazonas encontrou que os frutos maduros de Euterpe precatoria foram comidos por tucanos que dispersaram as suas sementes.

Do ponto de vista da comunidade florestal o nível de redução de $55 \%$ do recrutamento no Baixio pode ser alto, já que a colheita em excesso de sementes e frutos pode diminuir a disponibilidade de alimento para as populações de animais frugívoros, alterando o número de organismos, possivelmente diminuindo a diversidade da comunidade alterando outras relações tróficas (Hall \& Bawa, 1993) e o próprio potencial de dispersão de Euterpe precatoria. Estas mudanças podem afetar negativamente a espécie manejada, assim como outras espécies na comunidade, comprometendo a sustentabilidade da extração, já que E. precatoria possui uma alta densidade e provavelmente seus frutos são um importante item na dieta de vários animais. Por outro lado, esta afirmativa deve ser confirmada experimentalmente, pois sabe-se que a colheita de frutos pode afetar não apenas o recrutamento mas outras relações como as competições intra e interespecíficas que podem ser reduzidas pelas menores densidades afetando assim por exemplo a sobrevivência.

A simulação da colheita de frutos deve ser efetivamente testada no futuro.

\subsubsection{ESTIMATIVA DA ABERTURA DO DOSSEL NA FLORESTA DE BAIXIO E DE TERRA FIRME}

O teste estatístico de Kruskal- Wallis foi aplicado utilizando 20 e 63 medidas do densiômetro nas florestas de Baixio e de Terra Firme das colocações São Pedro (Seringal Caquetá) e Já Começa (Seringal Dois Irmãos) respectivamente. Como resultado obteve-se uma diferença significativa $(\mathrm{p}<0.01)$ da abertura do dossel maior no Baixio que na Terra Firme nas duas Colocações amostradas. Este resultado corrobora os dados de Lamotte (1990) que considerou o dossel das florestas periodicamente inundadas mais aberto que o das florestas de Terra Firme

\footnotetext{
${ }^{12}$ capacidade de suportar perturbações ambientais, de manter sua estrutura e padrão de comportamento quando modificada a sua condições de equilíbrio.
} 
A Figura 2.17 mostra que nos dois Baixios e Terra Firmes amostrados a porcentagem de penetração de luz no subosque foi maior no primeiro tipo de floresta.
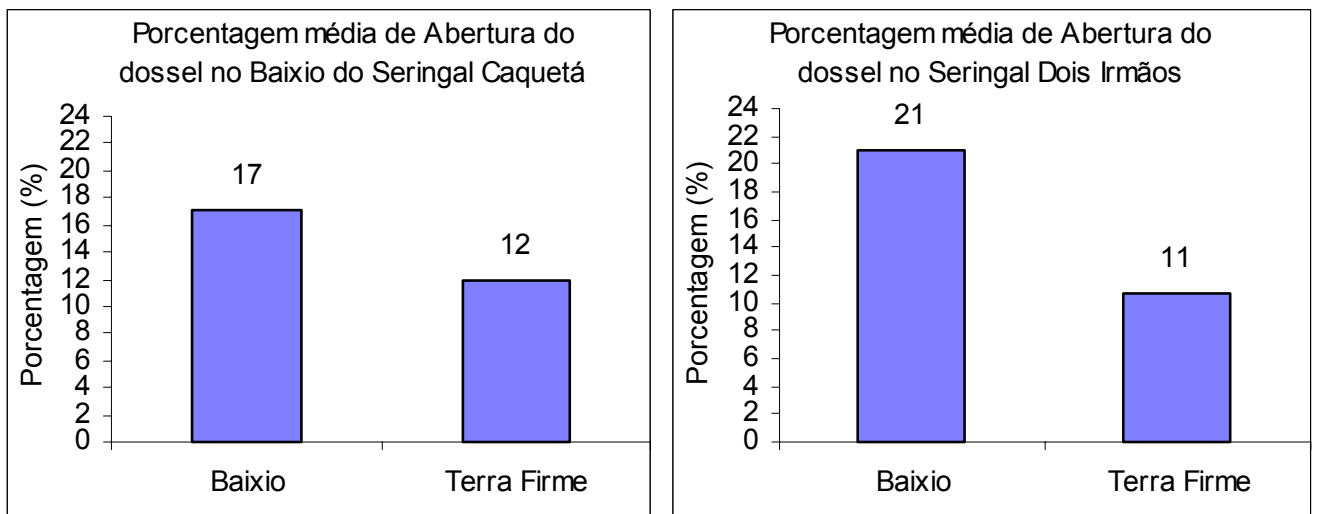

Figura 2.17 Porcentagem média da abertura do dossel nas Florestas de Baixio e de Terra Firme das Colocações São Pedro (Seringal Caquetá) e Já Começa (Seringal Dois Irmãos), AC. Medidas feitas em julho de 2000 e julho de 1997 (estação seca) respectivamente.

Uma maior penetração de luz favorece a regeneração e crescimento da maioria das espécies de palmeiras como também foi mostrado para as florestas da Costa Rica, (Chazdon 1986) citado por Kahn \& Granville (1992) e do México (Pinero et al. 1986).

Kahn \& De Granville (1992) apoiaram a conclusão de que as características das comunidades de palmeiras na floresta de Terra Firme (terrenos bem escoados) são largamente dependentes da declividade que determina a drenagem lateral do solo e da arquitetura da floresta que influencia a intensidade da luz que é recebida através das plantas de subosque. Segundo os mesmos autores os dois fatores são mutuamente dependentes. A topografia local não apenas determina a declividade, mas também a influência da freqüência de quedas de árvores, e assim, a arquitetura e dinâmica da floresta. Representa um papel imediato na modificação da drenagem e assim na provisão de água, e afeta a arquitetura da floresta que interfere na intensidade de luz no subosque .

A maior taxa de transição e a maior proporção entre plântulas : adultos encontrados neste estudo para Euterpe precatoria no Baixio em relação a Terra Firme pode assim estar relacionada com uma maior penetração de luz no subosque 
no primeiro tipo de floresta; Já que a luz interfere na germinação e no desenvolvimento de plântulas e estágios juvenis (Gomes-Pompa, \& Vazquez-Yanes, 1985; Martinez- Ramos, 1985; Del Amo \& Nieto De Pascual, 1985).

Conforme o discutido no item 2.3.2, no Baixio os indivíduos reprodutivos e pré reprodutivos apresentaram um menor número de folhas e um diâmetro menor que estas mesmas classes de tamanho na Terra Firme. Aqui novamente a causa do menor porte dos indivíduos no Baixio pode estar relacionado com a competição interespecifica menos intensa para a espécie neste ambiente mais aberto e úmido em relação a Terra Firme.

\subsubsection{PRODUÇÃO DE FRUTOS E POTENCIAL PRODUTIVO}

Os moradores do Seringal Dois Irmãos (RECM), e do Seringal Caquetá, concordam em dizer que Euterpe precatoria frutifica anualmente, primeiro na floresta de Baixio e depois na floresta de Terra Firme das suas áreas de florestas. A frutificação na Colocação Já Começa do Seringal Dois irmãos (RECM), foi de abril a setembro nos anos de 1997, 1998. Na Colocação S. Pedro do Seringal Caquetá a frutificação foi de março a setembro em 1999 e de abril a setembro em 2000. A informação da frutificação anual corrobora com o encontrado por Rigamonte (comunicação pessoal, 2000) estudando a fenologia da frutificação de E. precatoria em uma floresta secundária em Rio Branco, Acre, pelo período de três anos.

Peres (1994) observando a fenologia da frutificação de Euterpe precatoria em florestas inundadas sazonalmente no Amazonas encontrou que a espécie possui grande parte de seus frutos maduros entre os meses de fevereiro e julho.

As Tabelas 2.15, 2.16 e 2.17 mostram a estatística descritiva da produção de frutos de Euterpe precatoria nas florestas de Baixio e de Terra Firme do Seringal Caquetá, Município de Porto Acre. As palmeiras apresentaram de 1 a 3 cachos por adulto independente do tipo de floresta em que se encontraram. Em junho de 1999 obteve-se o número médio de 1.8 cachos ( $\mathrm{n}=15$ indivíduos) na floresta de Terra Firme. Em junho de 2000 obteve-se a média de 1.8 cachos ( $\mathrm{n}=10$ indivíduos), na floresta de Terra Firme e 2.4 cachos no Baixio ( $n=10$ indivíduos). O peso médio dos frutos encontrado foi de $1.14 \mathrm{~g}$ enquanto Castro (2000) trabalhando no Amazonas 
encontrou 1 g. O peso ( $\mathrm{kg}$ ) médio de frutos/cachos medido em junho de 1999 foi utilizado para alguns cachos que não puderam ser pesados.

Tabela 2.15 Produção de frutos de Euterpe precatoria na Floresta de Terra Firme da Colocação S. Pedro, AC. Junho de 1999. (n=15).

\begin{tabular}{lllll}
\hline & Num. cachos & $\begin{array}{l}\text { Peso(kg) } \\
\text { frutos/cacho }\end{array}$ & $\begin{array}{l}\text { Peso } \\
\text { frutos/palmeira }\end{array}$ & $\begin{array}{l}\text { frutos/palmeira } \\
\text { frum. }\end{array}$ \\
\hline Média & 1,8 & 4,6 & 8,5 & 7.449 \\
Desvio padrão & 0,6 & 2 & 3,3 & $2.883,5$ \\
Máximo & 3 & 11 & 13,1 & $11.482,5$ \\
Mínimo & 1 & 2 & 2,5 & 2.193 \\
\hline
\end{tabular}

Tabela 2.16 Produção de frutos de Euterpe precatoria na Floresta de Terra Firme da Colocação S. Pedro, AC. Junho de 2000. (n=10).

\begin{tabular}{lllll}
\hline & $\begin{array}{l}\text { Num. } \\
\text { Cachos }\end{array}$ & $\begin{array}{l}\text { Peso(kg) } \\
\text { frutos/cacho }\end{array}$ & $\begin{array}{l}\text { Peso } \\
\text { frutos/palmeira }\end{array}$ & $\begin{array}{l}\text { frutos/palmeira } \\
\text { frum. }\end{array}$ \\
\hline Média & 1,8 & 3,6 & 6,2 & 5.477 \\
Desvio padrão & 0,6 & 1,7 & 2,4 & 2.086 \\
Máximo & 3 & 7,5 & 9 & 7.895 \\
Mínimo & 1 & 1 & 3 & 2.632 \\
\hline
\end{tabular}

Tabela 2.17 Produção de frutos de Euterpe precatoria na Floresta de Baixio da Colocação S. Pedro, AC. Junho de 2000. $(\mathrm{n}=10)$.

\begin{tabular}{lllll}
\hline & $\begin{array}{l}\text { Num. } \\
\text { Cachos }\end{array}$ & $\begin{array}{l}\text { Peso(kg) } \\
\text { frutos/cacho }\end{array}$ & $\begin{array}{l}\text { Peso } \\
\text { frutos/palmeira }\end{array}$ & $\begin{array}{l}\text { frutos/palmeira } \\
\text { frum. }\end{array}$ \\
\hline Média & 2,4 & 3 & 7,5 & 6.581 \\
Desvio padrão & 0,7 & 1,5 & 4,2 & 3.696 \\
Máximo & 3 & 6 & 15 & 1.3272 \\
Mínimo & 1 & 1 & 1,5 & 1.316 \\
\hline
\end{tabular}

Wallace (1999) trabalhando em áreas da Reserva Extrativista Chico Mendes (Município de Xapuri) encontrou que as palmeiras de E. precatoria produziram de 1 a 4 inflorescências. Castro (2000) estudando na Amazônia central encontrou que Euterpe precatoria produz em média de 2 a 3 inflorescências, mas este número pode variar de 1 a 5 . Segundo a mesma autora, o Açaí produz de três a quatro cachos, mas raramente há mais que dois cachos maduros ao mesmo tempo. No Seringal Caquetá foi encontrado que $12 \%$ dos indivíduos $(\mathrm{n}=25)$ de Euterpe precatoria produziram 3 cachos que estavam maduros ao mesmo tempo. 
Em uma população peruana de Euterpe precatoria as palmeiras produziram de 2 a 6 inflorescências por ano. O tempo de maturação dos frutos foi de 7 a 8 meses, uma média de 6039 frutos $(\mathrm{s}=396 ; \mathrm{n}=5)$ por inflorescência foram contados (Kanh \& Granville, 1992). Os Açaís analisados no Seringal Caquetá produziram de 877 a 9649 frutos por cacho, sendo a média de $3514 \pm 1202$ frutos por cacho $(n=35)$. O valor médio encontrado neste estudo foi 1.7 vezes menor que o encontrado por Kanh \& Granville (1992) e aproximadamente 2 vezes maior ao encontrado por Fisch (1998) (média $=1787 ; \mathrm{n}=14$ ) para Euterpe edulis na Floresta Atlântica no Estado de São Paulo. Reis (1995) para a mesma espécie na Floresta Atlântica de Santa Catarina encontrou uma média de 3325 frutos por infrutescência e $3.5 \mathrm{~kg}$ de frutos por cacho, valores aproximados ao encontrado para Euterpe precatoria no Seringal Caquetá (3.8 $\mathrm{kg}$ de frutos/cacho e 3514 frutos/cacho). Castro, (2000) encontrou cada inflorescência madura apresentando em média $5.9 \mathrm{Kg}$ de frutos.

O rendimento vegetativo e reprodutivo muda de acordo com a situação ambiental (Martinez-Ramos, 1985); quando ocorre a abertura de uma clareira, as espécies tolerantes entram em um período de intenso crescimento apical e elevada atividade reprodutiva. (Richard \& Williamson, 1975, citado por Martinez-Ramos, 1985) que diminui com o fechamento da clareira (Martinez-Ramos, 1985). Em Astrocaryum mexicanum, a quantidade de frutos produzidos por indivíduo foi de $30.1 \pm 2.8$ no subosque e $60.2 \pm 12.7$ em clareiras (Pinero, et. al. 1984). A freqüência da reprodução de um indivíduo entre os anos também variou para esta espécie em situações de maior e menor incidência luminosa, logo a freqüência de clareiras ou a preferência para coleta em clareiras pode ser um item relevante para o manejo.

No Seringal Caquetá, o peso total de frutos de um cacho variou de 1 a 7.5 quilos para Euterpe precatoria. Assim tanto o peso total de frutos de um cacho como o número de frutos estimados por cacho foram extremamente variáveis. Esta variação pode estar relacionada com o ano, local do indivíduo, variação genética, polinização e dispersão, ou ainda com a perda de frutos, provocada pela queda abaixo da planta mãe na hora da colheita e perdas causadas pelo vento e tempestades (Castro, 2000). A variação pode ser também devido a diferença de polinização entre inflorescências ou diferenças do número de frutos já comidos e/ou dispersados anteriormente à extração e medida. 
Euterpe precatoria é mais denso no Baixio (Tabela 2.3) local mais úmido e com maior penetração de luz (Figura 2.19). Neste local o número de folhas, altura e diâmetro foram menores e produção de frutos $\mathrm{kg} /$ palmeira maiores, medidos em 2000 (Figuras 2.8 e Tabelas 2.16 e 2.17). Para sabermos se existe de fato uma relação inversa entre o número de folhas, diâmetro e altura versus a produção de frutos em termos de alocação de energia para a reprodução, medidas destas variáveis devem ser feitas ao longo de vários anos nos mesmos indivíduos.

Conforme Tabela 2.18, 2.16 e 2.17 a densidade média de Euterpe precatoria no Vale do Rio Acre foi $60 \pm 29$ (Baixio) e $28 \pm 12$ (Terra Firme) e o peso médio de frutos/palmeira para o ano de 2000 foi de 7,5 \pm 4.2 (Baixio) e 6,2 \pm 2.4 (Terra Firme) na Colocação São Pedro. Desta forma, a produção média encontrada em 1 hectare de floresta de Baixio (junho de 2000) foi de aproximadamente $450 \mathrm{~kg}$ de frutos/ha e na floresta de Terra Firme foi de aproximadamente $176 \mathrm{~kg}$ por hectare. Isto corresponde a 30 e 12 latas (1 lata é igual a $15 \mathrm{~kg}$ ) por hectare de floresta de Baixio e Terra Firme e que pode render ao seringueiro $\mathrm{R} \$ 134,00$ e $\mathrm{R} \$ 53,00$ respectivamente (Tabela 2.18)

Como a variação do peso de frutos/palmeira é muito grande, a avaliação da produção dever ser feita em indivíduos marcados ao longo de vários anos para que se tenha estimativas representativas do rendimento de frutos por hectare de floresta.

A floresta de Baixio apresentou-se com o maior potencial produtivo de frutos de Euterpe precatoria pela sua maior densidade de adultos. Para Euterpe edulis na Mata Atlântica a quantidade de cachos produzidos variou de 4 a 2 cachos nos anos 95/97 e 94/96 respectivamente. O clima, especialmente a distribuição de chuvas, exerceu importante papel no sucesso reprodutivo da espécie e por isto o monitoramento fenológico da frutificação em relação ao clima é uma ferramenta importante para uma estimativa da produção anual (Fisch, et. al., 2000). Considerando-se que a variação da precipitação (anos mais secos ou chuvosos) nas áreas de estudo pode provocar variação de frutificação de ano para ano, o conhecimento das safras em diferentes anos é importante para o manejo sustentável da espécie porque pode-se adequar a coleta dos cachos de acordo com uma maior ou menor pressão de colheita. 
Tabela 2.18 Estimativa do potencial produtivo de Euterpe precatoria das florestas de Baixio e de Terra Firme do Seringal Caquetá, AC.

\begin{tabular}{|c|c|c|c|c|}
\hline \multicolumn{5}{|c|}{ Floresta de Baixio } \\
\hline Colocação & Núm. de ndivíduo/há & Peso médio (Kg) /ha & Latas/ha & $\mathrm{R} \$ / \mathrm{ha}$ \\
\hline Santa Maria & 51 & $382,5 \pm 67,7$ & 25,5 & 114,8 \\
\hline Arraia & 118 & $885 \pm 156,7$ & 59,0 & 265,5 \\
\hline São Pedro & 50 & $375 \pm 66,4$ & 25,0 & 112,5 \\
\hline Morada Nova & 45 & $337,5 \pm 59,8$ & 22,5 & 101,3 \\
\hline Limoeiro & 48 & $360 \pm 63,8$ & 24,0 & 108,0 \\
\hline Já Começa & 46 & $345 \pm 61,1$ & 23,0 & 103,5 \\
\hline Média & $60 \pm 29$ & $450 \pm 79$ & 30 & 134 \\
\hline Máximo & 118 & $885 \pm 156,7$ & 59,0 & 265,5 \\
\hline Mínimo & 45 & $337,5 \pm 59,8$ & 22,5 & 101,3 \\
\hline \multicolumn{5}{|c|}{ Floresta de Terra Firme } \\
\hline Colocação & Núm. de indivíduo/ha & Peso médio $(\mathrm{Kg}) / \mathrm{ha}$ & Latas/ha I & $\mathrm{R} \$ / \mathrm{ha}$ \\
\hline Santa Maria & 21 & $130,2 \pm 15,9$ & 8,7 & 39,1 \\
\hline Arraia & 31 & $192,2 \pm 23,5$ & 12,8 & 57,7 \\
\hline São Pedro & 11 & $68,2 \pm 8,3$ & 4,5 & 20,5 \\
\hline Morada Nova & 35 & $217 \pm 26,6$ & 14,5 & 65,1 \\
\hline Limoeiro & 27 & $167,4 \pm 20,5$ & 11,2 & 50,2 \\
\hline Já Começa & 45 & $279 \pm 34,2$ & 18,6 & 83,7 \\
\hline Média & $28 \pm 12$ & $173 \pm 22$ & 12 & 53 \\
\hline Máximo & 45 & $279 \pm \overline{3} 4,2$ & 18,6 & 83,7 \\
\hline Mínimo & 11 & $68, \overline{2}+8,3$ & 4,5 & 20,5 \\
\hline
\end{tabular}

Peso médio de frutos $(\mathrm{kg}) /$ hectare = número de palmeiras multiplicado pelo peso médio/palmeira no Baixio (7,5 kg) e na Terra Firme (6,2 kg).

Latas $/$ hectare $=$ Estimativa utilizando a divisão do peso de frutos por hectare por 15. Considerando-se que uma lata de Açaí pesa $15 \mathrm{~kg}$.

Reais/hectare $=$ Estimativa utilizando a multiplicação do número de latas produzidas por hectare por 4,50. Considerando que uma lata de Açaí custe $\mathrm{R} \$ 4,50$.

\subsection{CONCLUSÃO}

A densidade de Euterpe precatoria (Açaí) apresentou-se alta e heterogênea entre as florestas de Baixio e de Terra Firme estudadas. Para os indivíduos reprodutivos a densidade foi maior no Baixio que na Terra Firme.

A espécie apresentou uma estrutura populacional do tipo J invertido, ou com um grande número de indivíduos menores em relação ao número de indivíduos maiores. No Baixio, esta proporção apresentou-se maior que na Terra Firme. 
Euterpe precatoria apresentou uma taxa de crescimento populacional crescente e estável na floresta de Baixio e Terra Firme respectivamente, no Seringal Caquetá. No Seringal Dois Irmãos a taxa foi decrescente tanto no Baixio quanto na Terra Firme. Estes valores devem ser confirmados com pelo menos mais dois anos de recenseamentos das mesmas populações. Independente da Colocação e tipo de floresta, o parâmetro demográfico que mais contribuiu para o valor de $\lambda$ foi a sobrevivência dos adultos e o crescimento das plântulas e jovens 1 . Na floresta de Baixio avaliada do Seringal Caquetá o componente que mais contribuiu para a taxa de crescimento populacional foi a probabilidade de Jovens 2 passarem para a classe dos adultos.

A simulação da colheita feita para a floresta de Baixio no Seringal Caquetá mostrou que do ponto de vista demográfico a manutenção de $55 \%$ do recrutamento inicial pode ser suficiente para manter a estabilidade da população. Na Terra Firme a estabilidade populacional foi mantida independentemente da diminuição do recrutamento na população. Porém, deve ser enfatizado que este resultado é baseado na suposição de que as plântulas que permanecerem em determinado local da floresta encontrem condições apropriadas para crescerem e se reproduzirem.

Do ponto de vista da comunidade florestal os níveis de redução do recrutamento nas florestas de Baixio e Terra Firme podem ser altos, já que a colheita de sementes e frutos pode diminuir a disponibilidade de comida para as populações de animais frugívoros, alterando o número de organismos, e o próprio potencial de dispersão de Euterpe precatoria. Como a espécie possui uma alta densidade, provavelmente seus frutos são um importante item na dieta de vários animais.

O potencial produtivo estimado para Euterpe precatoria na floresta de Baixio e de Terra Firme foi relativamente alto, porém, como a variação do peso de frutos/palmeira é muito grande, a avaliação da produção dever ser feita em indivíduos marcados ao longo de vários anos para que se tenha estimativas representativas do rendimento de frutos por hectare de floresta.

Este estudo mostrou um forte indicativo de que Euterpe precatoria possui características ecológicas favoráveis para seu manejo sustentável. 


\section{CAPÍTULO 3}

\section{ASPECTOS SOCIO-ECONÔMICOS DO SISTEMA DE PRODUÇÃO DO SERINGAL CAQUETÁ}

\subsection{INTRODUÇÃO}

O Estado do Acre possui aproximadamente 91\% de cobertura vegetal nativa (INPE, 2001), em sua maioria florestas habitadas por populações tradicionais. Por outro lado, nos últimos 25 anos a taxa média de desflorestamento bruto no estado variou de 358 a $620 \mathrm{~km}^{2} /$ ano (INPE, 2001). Este fato está diretamente relacionado com a expansão pecuária e a extração ilegal de madeira ocorridas nas últimas décadas no estado, e incentivadas como as únicas formas de produção. Outro fator relevante foi a queda do preço da borracha e da castanha, o que evidencia a fragilidade de um sistema extrativista baseado em poucos produtos da floresta.

Para tornar valorosas as áreas de florestas tropicais e consequentemente conter o desmatamento, o grande desafio das famílias de seringueiros localizadas dentro de reservas e assentamentos extrativistas no Acre é diversificar e aumentar a produtividade destas áreas e obter a sustentabilidade dos sistemas de produção (Viana et.al., 1998).

O manejo diversificado de produtos florestais não madeireiros realizado com os moradores da floresta, que são os agentes principais do processo, pode aumentar a produtividade das áreas de florestas, e assim gerar incentivos para o uso e conservação destas. Esta prática pode melhorar a economia rural gerando renda, e também ser um meio de conter o desmatamento crescente nas florestas tropicais. Desta forma, torna-se possível a conservação da diversidade de espécies de plantas e de animais que sustentam as comunidades rurais, através da coleta e da caça, além da conservação de espécies que são fontes potenciais de novos genes, novas drogas, valiosas para as indústrias farmacêuticas. (Hall \& Bawa, 1993).

O valor de exportação de produtos florestais não madeireiros foi de U\$11 milhões no Peru, U\$14 milhões no Equador, U\$22 milhões na Bolívia e U\$52 milhões no Brasil (Broekhoven, 1995 citado por Ros-Tonen, et al.1995). Algumas estratégias promissoras de mercado são fundamentais para pequenos produtores da 
floresta que querem comercializar seus produtos para gerar renda a curto prazo, como por exemplo, (1) escolher produtos florestais para os quais já haja mercado; (2) produtos que possibilitem a diversificação no número e tipo de usuários finais; (3) produtos capazes de agregar valor local, por exemplo, através do seu processamento (Clay, 1992).

Euterpe precatoria é uma palmeira que fornece os frutos que podem ser um recurso chave na diversificação florestal de algumas comunidades extrativistas no Acre. Isto se deve ao fato da espécie ser bastante conhecida já que seus frutos são coletados e utilizados pelos seringueiros desde a expansão da borracha. Além disso estes possuem um grande potencial econômico (Kahn et. al., 1993), e valores agregados nos mercados locais, regionais; e mais atualmente nacional (Alho, 1999).

Para diversificar a produção florestal e fundamentar a transformação do Seringal Caquetá em um Projeto de Assentamento Extrativista (PAE) e ainda complementar a renda obtida pelo extrativismo da borracha e castanha, em 1998 onze famílias de seringueiros iniciaram o manejo, a produção e a comercialização de frutos de Açaí. Isto foi feito em conjunto com a Associação dos Seringueiros e Pequenos Agricultores do Caquetá (ASPAC), Conselho Nacional dos Seringueiros (CNS) e o Parque Zoobotânico da Universidade Federal do Acre.

Desta forma, o presente capítulo propõe responder às seguintes questões:

(1) Os frutos de Euterpe precatoria são uma alternativa de renda para as famílias de seringueiros moradores do Caquetá? (2) Qual é a rentabilidade do manejo de frutos de Açaí? (3) Qual a forma de organização comunitária para a produção de Açaí a ser adotada no Caquetá ?

Para responder estas questões foram avaliadas a organização comunitária e a rentabilidade do manejo de E. precatoria, e de outros produtos como a borracha e castanha na comunidade do Seringal Caquetá. As rentabilidades dos três produtos florestais não madeireiros foram comparadas entre si e com a diária local de trabalho. Estudos deste tipo são necessários para termos uma indicação se o manejo e a comercialização dos frutos podem garantir um retorno sócio-econômico em relação aos investimentos efetuados.

Os objetivos deste capítulo foram: 
(1) Caracterizar as populações tradicionais, "Seringueiros", do Seringal Caquetá e seus modos de vida com ênfase na organização para o trabalho, considerando as atividades de subsistência e as que geram renda.

(2) Comparar a remuneração do manejo de Açaí com a obtida na produção de castanha e borracha e também com a diária local de trabalho no Seringal Caquetá.

\subsection{MATERIAL E MÉTODOS}

\subsubsection{CARACTERIZAÇÃO SÓCIO-ECONÔMICA}

Foi realizada uma caracterização sócio-econômica das famílias que sobrevivem tradicionalmente do extrativismo da borracha e da castanha, residentes do Seringal Caquetá. Foram avaliados também os sistemas de produção agrícola e o extrativista para a comercialização e subsistência no período de 1999 a 2000. As famílias envolvidas neste estudo moram nas colocações São Pedro, Arraia, Morada Nova, Floresta e nas Colocações Limoeiro, Feijão Duro, Cajueiro, sendo que todas estão no Seringal Caquetá, com exceção da Colocação Cajueiro, Município de Porto Acre - AC; conforme mostram as Figuras $2.1 \mathrm{~B}$ e 3.1 .

Os métodos utilizados para a caracterização sócio-econômica da comunidade extrativista do Seringal Caquetá foram a revisão da literatura, consulta a documentos oficiais, acompanhamento da comunidade na extração de frutos do Açaí para a comercialização durante os anos de 1998, 1999, 2000 (em um total de 9 meses), reuniões, e um questionário aplicado com 10 pessoas que representam 10 famílias no Seringal Caquetá.

A elaboração do questionário e as reuniões foram feitas durante o trabalho de extensão desenvolvido de Maio de 1998 a Agosto de 2000, solicitado pela Associação dos Seringueiros e Pequenos Agricultores do Caquetá (ASPAC) que visava a organização comunitária para o manejo e comercialização dos frutos de Euterpe precatoria neste Seringal. Existem aproximadamente 19 colocações ativas no Seringal Caquetá (figura 2.1). Destas foram estudadas 6 Colocações que representam $31,5 \%$. 
Além destas 19 colocações ativas que abrigam famílias que sobrevivem principalmente do extrativismo, o Seringal Caquetá possui os ribeirinhos, colonos e alguns fazendeiros.

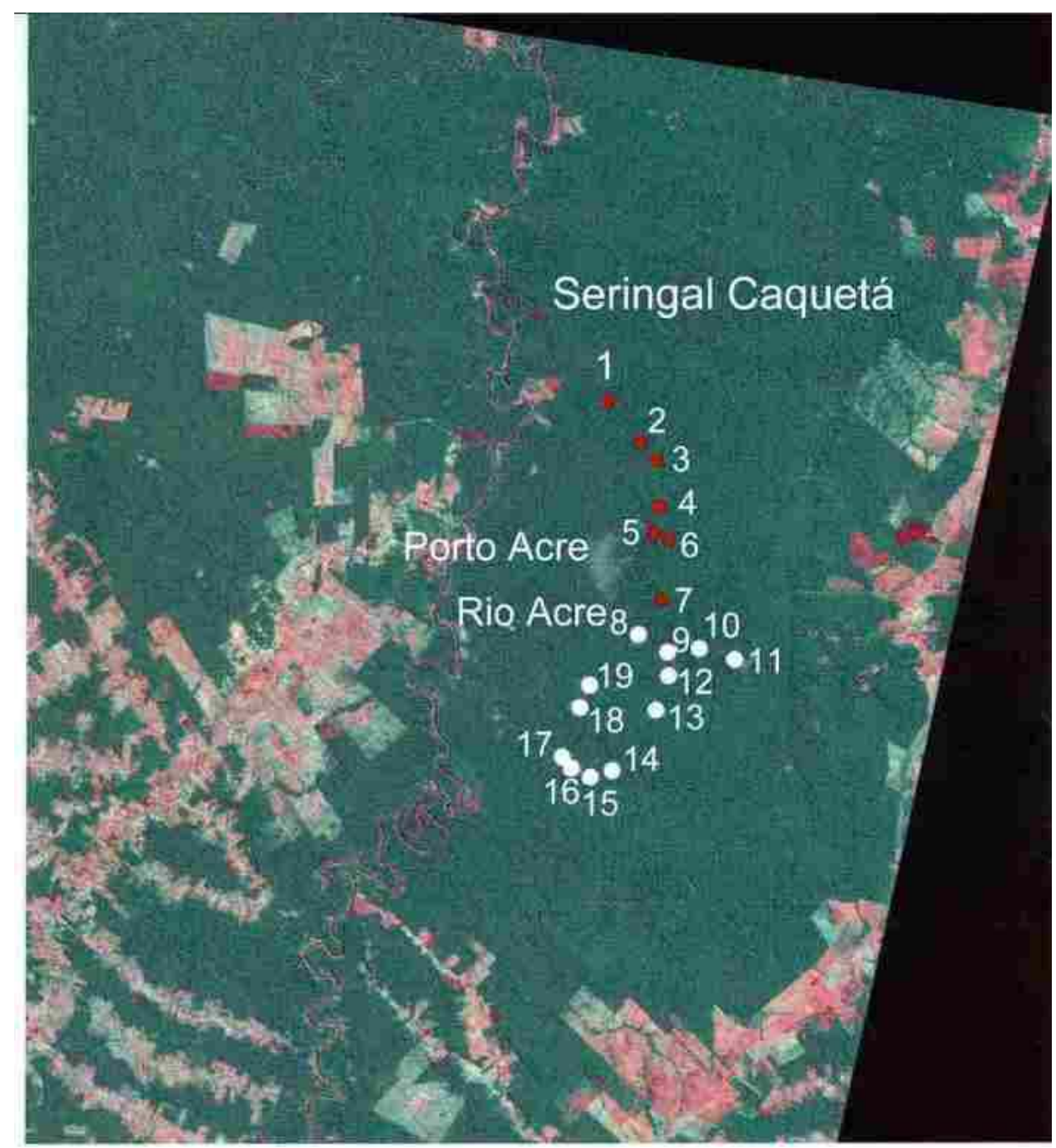

Figura 3.1 Colocações ativas do Seringal Caquetá habitadas por populações extrativistas, Município de Porto Acre, AC. 1 - Colocação Beirão; 2 - Floresta; 3 - Entauba; 4 - Arraia; 5 - São Pedro; 6 - Morada Nova; 7 - Feijão Duro; 8 - Limoeiro; 9 - Santa Isabel; 10 - Igarapé das pedras; 11 - Auto da fome; 12 - Bufador; 13 - Rabo da Besta; 14 - África; 15 - Boa vista; 16 - São Sebastião; 17 - São Francisco; 18 - Alto Alegre; 19 - Refugo. 


\subsubsection{CARACTERIZAÇÃO DAS FAMÍLIAS}

A caracterização de 10 famílias moradoras do Seringal Caquetá foi feita a partir das informações contidas no quadro 3.1, da revisão de documentos e da experiência no projeto de extensão desenvolvido pela autora.

Os critérios para seleção das famílias nas quais foram aplicados os questionários foram: (1) Que coletem e utilizem os frutos do Açaí em casa; (2) de morarem dentro da área a mais de 10 anos ou serem sócias da ASPAC.

Quadro 3.1 Questionário para a caracterização das 10 famílias no Seringal Caquetá, AC. Julho de 2000. 


\subsubsection{SISTEMAS DE PRODUÇÃO EXTRATIVISTA}

\subsection{BORRACHA E CASTANHA}

O estudo da produção extrativista da castanha e borracha foi feito através do questionário da Tabela 3.1, aplicado em 10 famílias do Seringal Caquetá.

Tabela 3.1 Questionário feito com 10 pessoas para a caracterização sócio-econômica dos sistemas de produção dos principais produtos florestais não madeireiros, castanha e borracha. Julho de 2000.

\begin{tabular}{|l|l|l|}
\hline Perguntas & Castanha & Borracha \\
\hline A. Quantos dias por semana trabalha coletando o produto? & & \\
\hline B. Que horas sai de casa para trabalhar com o produto? & & \\
\hline C. Que horas chega? & & \\
\hline D. Quantas pessoas na sua casa trabalham com o produto? & & \\
\hline E. Função de cada uma na atividade & & \\
\hline F. Quanto recebeu por uma lata ou um quilo do produto no ano passado? & & \\
\hline G. Quantos latas ou quilos do produto comercializou o ano passado? & & \\
\hline H. Quantas latas ou quilos do produto você coleta por dia? Máximo e Mínimo. & & \\
\hline I. Qual a época do ano do produto? & & \\
\hline J. Quanto tempo gasta para transportar o produto? & & \\
\hline L. Como transporta o produto? & & \\
\hline M. Que diferença o transporte faz no preço do produto? & & \\
\hline N. Onde comercializou o produto? & & \\
\hline P. Forma de pagamento & & \\
\hline Q. Existe algum subsidio para a produção? & & \\
\hline R. Qual? & & \\
\hline S. Quanto? & & \\
\hline T. Quem oferece este subsidio? & \\
\hline
\end{tabular}

\subsection{AÇAI}

A produção de frutos de Açaí para a comercialização no Seringal Caquetá iniciou-se em 1998 quando 11 famílias de seringueiros moradoras e sócias da ASPAC pretendiam : (1) diversificar a produção florestal tornando as áreas de florestas produtivas e valorosas para fundamentar a transformação do Seringal em um Projeto de Assentamento Extrativista e (2) complementar a renda conseguida pelo extrativismo da borracha e castanha. A produção extrativista de frutos de Açaí foi avaliada através do acompanhamento dos moradores na extração para a 
comercialização durante os anos de 1998, 1999 e 2000 e da revisão da literatura. Do sistema produtivo do Açaí foi avaliado a organização comunitária para o trabalho, a produtividade e a rentabilidade.

\subsubsection{SISTEMAS DE PRODUÇÃO DE SUBSISTÊNCIA}

\subsection{AGRÍCOLA E ANIMAL}

Para caracterizar a produção agrícola e animal de subsistência para 10 famílias no Seringal Caquetá foram levantadas as informações do quadro 3.2

\begin{tabular}{|c|c|c|c|c|c|c|c|}
\hline Produtos & Unidade & Período & Quant. plantada & Área* & Quant. colhida & Período & Preço \\
\hline \multicolumn{8}{|l|}{ Arroz } \\
\hline \multicolumn{8}{|l|}{ Feijão } \\
\hline \multicolumn{8}{|l|}{ Farinha } \\
\hline \multicolumn{8}{|l|}{ Milho } \\
\hline \multicolumn{8}{|l|}{ Café } \\
\hline \multicolumn{8}{|l|}{ Outros } \\
\hline & & & & & & & \\
\hline & & & & & & & \\
\hline & & & & & & & \\
\hline
\end{tabular}

* 1 Tarefa $=2500 \mathrm{~m}^{2}$

Quantidade $=\mathrm{kg}$ ou saco $(50 \mathrm{~kg})$

Esta safra/ o que vai plantar este ano:

\begin{tabular}{|l|l|l|}
\hline Cultura & Período & Área * \\
\hline & & \\
\hline & & \\
\hline & & \\
\hline & & \\
\hline & & \\
\hline & & \\
\hline
\end{tabular}

$* 1$ Tarefa $=2500 \mathrm{~m}^{2}$

A. Quais as fruteiras que existem na sua Colocação?

B. Quais (quantos) animais domésticos você cria ?

C. Possui animais de carga? Quantos? Quantos quilos o animal carrega por viagem ?

Quadro 3.2 Questionário feito com 10 pessoas para o levantamento da produção agrícola e pecuária de subsistência no Seringal Caquetá, AC. 


\subsection{EXTRATIVISMO DA FLORESTA}

A produção florestal de subsistência foi avaliada ao longo de todo o trabalho de extensão feito com a comunidade do Seringal Caquetá e através de perguntas feitas para 10 pessoas que representam 10 famílias (quadro 3.3).

Quadro 3.3 Questionário da análise qualitativa da produção florestal de subsistência das famílias extrativistas do Seringal Caquetá, AC.

\subsubsection{TRABALHO REMUNERADO (DIARISTA).}

O trabalho remunerado como diarista inclui trabalhos braçais como: "a broca", (desmatamento de floresta madura para o plantio de roçados), ou ainda a coleta de castanha, a construção de casas ou a formação de pastos. Para fazer um levantamento da diária local de trabalho foram feitas as perguntas apresentadas no quadro 3.4 para 15 pessoas de 17 a 60 anos, moradores do Seringal Caquetá.

\footnotetext{
8. Diária e Aposentadoria

A. Quanto é a diária local por um dia de trabalho?

B. Você trabalha como diarista?

C. Quantos dias por mês?

D. Quantas horas você trabalha por dia como diarista?

E. Existe algum aposentado na família?

F. Existe ( ) pouca ( ) média ou ( ) muita oferta de emprego como diarista?

G. Quantos dias por mês e meses por ano você trabalha como diarista?

H. Existe ( ) pouca, média ( ) ou muita oferta de trabalho como diarista?

I. Você tem alguma renda ou salário ou possui aposentado na família?
}

Quadro 3.4 Questionário feito com 15 pessoas no Seringal Caquetá que representam 10 famílias para o levantamento da diária local de trabalho e de outras fontes de renda no Seringal Caquetá, AC. Julho de 2000 


\subsubsection{DIÁRIA LOCAL E OUTROS USOS DA TERRA VERSUS MANEJO DO}

AÇAÍ.

Os dados obtidos da análise sócio-econômica da comercialização de frutos de Açaí, da borracha, da castanha e da diária local foram comparados entre si. O intuito foi verificar se a atividade produtiva com os frutos de Euterpe precatoria tem um alto potencial econômico para ser utilizado pela comunidade extrativista do Caquetá como forma de complementar a renda anual por família.

\subsection{RESULTADOS E DISCUSSÃO}

\subsubsection{CARACTERIZAÇÃO SÓCIO-ECONOMICA}

O Seringal Caquetá está localizado no estado do Acre no município de Porto Acre, dentro de uma área de 28686 hectares (Figura 3.1) . O acesso é através da estrada BR-317, rodovia AC 22 e através do Rio Acre e seus afluentes, no período chuvoso (INCRA, 1997). Informações sobre o clima, relevo e vegetação encontra-se no item Áreas de estudo do capítulo 2.

A área do Seringal Caquetá foi declarada de interesse social para fins de reforma agrária quando uma área de 28.685 ha foi demarcada e dividida em lotes urbanos e rurais, de assentamento agrícola, de assentamento agroextrativista e lotes de reserva legal coletiva. As áreas que se tornaram assentamento agroextrativista totalizam 9.686 ha e foram destinadas às famílias de seringueiros que já ocupavam o Seringal Caquetá. (INCRA, 1997).

Os seringueiros da área são organizados na Associação dos Seringueiros e Pequenos Agricultores do Caquetá (ASPAC) que atualmente possui aproximadamente 20 associados. Esta associação foi criada em 1998 com o intuito de : (1) garantir o acesso aos créditos e benefícios que todo Assentamento tem direito junto ao Instituto Nacional de Colonização e Reforma Agrária (INCRA); (2) pressionar a regularização fundiária da área junto ao INCRA; (3) coordenar alguns processos da diversificação produtiva. 
A maioria das famílias realiza o extrativismo da borracha (Hevea spp.) e da castanha do Brasil (Bertholetia excelsa) para obtenção de renda, além da agricultura e colheita de outros produtos da floresta, tais como frutos, fibras, madeira para a subsistência.

A estrutura familiar é importante e decisiva na divisão social de trabalho. $\mathrm{O}$ Seringal Caquetá tem pelo menos 19 colocações ativas (Figura 3.1) sendo que algumas estão incluídas no projeto de reforma agrária e outras não. Segundo a população local, a área total de cada família localizada no Assentamento Agroextrativista é de 100 hectares.

Não existe posto de saúde no Caquetá. Há uma escola que funciona na Colocação São Pedro, com o professor da comunidade sendo contratado pelo município.

As áreas e limites de uma Colocação sempre são naturais, separadas por rios, igarapés, linhas de árvores de borracha ou castanha e os caminhos pertencem a todo mundo, sendo mantidos limpos com um sistema coletivo de trabalho (mutirão).

Os moradores das áreas do Assentamento agroextrativista no Seringal Caquetá através da ASPAC e do CNS no Acre, têm procurado aumentar a produtividade de suas áreas de florestas, para que estas gerem mais renda, tentando conciliar o uso e a conservação das mesmas. Por isto, desde 1998 a ASPAC como forma de aumentar a produção florestal e a renda a curto e médio prazo vem desenvolvendo projetos de extensão que tem o propósito de apoiar o manejo, a produção e a comercialização dos frutos de Euterpe precatoria (Açaí) para a diversificação da produção extrativista do Seringal Caquetá.

\subsubsection{CARACTERIZAÇÃO DAS FAMÍLIAS}

A Tabela 3.2 mostra os dados das 10 pessoas entrevistadas que representam 10 famílias extrativistas, moradoras do Seringal Caquetá, e informações individuais de cada entrevistado. 
Tabela 3.2 Colocação onde mora, idade, número de pessoas na família, tempo que mora no local, área (ha) utilizada por família, número de pessoas na família que trabalham fora de casa, dos seringueiros entrevistados .

\begin{tabular}{lccccc}
\hline Colocação & Idade & $\begin{array}{l}\text { Numero de pessoas/ } \\
\text { Família }\end{array}$ & $\begin{array}{l}\text { Tempo no } \\
\text { local (anos) }\end{array}$ & $\begin{array}{l}\text { Área utilizada } \\
\text { (ha) }\end{array}$ & $\begin{array}{l}\text { Num. de pessoas } \\
\text { que trabalham }\end{array}$ \\
\hline Floresta & 21 & 3 & 21 & 100 & 2 \\
Cajueiro & 27 & 4 & 10 & 200 & 3 \\
Limoeiro & 54 & 2 & 54 & 300 & 1 \\
Limoeiro & 37 & 6 & 28 & 300 & 3 \\
São Pedro & 39 & 7 & 19 & 100 & 3 \\
Floresta & 48 & 5 & 48 & 100 & 1 \\
São Pedro & 68 & 2 & 27 & 100 & 2 \\
Arraia & 29 & 5 & 18 & 100 & 3 \\
Morada Nova & 46 & 6 & 46 & 100 & 1 \\
Arraia II & 21 & 3 & 21 & 100 & 1 \\
\hline
\end{tabular}

Foram entrevistados portanto, 10 seringueiros, envolvendo um total de 43 pessoas residentes do Seringal Caquetá. Dos 10 seringueiros entrevistados, 70\% nasceram no Seringal. O tempo médio de permanência no local para os moradores entrevistados foi de 29 anos, sendo que o morador mais recente está na área há 10 anos e o mais antigo há 54 anos. A idade média foi de 39 anos, sendo que o mais velho tem 68 anos e o mais novo 21 anos.

Todas as famílias possuem algum grau de parentesco. O número de pessoas por família, é em média, de $4,4 \pm 1,81$ pessoas e o coeficiente de variação é de $40 \%$. O número médio de pessoas que trabalham por família foi 2, sendo no máximo $3 \mathrm{e}$ no mínimo 1 pessoa.

A área utilizada por $80 \%$ das famílias é de 100 hectares, enquanto para $20 \%$ é de 300 hectares. Além desta área, todas as famílias podem utilizar a área de uso coletivo para a extração de produtos da floresta.

Setenta por cento das famílias entrevistadas realizam unicamente o extrativismo da borracha (Hevea ssp.) e da castanha do Brasil (Bertholetia excelsa) como renda, além da agricultura e colheita de outros produtos da floresta, tais como frutos, fibras e madeira.

As principais atividades coletivas da comunidade são os encontros religiosos, os campeonatos de futebol, as reuniões da ASPAC e as festas. 
Quando indagados em relação aos principais problemas da comunidade, a maioria dos moradores concorda que são a falta de animais de carga para transporte e os "varadouros" (estradas que dão acesso a Porto Acre) ruins. Estes problemas afetam diretamente os custos de produção extrativista dentro do Seringal Caquetá deixando-os maiores. Os varadouros são mantidos pelo sistema de mutirão pela própria comunidade e os animais de carga são adquiridos particularmente ou em conjunto através da ASPAC.

Todas as famílias estudadas participam das reuniões da ASPAC e o principal motivo apontado por elas foi porque a sua participação é importante para que possam usufruir dos benefícios de subsídios monetários e de transporte para a sua produção de borracha e castanha e poder discutir soluções para problemas comuns da comunidade. A maioria dos seringueiros disseram "andorinha sozinha não faz verão".

As principais atividades que deveriam ser feitas no Seringal para aumentar a renda das famílias são a melhoria das estradas que ligam as colocações do Seringal Caquetá ao Município de Porto Acre, animais de carga para escoar a produção, treinamento de pessoas que lidam com animais de carga, treinamentos para aumentar a eficiência da produção.

Talvez o principal problema da comunidade do Seringal Caquetá seja a dificuldade da organização comunitária para a produção, assim como ocorre em diversas comunidades tradicionais que desenvolvem projetos de produção florestal na Amazônia brasileira. A maioria dos entrevistados não souberam ao certo como resolver os princiapais problemas da comunidade quando indagados em relação a eles. 


\subsubsection{SISTEMAS DE PRODUÇÃO EXTRATIVISTA}

\subsection{BORRACHA E CASTANHA}

As colocações do Seringal Caquetá apresentam em média 3 estradas de seringa, cada uma com uma média de $457 \pm 87$ seringueiras, com máximo de 650 e no mínimo de 310 indivíduos. A produção de borracha é uma atividade basicamente desenvolvida pelo homem e raramente por mulheres.

Na Tabela 3.3 verifica-se que em média $829 \mathrm{~kg}$ de borracha por ano foram produzidos por seringueiro. Este dado é similar ao encontrado por Sobrinho (1992) que concluiu que a produção média por homem está entre 700 e $1000 \mathrm{~kg}$ de borracha. A renda conseguida por hora de trabalho da última vez que cada seringueiro extraiu a borracha e a comercializou variou de $\mathrm{R} \$ 227,60$ a $\mathrm{R} \$ 1.296,00$ por ano, com uma média de $\mathrm{R} \$ 742,10 \pm \mathrm{R} \$ 345,11$. Apenas 30\% vendeu borracha em 1999, os outros $60 \%$ alegaram que não o fizeram porque o preço estava muito baixo. Na época da entrevista, $90 \%$ dos seringueiros disseram que iriam voltar a extrair a borracha naquele ano porque o preço por quilograma havia subido, de $\mathrm{R} \$ 0,60$ para $\mathrm{R} \$ 1,00$, devido a um subsídio do governo estadual e federal, de $\mathrm{R} \$ 0,40$ por $\mathrm{kg}$ de borracha. Apesar disso, na prática os dez seringueiros comercializaram a $\mathrm{R} \$ 0,90$ o quilo da borracha. Outra forma de subsídio foi a possibilidade de comercializar o produto diretamente com uma cooperativa, que transporta a produção de borracha de Porto Acre a Rio Branco a custo zero para os extrativistas (Depoimento dos sócios da ASPAC). 
Tabela 3.3 Caracterização econômica da produção de borracha no Seringal Caquetá $(n=10)$.

\begin{tabular}{lrrrrrrrr}
\hline Colocação & $\begin{array}{l}\text { Número de } \\
\text { seringueiras }\end{array}$ & Hora /Dia & $\mathrm{Kg} /$ dia & $\mathrm{Kg} /$ ano & $\begin{array}{l}\text { Outros } \\
\text { Custos* }\end{array}$ & $\begin{array}{l}\text { Custo de } \\
\text { transporte }\end{array}$ & $\mathrm{R} /$ dia & $\mathrm{R}$ /ano \\
\hline Floresta & 310 & 10 & 7,5 & 720 & 0,34 & 4 & 3,16 & 644 \\
Cajueiro & 650 & 10 & 10 & 1.440 & 0,34 & 0 & 9,6 & 1.296 \\
Limoeiro & 515 & 10 & 5,5 & 880 & 0,34 & 0,80 & 4,3 & 791,2 \\
Limoeiro & 450 & 9 & 7 & 784 & 0,34 & 2 & 4,6 & 703,6 \\
São Pedro & 490 & 9 & 6 & 1.152 & 0,34 & 0,80 & 4,8 & 1036 \\
Floresta & 400 & 11 & 2,7 & 264 & 0,34 & 10 & 7,6 & 227,6 \\
São Pedro & 490 & 10 & 5 & 400 & 0,34 & 14 & 9,3 & 344,2 \\
Arraia & 330 & 8 & 9 & 1.152 & 0,34 & 1,40 & 7,2 & $1.035,4$ \\
Morada Nova & 330 & 9 & 7,5 & 1.050 & 0,34 & 1 & 6,1 & 944 \\
Arraia II & Não sabe & 9 & 3,5 & 448 & 0,34 & 0,8 & 2,3 & 402,4 \\
Média & $\mathbf{4 5 6 , 9}$ & $\mathbf{9 , 5}$ & $\mathbf{6 , 4}$ & $\mathbf{8 2 9}$ & $\mathbf{0 , 3 4}$ & $\mathbf{4 , 5}$ & $\mathbf{2 , 5}$ & $\mathbf{7 4 2 , 1}$ \\
\hline
\end{tabular}

Hora/dia $=$ Calculado da diferença do horário que o seringueiro sai e volta para casa ao final de um dia de trabalho.

$\mathrm{Kg} /$ dia = média entre máximo e mínimo de borracha que o seringueiro coleta por dia de trabalho.

$\mathrm{Kg} / \mathrm{ano}=$ Calculado a partir da quantidade por mês multiplicado pelo número de meses de coleta praticado por cada seringueiro que variou de 4 a 8 meses.

Preço do transporte $=$ os dois seringueiros que gastaram $\mathrm{R} \$ 10,00$ e $\mathrm{R} \$ 15,80$ não comercializaram o produto em Porto Acre, mas sim em Rio Branco, portanto, nestes valores estão incluídos o custo das passagens de ônibus. Os demais seringueiros comercializaram o produto em Porto Acre.

$\mathrm{R} \$ /$ dia $=\mathrm{Kg} /$ dia multiplicado por $\mathrm{R} \$ 0,90(1 \mathrm{~kg}$ de borracha $)$.

* outros custos $=$ embalagem e custo boi (vacina e sal) por dia.

$\mathrm{R} \$ / \mathrm{ano}=$ renda líquida .

Cada Colocação possui em média $207 \pm 146$ castanheiras com no máximo 700 e no mínimo 50 indivíduos. A safra da castanha coincide com o período de chuvas intensas (Dezembro a Março) quando a extração da borracha é paralisada. Segundo CNS/ FUNTAC e ACDI (1992) os homens representam 80\% da força de trabalho e as mulheres $20 \%$ na extração da castanha.

A Tabela 3.4 mostra a renda conseguida por hora de trabalho através da extração e comercialização da castanha no ano de 1999 no Seringal Caquetá. A renda variou de R\$ 704,20 a R\$ 8390,00 por ano, com uma média de R\$2982,26 \pm R\$ 2293,85. No caso da castanha, a produção na segunda Colocação é uma exceção das demais. Para coletar a quantidade conseguida o morador desta Colocação paga díarias para que outros castanheiros o auxilie. Desta forma na renda de $\mathrm{R} \$ 8390,00$ não está implícito este custo. Excluindo este dado a renda anual da castanha pode variar de R\$ 704,20 a R\$ 3789,80 com uma média de R\$ 2381,40 \pm R\$ 1363,00, valores que parecem ser mais representativos. 
Diferentemente da Borracha, 100\% dos seringueiros disseram extrair castanha todos os anos para comercialização. Apesar dos governos estadual e federal não estarem subsidiando a extração da castanha, os seringueiros estão comercializando o produto para uma cooperativa em Rio Branco. Esta cooperativa transporta o produto a custo zero de Porto Acre a Rio Branco, pagando preços melhores. Desta forma, os seringueiros custeiam somente o trabalho para levar os produtos das suas Colocações até a beira do Rio Acre e o óleo diesel para atravessar sua produção no Rio Acre.

Tabela 3.4 Caracterização econômica da produção de castanha no Seringal Caquetá $(n=10)$.

\begin{tabular}{|c|c|c|c|c|c|c|c|c|}
\hline Colocação & $\begin{array}{l}\text { Número de } \\
\text { castanheiras }\end{array}$ & Hora/dia & $\mathrm{Kg} / \mathrm{dia}$ & $\mathrm{Kg}$ /ano & $\begin{array}{l}\text { Outros } \\
\text { Custos* }\end{array}$ & $\begin{array}{l}\text { Custo } \\
\text { transporte }\end{array}$ & $\mathrm{R} \$ /$ dia & $\mathrm{R} \$$ /ano \\
\hline Floresta & n sabe & 9 & 72 & 3.024 & 0,34 & 4 & 25,6 & 2.156 \\
\hline Cajueiro & 700 & 11 & 240 & 16.800 & 0,34 & 10 & 89,6 & 8.390 \\
\hline Limoeiro & 100 & 6 & 78 & 1.820 & 0,34 & 0,8 & 31,3 & $1.299,2$ \\
\hline Limoeiro & 100 & 7 & 108 & 6.048 & 0,34 & 2 & 42,6 & 4.318 \\
\hline São Pedro & 300 & 5 & 96 & 4.032 & 0,34 & 0,8 & 38,8 & $2.303,2$ \\
\hline Floresta & 200 & 11 & 48 & 1.792 & 0,34 & 10 & 9,6 & 1.014 \\
\hline São Pedro & 50 & 11 & 24 & 1.008 & 0,34 & 15,8 & $-6,1$ & 704,2 \\
\hline Arraia & 60 & 9 & 120 & 6.300 & 0,34 & 6 & 43,6 & 4.494 \\
\hline Morada Nova & 150 & 9 & 84 & 4.410 & 0,34 & 1 & 33,6 & 3.149 \\
\hline Arraia II & - & 9 & 60 & 2.800 & 0,34 & 5 & 19,6 & 1.995 \\
\hline Média & 207,5 & 8,7 & 93 & $4.803,4$ & $\mathbf{0 , 3 4}$ & 5,4 & 32,8 & 2.982 \\
\hline
\end{tabular}

Hora/dia = Calculado da diferença do horário que o seringueiro saí e volta para casa ao final de um dia de trabalho.

$\mathrm{Kg} /$ dia = Calculado através da multiplicação do número de latas de castanha coletadas por dia e o peso de cada lata de castanha molhada $(12 \mathrm{~kg})$

$\mathrm{Kg} /$ ano = Calculado a partir da quantidade por mês multiplicado pelo número de meses de coleta praticado por cada seringueiro que variou de 3 a 4 meses.

Custo do transporte $=$ os três seringueiros que gastaram $\mathrm{R} \$ 10,00$ e $\mathrm{R} \$ 15,80$ não comercializaram o produto em Porto Acre, mas sim em Rio Branco, portanto, nestes valores estão incluídos o custo das passagens de ônibus. Os demais seringueiros comercializaram o produto em Porto Acre.

$\mathrm{R} \$ /$ dia $=$ considerando que 1 lata vale em média $\mathrm{R} \$ 5,00$.

* outros custos $=$ embalagem e custo boi (vacina e sal) por dia.

$\mathrm{R} \$ / \mathrm{ano}=$ renda líquida.

Tanto a borracha quanto a castanha são transportadas nas costas de animais de carga. Segundo os moradores do Seringal Caquetá um boi com mais de três anos ("bem formado") carrega $180 \mathrm{~kg}$ de borracha e 10 latas de castanha molhada (120 $\mathrm{kg}$ ) por dia de trabalho. 
Até 1998 um mínimo de 32 famílias do Caquetá comercializava toda a produção de castanha e borracha para um único comerciante em Porto Acre. Segundo o depoimento de todos os seringueiros entrevistados, raramente tinham dinheiro na mão porque a borracha era trocada diretamente por mantimentos como café, açúçar, sal, macarrão. Aqui é demonstrado um remanescente da figura cultural do patrão, outrora seringalista e hoje comerciante e o sistema de aviamento.

O patrão é um pequeno comerciante que possui um armazém de produtos industrializados e o maior barco para cargas da região. Ele negocia toda a produção de borracha e de castanha em troca de seus produtos industrializados e estabelece preços muito baixos para os produtos da floresta.

Os incentivos de subsídio para a produção e transporte de borracha e castanha não são fundamentais para que a comercialização destes produtos continue, visto que existe um comprador (patrão) destes produtos no mercado em Porto Acre. Por outro lado, estes incentivos são imprescindíveis para que os extrativistas alcancem a auto suficiência econômica, maximizem o valor e a variedade de produtos da floresta e diminuam o vazamento de dinheiro para intermediários como o patrão. Atualmente no Seringal Caquetá há uma organização através da ASPAC para a comercialização de seus produtos diretamente com as cooperativas em Rio Branco.

\subsection{AÇAÍ}

O método para processar os frutos de Euterpe precatoria é semelhante ao do processamento de Euterpe oleracea descrito detalhadamente por Rogez (2000).

A fabricação do vinho de Açaí nos seringais do Acre é feita da seguinte maneira: (1) Os frutos são aquecidos em uma bacia de água quente onde permanecem alguns minutos; (2) Em seguida, os frutos são batidos dentro de um balde com o fundo de uma garrafa, semelhante a um pilão, o que separa o mesocarpo da semente. (3) Depois de pilar bastante os frutos, o líquido fica espesso e é coado juntamente com um pouco de água em outro recipiente; (4) As sementes sem o mesocarpo são retiradas do balde e se reinicia o processo. 
O suco ou mais conhecido "vinho" de Açaí fica concentrado e é consumido freqüentemente com açúcar e farinha de macaxeira (mandioca) logo depois do processamento.

Segundo depoimentos de extrativistas do Seringal Caquetá sobre a coleta de frutos:

"No pico da safra do Açaí demora mais ou menos 10 minutos para encontrar e extrair os cachos de um Açaízeiro. Dá pra fazer 6 Açaís em 1 hora trabalhando tranquilamente. Para debulhar e guardar no saco pode pôr mais uns 5 minutos.... Pode até sê que demore um pouquinho mais pra fazer este último serviço aí, mais descontando com os minutos que vão sobrar da procura e da colheita fica elas por elas. Bem, voltando a dizer que esta é uma forma de trabalhar bem tranquila”. Djani do Carmo.

"Cinco minutos para encontrar o Açaí, 5 minutos para subir e colher os cachos, 5 minutos para debulhar e pôr no saco. 15 minutos por Açai". Arcelino do Nascimento.

Fazendo o cálculo utilizando a precaução e os depoimentos acima como exemplos: Em 1 hora uma mesma pessoa sobe em 2 Açaís, retira os cachos e coloca no saco. Então em 7 horas pode-se coletar frutos em 14 palmeiras. Considerando-se a produção média por palmeira de 7,5 $\pm 4,2$ (Tabela 2.17), em 7 horas pode-se coletar aproximadamente $105 \mathrm{~kg}$ de frutos, o que corresponde a 7 latas de frutos. Comercializando cada lata pelo preço de $\mathrm{R} \$ 4,50$ (preço pago nos meses de abril, maio e junho) pode-se ganhar uma renda bruta de $\mathrm{R} \$ 31,50$ por dia de trabalho.

Assim como a borracha e a castanha, o Açaí é transportado nas costas de animais de carga. Durante o acompanhamento das famílias na extração de frutos do Açaí no Seringal Caquetá observou-se que um boi com mais de três anos carrega 8 latas de Açaí $(120 \mathrm{~kg})$.

Os custos para transportar a produção de frutos da floresta até os pontos de venda em Rio Branco são R \$10,00 de transporte (taxi ida e volta a Rio Branco) e R \$ 0,50 por lata de Açaí transportada. Para cada 7 latas de Açaí transportada tem-se um custo de $\mathrm{R} \$ 3,50+\mathrm{R} \$ 10,00=\mathrm{R} \$ 13,50$. Desta forma, por dia de trabalho um seringueiro pode ganhar uma renda líquida de aproximadamente ( $R$ \$ 31,50 - R\$ 13,50) R\$ 18,00 (Tabela 3.7). 
No capítulo 2 foi calculado o potencial médio produtivo de frutos de Açaí por hectare de florestas de Baixio e de Terra Firme como sendo de aproximadamente 30 e 12 latas respectivamente. Desta forma, se um seringueiro pode coletar $105 \mathrm{~kg}$ de frutos por dia, ele pode fazê-lo em um único hectare independente do tipo florestal. Considerando que nem todos os indíviduos adultos frutificam todos os anos, é razoável dizer que para coletar o equivalente conseguido por dia de trabalho, um seringueiro não deve andar mais que 1 hectare de floresta para a coleta do Açaí. Assim, a crítica que se faz com freqüência ao extrativismo de que seu rendimento é fraco por hectare tem muito pouca relevância no caso dos frutos de Açaí no Seringal Caquetá.

Na extração e comercialização de frutos de Euterpe precatoria no Seringal Caquetá em 1998, 1999, os seringueiros declararam ter comercializado conjuntamente cerca de 80 latas por ano, o que resulta em aproximadamente 1200 $\mathrm{kg}$ de frutos/ano e uma renda de $\mathrm{R} \$ 360,00$. Desta forma, cada seringueiro produziu $150 \mathrm{~kg}$ de frutos (10 latas) por ano e ganhou aproximadamente $\mathrm{R} \$ 45,00$. Considerando que foi gasto $\mathrm{R} \$ 15,00$ para transportar as 10 latas, cada seringueiro ganhou R\$30,00.

Como é possível notar, a quantidade produzida se encontra bem abaixo do potencial produtivo estimado. Um dos motivos para explicar este fato é o custo de transporte do Açaí ser aproximadamente $42,8 \%$ do ganho total. Quatro seringueiros disseram ser pouco a renda que ganharam com a extração do Açaí, mas a possibilidade de ter "dinheiro vivo" no bolso foi uma vantagem. Segundo eles, até 1998 como a comercialização da borracha e da castanha era feita para um comerciante em Porto Acre, raramente viam o dinheiro porque grande parte das vezes trocava-se os produtos por mercadorias no mesmo estabelecimento (sistema de aviamento).

Um total aproximado de R\$ 150,00 do dinheiro ganho com a extração do Açaí foi aplicado para a compra de uma moto serra para a ASPAC. Isto sugere que a comercialização do Açaí trouxe também a possibilidade do seringueiro investir em ferramentas necessárias sem necessitar de financiamentos ou de ficar endividado pelo sistema de aviamento a algum barracão. 
Diferentemente da castanha e da borracha, o Açaí não possui mercado certo todos os anos no mesmo lugar. Isto implica que todos os anos devem ser feitos esforços para encontrar e manter o mercado (beneficiador dos frutos na cidade). As casas comerciais que beneficiam e comercializam o Açaí em Rio Branco raramente combinam previamente à safra a compra do produto. Na maioria das vezes fazem acordo verbal da compra do produto, e caso apareça um outro vendedor de frutos com um Açaí de mesma qualidade e mais barato o contrato pode ser desfeito. Para a boa aceitação do produto é necessário o cuidado para que se venda frutos maduros, não havendo mistura dos frutos verdes que diminuem o rendimento e estraga o gosto do vinho.

No Acre, em geral, existe muito o costume de se derrubar o Açaí para a coleta do cacho evitando a subida, e o beneficiador de frutos na cidade compra o produto independentemente de como está sendo feita sua colheita, levando em consideração apenas seu preço e qualidade.

A estratégia de organização adotada para o trabalho com o Açaí foi a de mutirão, com a partilha dos lucros independente da Colocação que ocorreu a extração para cumprir a entrega de alguma venda. Este tipo de organização não é comum no trabalho com a borracha, castanha ou mesmo nos plantios de subsistência nos quais a organização é familiar. As vantagens do mutirão como organização para a atividade produtiva são: (1) propiciar a divisão de recursos necessários para a atividade como frutos, mão de obra, animais de carga; (2) diminui o tempo despendido para a realização de uma atividade econômica nova no Seringal; (3) permite o envolvimento de todos os seringueiros interessados no trabalho, uma vez que cada um deles possuem afinidades diferentes com as várias etapas deste, tais como coleta, debulhamento, transporte e venda dos frutos; (4) facilita a efetividade do processo de fiscalização que deve ser feita pelos próprios moradores. Já as desvantagens são: (1) não é a maneira tradicional de produzir dos seringueiros, portanto não funciona para famílias mais velhas e bem estruturadas do Seringal; (2) não considera possíveis problemas internos entre os moradores; (3) dificuldade de se estabelecer regras claras para o uso comum de bens particulares.

Das onze famílias que iniciaram a produção e comercialização dos frutos de Açaí em 1998, quatro pararam um ano depois, e duas outras iniciaram. Das que 
pararam, uma família alegou não estar compensando o trabalho com o Açaí e três alegaram que preferiam produzir e comercializar os frutos em épocas ocasionais da safra tendo como base de organização a estrutura familiar. Estas três famílias possuem animais de carga e membros que sobem no Açaí, o que possibilita uma independência para realizar a atividade sem a participação de membros externo ao núcleo familiar. Porém apenas uma extraiu e comercializou o Açaí no ano seguinte tendo como base a organização familiar.

Para a coleta do Açaí em mutirão as atividades foram divididas de acordo com a afinidade das pessoas para a realização de cada etapa do trabalho, sendo estas: Coleta, Debulho e Transporte. Os coletores sobem pelos estipes da palmeira com a ajuda de um instrumento rústico de escalada chamado localmente de peconha, que consiste em um anel torcido em oito, feito com um saco de estopa ou com fibras da floresta, a qual passada ao redor dos pés, permite o apoio sobre o estipe. Eles levam uma faca na boca ou enfiada em uma bainha no cinto e sobem a palmeira apoiando o pé e puxando o corpo com os braços. Para descer, o coletor desliza os pés pelo estipe afrouxando as mãos da palmeira. Geralmente trazem dois cachos por vez, cada um apoiado em uma perna. (fotos 3.1 e 3.2 ).

Os treinamentos com métodos e equipamentos mais seguros de escalada facilitariam uma maior participação das famílias interessadas.

Abaixo da palmeira estão os debulhadores, responsáveis pela retirada dos frutos dos cachos e de ensacar os frutos para o transporte. Geralmente o coletor e o debulhador andam e trabalham juntos na mata (foto 3.3 e 3.4 ).

O transporte da floresta até a casa geralmente é feito pelo debulhador, mas dependendo da quantidade colhida outras pessoas da família são chamadas para auxiliar no transporte (foto 3.5).

$\mathrm{Na}$ organização de estrutura familiar, os debulhadores são muitas vezes os filhos e as mulheres dos seringueiros que são os coletores.

Os responsáveis pelo transporte dos frutos do Seringal Caquetá até o ponto de comercialização (foto 3.6) geralmente são pais de família que têm um melhor jeito para os negócios e conseguem lidar com animais de carga, função tão especializada quanto a de subir na palmeira para a coleta de frutos. 


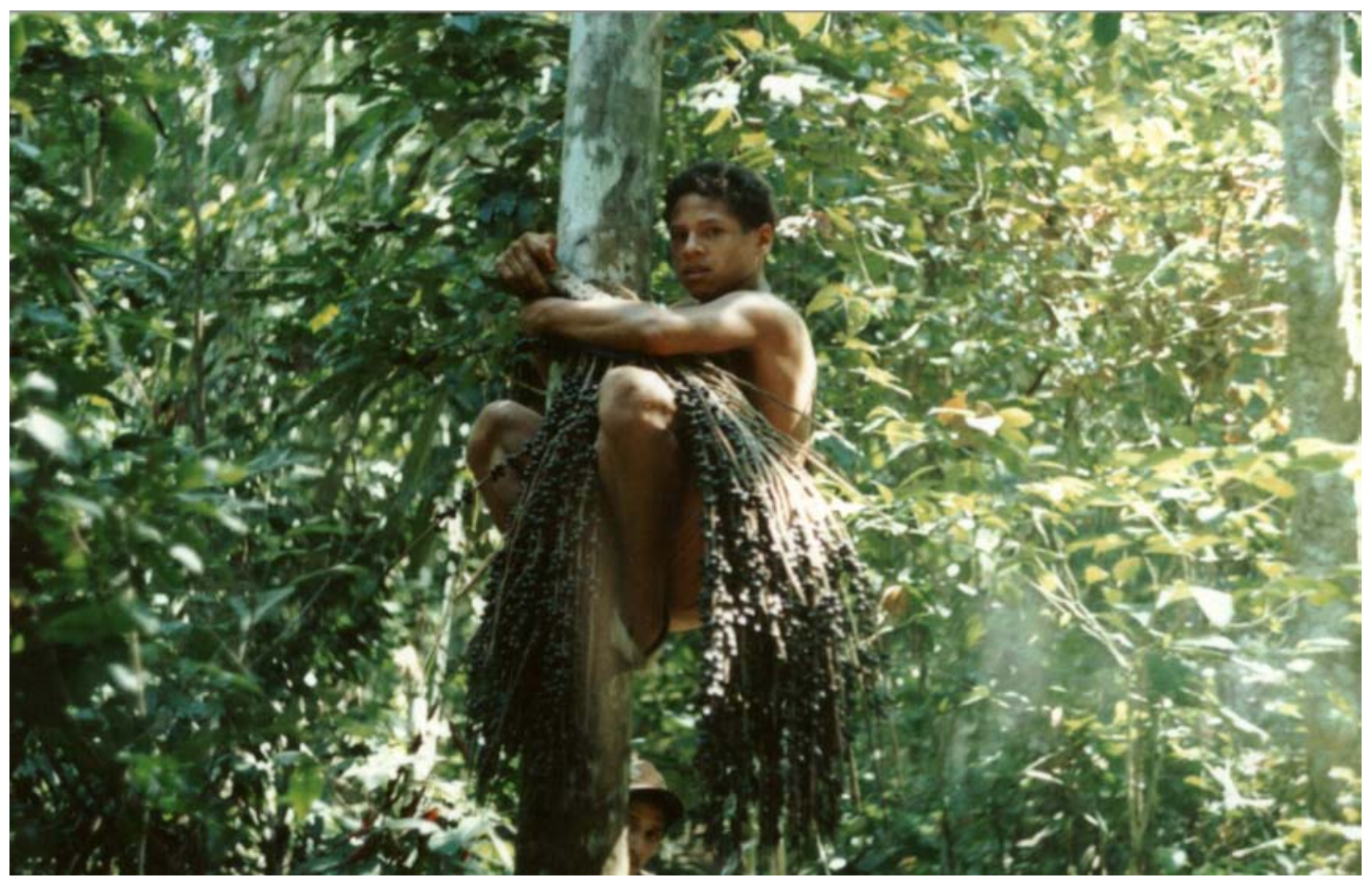

Foto 3.1 Coletor de Açaí Louro, Seringal Caquetá, AC, 1998.

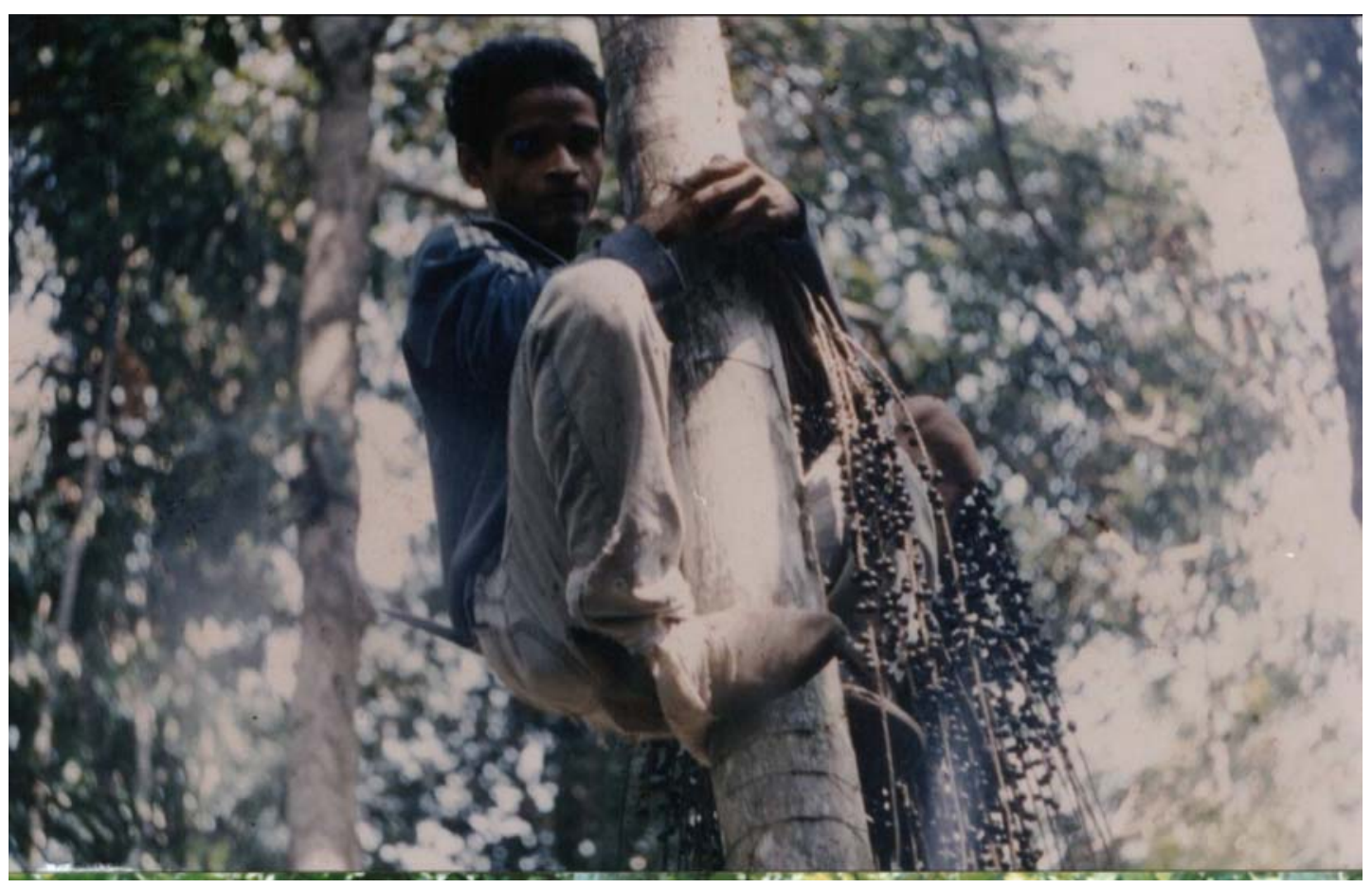

Foto 3.2 Coletor de Açaí Djani, Seringal Caquetá, AC, 1998 


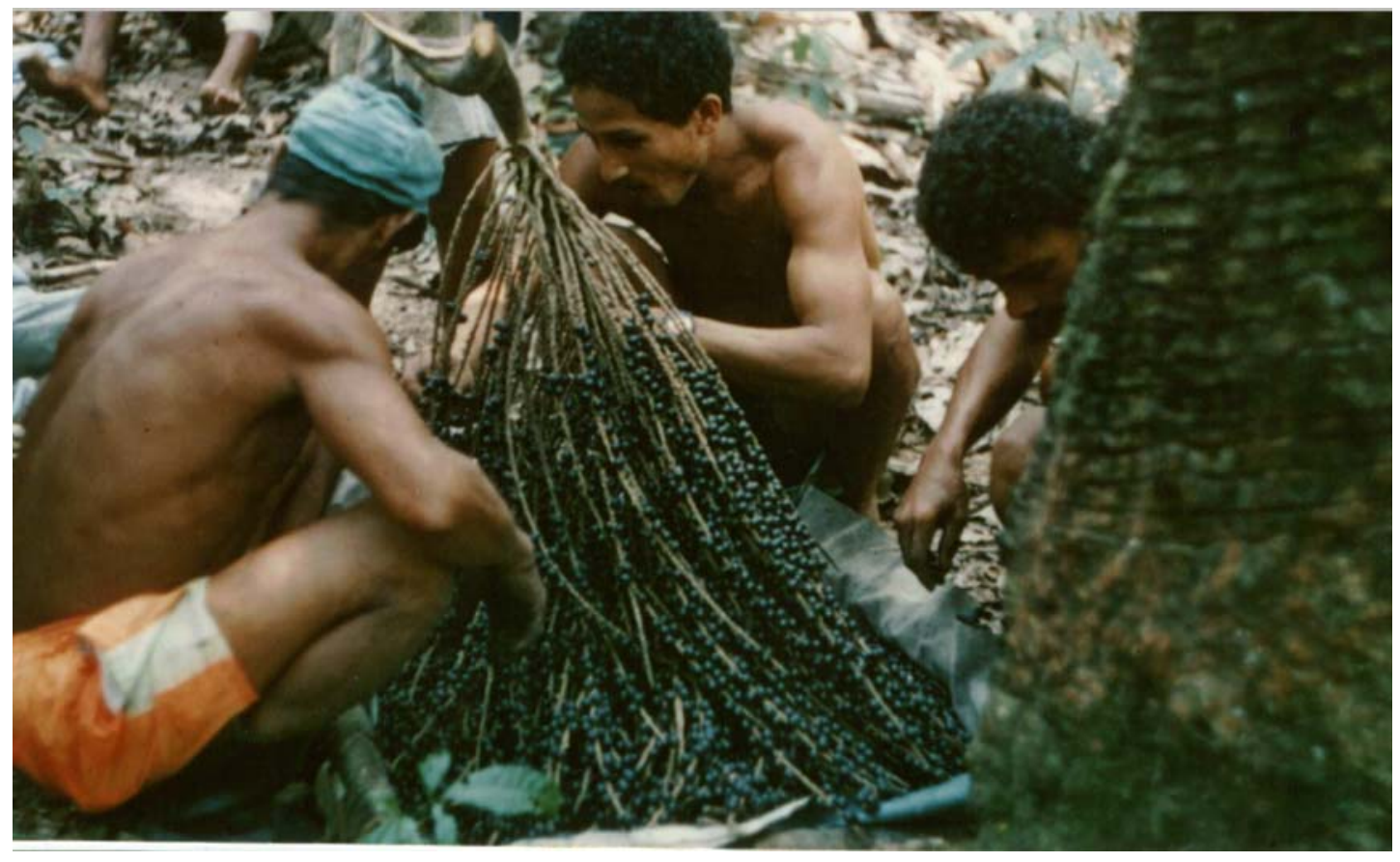

Foto 3.3 Debulhadores de frutos de Açaí, Seringal Caquetá, AC, 1998.

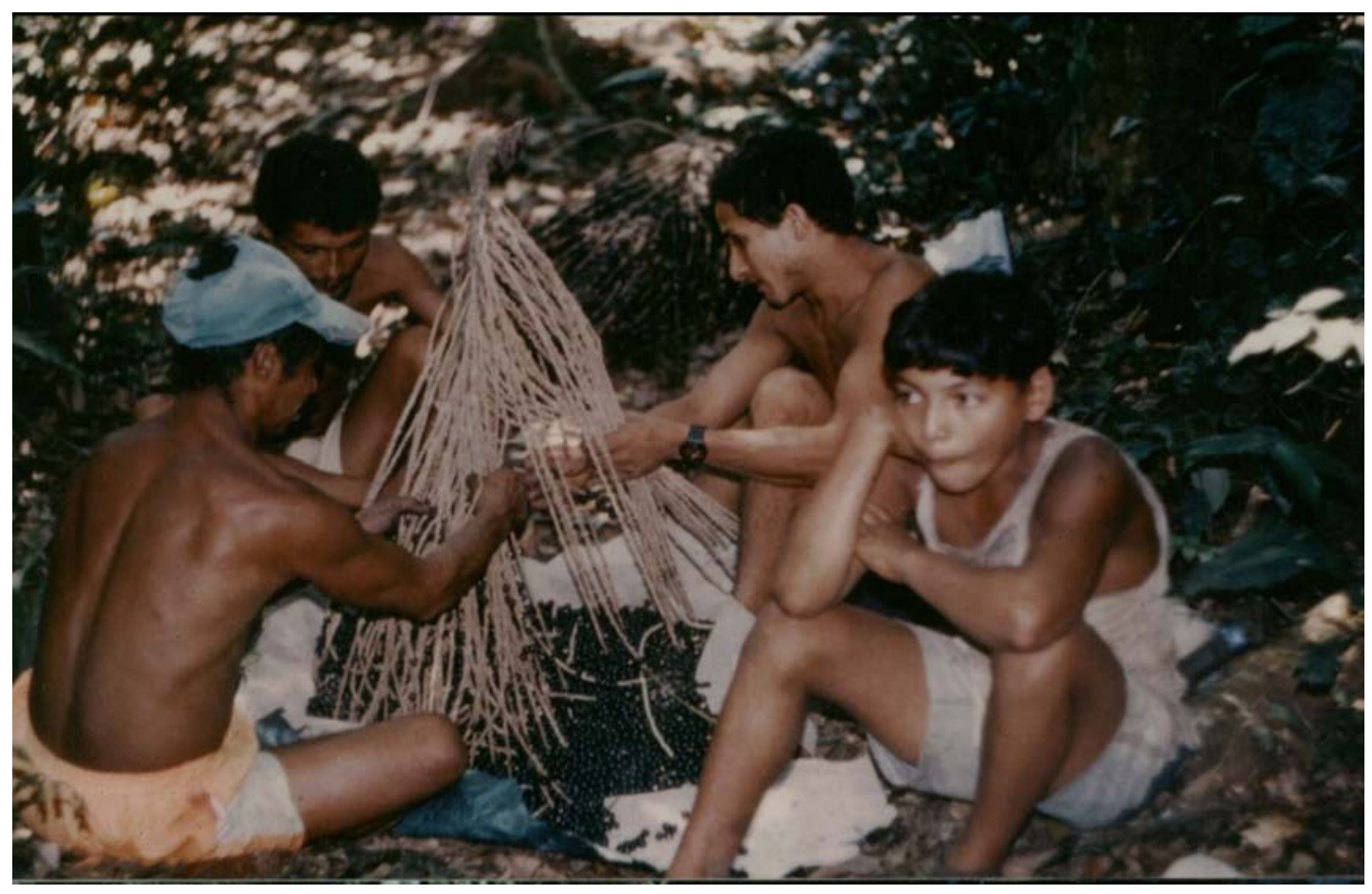

Foto 3.4 Debulhadores de frutos de Açaí, Seringal Caquetá, AC, 1998. 


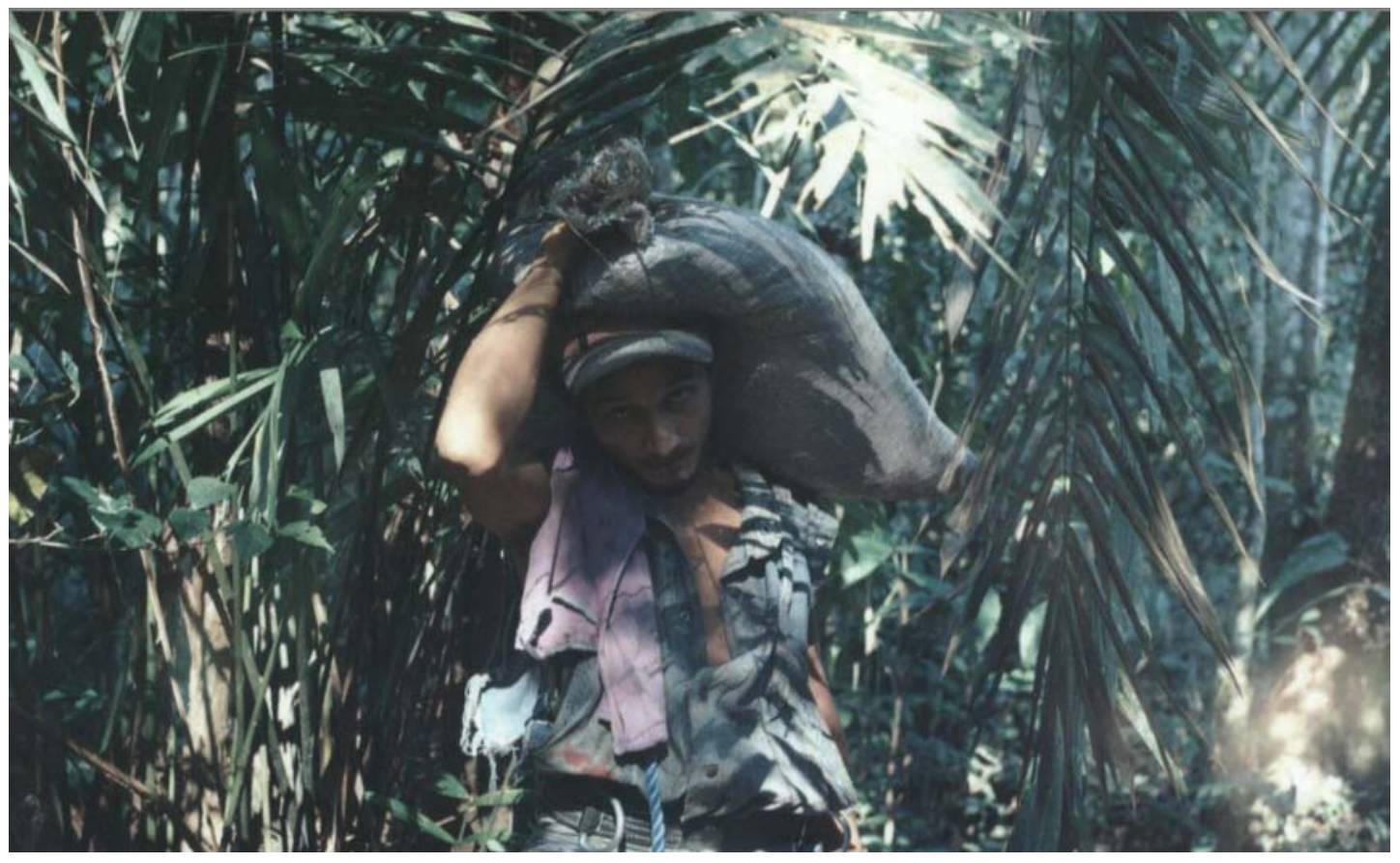

Foto 3.5 Transporte do Açaí da Floresta à casa, Seringal Caquetá, AC, 1999.

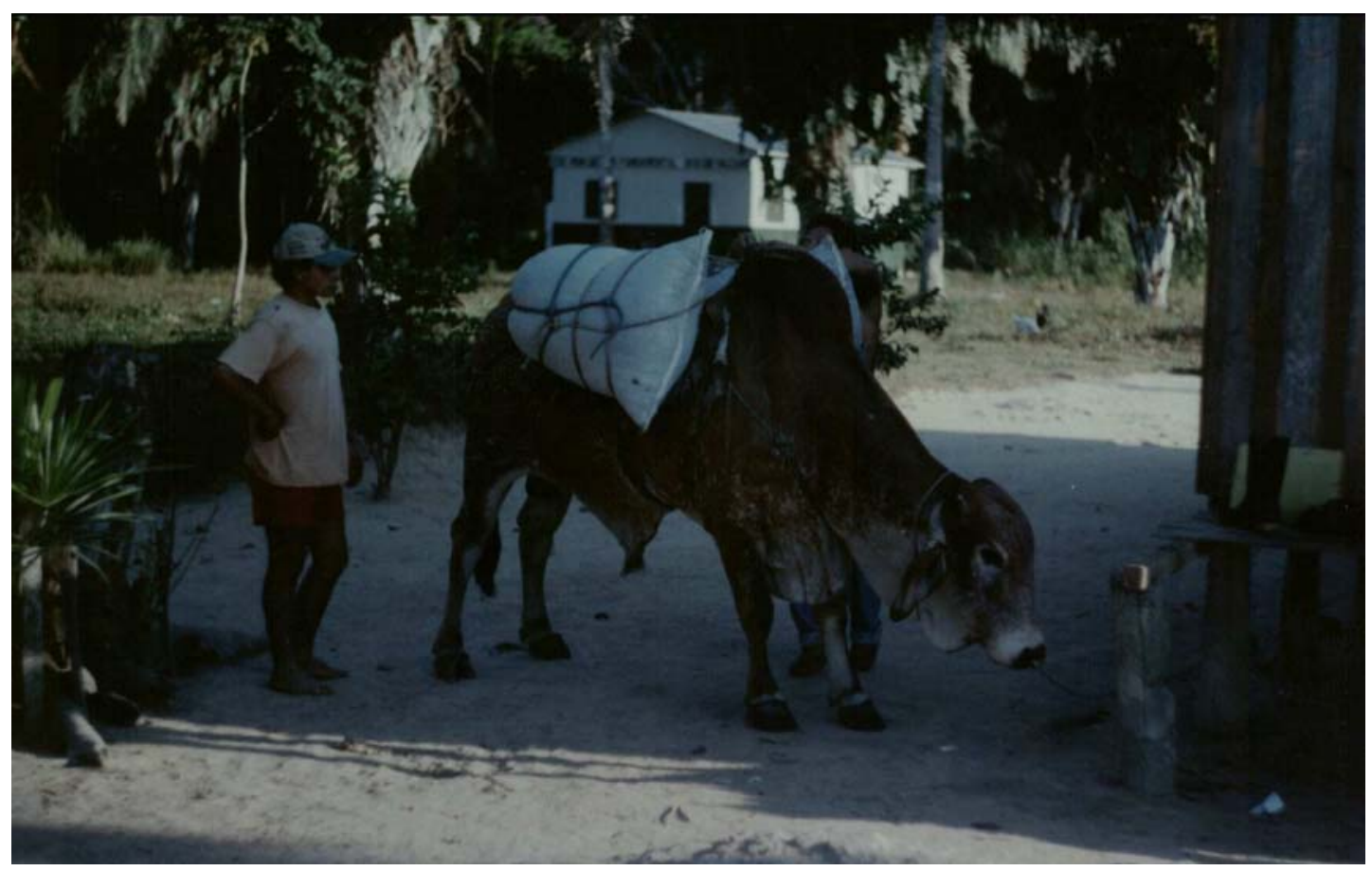

Foto 3.6 Transporte do Açaí do Seringal até os pontos de comercialização feito nas costas de boi, Seringal Caquetá, AC, 1999. 
A escolha ou não da extração de Açaí como atividade econômica está relacionada basicamente com a disponibilidade de recursos como: palmeiras em suas Colocações, mão de obra, capacidade de se relacionar com o mercado e transporte da produção. Como em qualquer outra comunidade, a extrativista do Caquetá é composta por famílias heterogêneas em relação a um ou mais destes recursos.

No Seringal Caquetá existem famílias de seringueiros que possuem a infraestrutura básica para trabalhar com o manejo do Açaí como: (1) muitos filhos na família; (2) membro(s) que sobe(m) no Açaí; (3) animais de carga para transportar a produção (além dos animais de carga da ASPAC) (4) um membro da família que consegue lidar (pegar, celar e guiar pelas trilhas) com animais de carga. Por outro lado, das 11 famílias estudadas apenas 5 possuem a infra-estrutura completa. Para as outras famílias provavelmente é muito difícil fornecer frutos de forma regular a um processador de frutos urbano trabalhando de maneira isolada.

Para o primeiro tipo de família a extração de frutos de Açaí orientada para o mercado pode ser bem sucedida caso a organização para o trabalho seja familiar como ocorre para a produção de borracha, castanha e roçados de subsistência. Nestas famílias, caso falte algum recurso para a realização da atividade produtiva com o Açaí (como por exemplo quem consiga lidar com animais de carga, ou subir na palmeira), por serem famílias de maiores recursos financeiros, é possível a elas pagar a diária local para a realização de parte do serviço como muitas vezes é praticado para a feitura dos roçados de subsistência. Para o segundo tipo de família, geralmente as mais jovens, com pouca infra- estrutura e limitadas alternativas de renda, a extração de frutos orientada para o mercado só poderá ser empreendida, se trabalharem juntas, porque assim podem unir os seus recursos, e com isso possibilitar a sua inserção no mercado com maiores margens de lucro (Wallace, 1999).

A organização familiar para o trabalho com o Açaí pode excluir famílias da atividade produtiva devido a falta de recursos de todas as famílias e/ou grupos para a realização do trabalho, como por exemplo as famílias mais jovens ou então grupos de jovens do Seringal. Na organização em mutirões cada membro pode contribuir com a etapa do trabalho que ele melhor consiga realizar, mas esta é também uma forma de excluir famílias de seringueiros mais velhos e bem estruturados, já que o método de 
mutirão para a produção de frutos de Euterpe precatoria não é a maneira tradicional de produzir do Seringal.

\subsubsection{SISTEMAS DE PRODUÇÃO DE SUBSISTÊNCIA}

\subsection{PRODUÇÃO AGRÍCOLA E ANIMAL}

A agricultura é considerada como meio de subsistência. Os roçados têm em média 1.1 hectares. Todas as famílias que plantam declararam realizar o sistema de coivara, onde a vegetação é cortada ('brocada”) e queimada antes da plantação da chamada lavoura branca (no primeiro ano arroz, no segundo milho e feijão e posteriormente a mandioca). Geralmente estas áreas são utilizadas por um período de 3 a 4 anos porque o sistema de coivara tradicionalmente exige que a área tenha um período de descanso, para a recuperação da fertilidade do solo.

A alimentação básica no Seringal Caquetá é constituída de arroz, farinha de mandioca, caça, feijão, milho. Oito das nove famílias declararam que não comercializam nenhum dos produtos agrícolas para complementar a renda. Os plantios nestes casos são apenas para a subsistência da família. Um dos entrevistados disse comercializar a farinha excedente da subsistência no ano que isto acontece. Os eventuais excedentes de produção deste morador são comercializados para o dono do armazém (patrão) no município de Porto Acre como pagamento de dívidas ou para a compra de produtos como sal, açúcar e café .

Segundo CNS/ FUNTAC e ACDI (1992) na Reserva Extrativista Chico Mendes e em Projetos de Assentamento Extrativista da região do Vale do Rio Acre, a agricultura é a atividade que mais depende do tempo de trabalho na Colocação, sendo que $62 \%$ desta mão de obra é masculina e $38 \%$ feminina.

As principais etapas são: a abertura da roça, o plantio, a manutenção e a colheita. "Quando o plantio é realizado na mata bruta requer mais tempo que quando na capoeira mas rende muito mais". De maneira geral, os roçados requerem muito mais trabalho que a coleta de produtos da floresta. Este pode ser um motivo para os extrativistas não produzirem um excedente agrícola para comercializar todos os anos, além da falta de mercado certo para os produtos agrícolas. 
No Caquetá em geral a mão de obra para os plantios de subsistência é familiar. Já na região de Manaus, em circunstâncias particulares, como grandes roças ou a ausência de uma parte da família, o chefe familiar pode organizar um trabalho coletivo juntando parentes e aliados (Pinton \& Emperaire, 2000).

Tabela 3.5 Produção agrícola de subsistência de 1999 de 9 famílias Extrativistas do Seringal Caquetá, AC. Área plantada $\left(\mathrm{m}^{2}\right)$, quantidade colhida $(\mathrm{kg})$ e preço de venda (R\$) do Arroz, Feijão, Farinha e Milho, principais produtos de subsistência cultivados no estado do Acre.

\begin{tabular}{l|rrr|rrr}
\hline & \multicolumn{3}{|c|}{ Arroz } & \multicolumn{3}{c}{ Feijão } \\
\hline Colocação & Área $\left(\mathrm{m}^{2}\right)$ & $\begin{array}{l}\text { Quantidade } \\
\text { colhida }(\mathrm{kg})\end{array}$ & Preço (R\$) & Área $\left(\mathrm{m}^{2}\right)$ & $\begin{array}{l}\text { Quantidade } \\
\text { colhida }(\mathrm{kg})\end{array}$ & Preço (R\$) \\
\hline Floresta & 10000 & 500 & 230 & 2500 & 12 & 16,0 \\
Cajueiro & 10000 & 500 & 230 & 10000 & 62 & 82,7 \\
Limoeiro & 15000 & 500 & 230 & 10000 & 200 & 266,7 \\
Limoeiro & 10000 & 550 & 253 & 5000 & 350 & 466,7 \\
São Pedro & 10000 & 1150 & 529 & 10000 & 125 & 166,7 \\
Floresta & 10000 & 200 & 92 & 10000 & 300 & 400,0 \\
São Pedro & 5000 & 1200 & 552 & 7500 & 800 & 1066,7 \\
Arraia & 7500 & 200 & 92 & 7500 & 0 & 0,0 \\
Morada Nova & 10000 & 1500 & 690 & 10000 & 400 & 533,3 \\
$\quad$ Total & $\mathbf{8 7 5 0 0}$ & $\mathbf{6 . 3 0 0}$ & $\mathbf{2 8 9 8}$ & & $\mathbf{2 2 4 9}$ & $\mathbf{2 9 9 8 , 6}$ \\
\multicolumn{1}{r|}{ Média } & & $\mathbf{7 0 0}$ & $\mathbf{3 2 2}$ & & $\mathbf{2 4 9 , 9}$ & $\mathbf{3 3 3 , 2}$ \\
\hline
\end{tabular}

\begin{tabular}{|c|c|c|c|c|c|c|}
\hline & \multicolumn{3}{|c|}{ Farinha } & \multicolumn{3}{|c|}{ Milho } \\
\hline Colocação & Área $\left(\mathrm{m}^{2}\right)$ & $\begin{array}{l}\text { Quantidade } \\
\text { colhida }(\mathrm{kg})\end{array}$ & Preço (R\$) & Área $\left(\mathrm{m}^{2}\right)$ & $\begin{array}{l}\text { Quantidade } \\
\text { colhida (kg) }\end{array}$ & Preço (R\$) \\
\hline Floresta & 15000 & 0 & 0,0 & 10000 & 400 & 66,7 \\
\hline Cajueiro & 24000 & 800 & 368,0 & 10000 & 350 & 58,3 \\
\hline Limoeiro & 15000 & 900 & 414,0 & 15000 & 500 & 83,3 \\
\hline Limoeiro & 10000 & 2500 & 1150,0 & 10000 & 350 & 58,3 \\
\hline São Pedro & 10000 & 6000 & 2760,0 & 10000 & 1.000 & 166,7 \\
\hline Floresta & 15000 & 10500 & 4830,0 & 7500 & 100 & 16,7 \\
\hline São Pedro & 5000 & 2000 & 920,0 & 10000 & 1.000 & 166,7 \\
\hline Arraia & 7500 & 2000 & 920,0 & 10000 & 1.000 & 166,7 \\
\hline Morada Nova & 10000 & 24700 & $11.362,0$ & 15000 & 0 & 0,0 \\
\hline Total & & 49400 & 22.724 & & 4700 & 783,3 \\
\hline Média & & 5488,9 & $2.524,9$ & & 522,2 & 87 \\
\hline
\end{tabular}

Nota: Preço usado na estimativa do Arroz $-50 \mathrm{~kg}=\mathrm{R} \$ 23.00$; Feijão $-60 \mathrm{~kg}=\mathrm{R} \$ 80.00$; Farinha - 50 $\mathrm{kg}=\mathrm{R} \$ 23.00$; Milho $-50 \mathrm{~kg}=\mathrm{R} \$ 10.00$. Segundo MONTENEGRO et. al., 1999 COOPEAGRO $($ INCRA). 1 dólar $=2.5$ reais

A produção da farinha de mandioca sempre foi um elemento muito importante para os seringueiros porque é um alimento de longa conservação o que 
garante uma auto-suficiência. Na Tabela 3.5 este fato ficou evidenciado, visto que foi o produto que mais foi produzido nos roçados de subsistência.

Os principais animais domésticos são galinha, pato, porco, boi e cavalo. Das famílias estudadas, $90 \%$ possuem galinhas, patos e porcos, mas apenas $40 \%$ possuem animais de carga. Os moradores que não possuem animais de carga podem utilizar os três animais que a ASPAC tem através de uma organização de rodízio entre eles. Galinhas, patos e porcos são comercializados ou consumidos apenas no caso de necessidade, estes animais representam uma "caderneta de poupança" dos moradores extrativistas.

As principais árvores "fruteiras" observadas foram banana, tangerina, limão, laranja e abacate.

\subsection{EXTRATIVISMO DA FLORESTA}

Os recursos da floresta mais procurados são a caça, em seguida, frutos, e depois a pesca.

Quando indagados sobre a freqüência de pesca, das 10 famílias entrevistadas, apenas uma nunca realiza esta atividade, as outras pescam esporadicamente. Geralmente esta é feita pelas mulheres e crianças nos igarapés próximos às suas casas. Os peixes encontrados são piaba, cará, piau, jacundá, jiju, mandim, pacu, piranha e arraia.

A caça é a principal fonte de subsistência, além das lavouras. Os animais mais caçados são veados, pacas, cutias, porcos, tatus, macacos, quatipurus (esquilo), jabutis, tucanos, jacus e papagaios.

A colheita de frutos da floresta também é importante para a complementação da dieta dos seringueiros. Entre as espécies coletadas estão Açaí (Euterpe precatoria), castanha (Bertholletia excelsa), Buriti (Mauritia flexuosa), Bacaba (Oenocarpus mapora) Patauá (Oenocarpus bataua), Cacau (Theobroma sp.), Tucumã (Astrocayum sp.), Ouricuri (Scheelea sp.), piqui (Caryocar sp.), Maracujá (Passiflora sp), das quais, os frutos mais consumidos são os do Açaí. Foi observado que a maioria dos coletores de Açaí do Seringal Caquetá consomem mais de 1,5 litros de vinho quando realizam o trabalho de extração. 


\subsubsection{TRABALHO REMUNERADO (DIARISTA).}

Dos 10 entrevistados 30\% trabalham como diaristas em média 8.3 horas/dia, destes, $20 \%$ trabalham no máximo 1 vez por mês e $10 \%$ trabalha 22 dias por mês. A diária local de trabalho é de $\mathrm{R} \$ 10,00$ (Tabela 3.6).

Pelo menos $60 \%$ dos seringueiros entrevistados afirmaram que não existe muita oferta de emprego como diarista no Seringal Caquetá, dos $40 \%$ que acham que existe oferta de emprego, $20 \%$ disseram que muitas vezes o trabalho não compensa pela demora em receber o dinheiro.

Tabela 3.6 Questionário aplicado em representantes de 9 famílias do Seringal Caquetá, AC para o levantamento de informações sobre a diária local de trabalho.

\begin{tabular}{llllrrr}
\hline Colocação & A & B & \multicolumn{1}{c}{ C } & \multicolumn{2}{c}{ E } & \multicolumn{1}{c}{ } \\
\hline Floresta & 10 & S & 1 & 7 & $\mathrm{~N}$ & $\mathrm{~N}$ \\
Cajueiro & 10 & S & 22 & 8 & $\mathrm{~N}$ & $\mathrm{~N}$ \\
Limoeiro & 10 & $\mathrm{~S}$ & 1 & 10 & $\mathrm{~N}$ & $\mathrm{~N}$ \\
Limoeiro & 10 & $\mathrm{~N}$ & - & - & $\mathrm{N}$ & $\mathrm{N}$ \\
São Pedro & 10 & $\mathrm{~N}$ & - & - & $\mathrm{S}$ & $\mathrm{S}$ \\
Floresta & 10 & $\mathrm{~N}$ & - & - & $\mathrm{N}$ & $\mathrm{N}$ \\
São Pedro & 10 & $\mathrm{~N}$ & - & - & $\mathrm{S}$ & $\mathrm{S}$ \\
Arraia & 10 & $\mathrm{~N}$ & - & - & $\mathrm{N}$ & $\mathrm{S}$ \\
Morada Nova & 10 & $\mathrm{~N}$ & - & - & $\mathrm{N}$ & $\mathrm{S}$ \\
Arraia II & 10 & $\mathrm{~N}$ & - & - & $\mathrm{N}$ & $\mathrm{N}$ \\
\hline
\end{tabular}

$\mathrm{A}=$ Qual é a diária local de trabalho $(\mathrm{R} \$) ; \mathrm{B}=$ Você trabalha como diarista?; $\mathrm{C}=$ Quantos dias por mês? $\mathrm{D}=$ Quantas horas por dia?; $\mathrm{E}=$ Você tem algum aposentado na família? $\mathrm{F}=$ Você ganha algum salário?

$\mathrm{Sim}=\mathrm{S} ; \mathrm{Não}=\mathrm{N}$

$\mathrm{U} \$ 1.00=\mathrm{R} \$ 2,50$

\subsubsection{DIÁRIA LOCAL E OUTROS USOS DA TERRA VERSUS MANEJO DO} AÇAÍ.

A Figura 3.2 mostra o calendário anual de produção de 10 seringueiros no Seringal Caquetá. Este calendário foi feito com o intuito de obter uma estimativa das épocas do ano em que se distribuem os diferentes trabalhos no Seringal. Através do calendário é possível perceber que todos os seringueiros estão trabalhando com a 
castanha de Janeiro a Março e que $90 \%$ dos seringueiros estão trabalhando com a borracha de Maio a Outubro. Em relação aos plantios, 80\% planta arroz em Março e $90 \%$ colhe em Outubro e $60 \%$ planta o feijão em Março sendo que a colheita ocorre em épocas distintas. Não foi possível encontrar um padrão da época de trabalho para o plantio da mandioca e milho entre os moradores do Seringal Caquetá.

\begin{tabular}{|c|c|c|c|c|c|c|c|c|c|c|c|c|}
\hline FAM & JAN & FEV & MAR & ABR & MAI & JUN & JUL & $\mathrm{AGO}$ & SET & OUT & $\mathrm{NOV}$ & DEZ \\
\hline 1 & $\square$ & $\square$ & $\square+$ & $* \square \bullet \#$ & $*$ & $* \bullet+$ & $*$ & $*$ & $*$ & $*_{-}$ & & $\square$ \\
\hline 2 & $\square \wedge$ & $\square$ & $\square$ & $\square \bullet$ & $* \bullet+-$ & $*$ & $* \quad \bullet$ & $*$ & $*+$ & $\#$ & & $\square$ \\
\hline 3 & $\square$ & $\square$ & $+\#$ & $\bullet$ & $*$ & $* \bullet-$ & $* \bullet+$ & $*$ & $*$ & $* \#-$ & $*$ & $*$ \\
\hline 4 & $\square$ & $\square$ & $\square+$ & $\square \bullet$ & - & $\bullet *+$ & - * * & •* & $*$ & $* \#--1$ & $*$ & $*$ \\
\hline 5 & $\square \wedge$ & $\square$ & $\square \#+$ & $\bullet$ & $*$ & $* \bullet+$ & $*$ & $*$ & $*_{-}$ & $* \#$ & $*$ & $*$ \\
\hline 6 & $\square$ & $\square$ & $\square \#$ & $\square \bullet$ & $* \bullet$ & * $\bullet+$ & $*$ & $\bullet+$ & - & $*$ & $* \#$ & $*$ \\
\hline 7 & $\square$ & $\square$ & $\square \#$ & $\bullet+$ & $*$ & $* \bullet$ & $*$ & $\bullet+$ & --1 & $* \#$ & $*$ & $*$ \\
\hline 8 & $\square$ & $\square$ & $\square \#+$ & $*$ & $* \bullet+$ & $*$ & $*$ & $*$ & $* \#$ & $*$ & $*$ & $\square$ \\
\hline 9 & $\square$ & $\square \Delta$ & $\square \#+$ & $\bullet$ & $*$ & $* \bullet+$ & $* \quad \bullet-$ & $*$ & $*$ & $* \#$ & $* \square-$ & $\square \wedge$ \\
\hline 10 & $\square$ & $\square$ & $\square \#$ & $*$ & $*$ & $* \bullet-$ & $*$ & $*$ & $*$ & $* \#$ & $*$ & $\square$ \\
\hline
\end{tabular}
FAM $=$ Família. $(*)$ Borracha
$(\square)$ Castanha
(•) Açaí
(\#) Arroz
(+) Feijão

(-)Mandioca

Figura 3.2 Calendário anual da produção extrativista e de roçados de subsistência no Seringal Caquetá, Municicípio de Porto Acre. (n=10 famílias).

O período de frutificação de Euterpe precatoria no Seringal Caquetá é de março a setembro e consequentemente é a época possível de se comercializar frutos, como apontado pelos seringueiros no calendário.

A inserção de novos produtos florestais não madeireiros, como o Açaí, na economia de algumas populações extrativistas está diretamente relacionada com a disponibilidade de tempo que as famílias possuem para a atividade. Este período não deverá coincidir com aquele para a realização de tarefas prioritárias, como o plantio de roçados e a extração de castanha ou em alguns casos da borracha.

A partir do calendário de produção anual do Caquetá, pode-se observar que a extração de frutos do Açaí de Maio a Agosto coincidiria com a atividade de extração da borracha e com o plantio do feijão, para a maioria dos entrevistados. Isto poderia ser uma desvantagem caso o seringueiro trabalhasse todos os dias com a borracha. A maioria dos entrevistados não corta seringa todos os dias na safra, geralmente trabalham com a borracha durante 5 dias por semana no máximo. Muitas atividades extrativistas como a coleta de Açaí, podem ser realizadas em períodos que exigem 
pouca força de trabalho para a atividade agrícola. Há então uma complementariedade de atividades que possibilitam a inserção dos frutos de Euterpe precatoria no sistema de produção.

A Tabela 3.7 mostra as rendas $(\mathrm{R} \$)$ por dia de trabalho no Seringal Caquetá que podem ser conseguidas com a castanha, borracha, Açaí e o trabalho remunerado. A renda que pode ser obtida com a comercialização do Açaí é menor do que a renda com a castanha e maior que a conseguida com a borracha e com a diária local. Então, porque o manejo dos frutos de Açaí não é feito em uma escala maior?

Uma primeira hipótese para responder esta pergunta é que a procura de mercados de frutos que deve ser feita todos os anos antes da extração do Açaí, dificulta a comercialização, diferentemente do que acontece com a castanha e borracha, onde no momento que o seringueiro sai de casa para a extração, ele já sabe onde e para quem vender. Uma segunda hipótese se refere a ausência completa de subsídios para a comercialização do Açaí, diferentemente do que acontece com a castanha e borracha, que têm o transporte e produção subsidiados (borracha). O custo para transportar a produção de frutos de Açaí da Colocação até os mercados compradores representa aproximadamente $42,8 \%$ do custo total. Isto significa que caso fosse fornecido ao Açaí o subsídio do transporte como acontece com a castanha e a borracha o seringueiro poderia ganhar aproximadamente $\mathrm{R} \$ 31,50$ por dia de trabalho ( $\mathrm{R} \$ 18,00+\mathrm{R} \$ 13,50)$. A renda diária conseguida com a comercialização do Açaí na ausência de subsídios de transporte varia de acordo com a distância da área de escoamento da produção.

Um outro ponto a ser considerado é sem dúvida a importância econômica histórica e tradicional da castanha e borracha se comparada com a comercialização do Açaí para a comunidade do Seringal Caquetá. Os frutos de Euterpe precatoria, como já dito, são altamente consumidos pelas comunidades extrativistas, porém, menos comercializados comparativamente com os outros dois produtos. A comercialização de "novos" produtos florestais não madeireiros como por exemplo os frutos de Euterpe precatoria implica na combinação de práticas tradicionais e novas práticas de organização para o trabalho e de subsídios econômicos e políticos para a atividade produtiva, assim como acontece com a castanha e borracha. 
A proximidade relativa dos pontos de comercialização de frutos de Açaí em relação ao Caquetá possibilita uma comercialização do produto independente do sistema tradicional do aviamento. Este produto parece ser capaz de somar valor local, caso o seu transporte seja subsidiado até os mercados beneficiadores, ou ainda seja feito o processamento dos frutos em "vinho de Açaí" no local.

Tabela 3.7 Custo benefício da produção de Açaí, castanha e borracha e do trabalho assalariado de 1 dia de trabalho (8 horas) no Seringal Caquetá, AC, considerando os dados das Tabelas 2.3, 2.4, 2.6 e os cálculos do potencial produtivo do Açaí.

\begin{tabular}{lrrrc}
\hline & Borracha & Castanha & Açaí & $\begin{array}{c}\text { Trabalho } \\
\text { remunerado }\end{array}$ \\
\hline Transporte Colocação - Porto Acre & 2,9 & 5,4 & 0 & - \\
Transporte Porto Acre -Rio Branco & 0 & 0 & 13,5 & - \\
Custo boi (R\$) & 0,04 & 0,04 & 0,04 & - \\
Custo embalagem (R\$) & 0,3 & 0,3 & 0,3 & - \\
Custo total/real (R\$) & 3,2 & 5,7 & 14,8 & - \\
Custo total/dólar (US\$) & 1,3 & 2,3 & 5,9 & \\
Kg de frutos/dia & 5,4 & 85,2 & 105 & - \\
Latas de frutos/dia & 5,4 & 7,1 & 7 & - \\
Renda (R\$)/dia Bruta & 5,4 & 35,5 & 31,5 & 10 \\
Renda (R\$)/dia líquida & 2,1 & 29,7 & 18,0 & 10 \\
Renda (US\$)/dia líquida & 0,8 & 11,9 & 7,2 & 4 \\
\hline
\end{tabular}

$\mathrm{R} \$ 2,50=\mathrm{US} \$ 1,00$.

Borracha : Uma lata de borracha $(1 \mathrm{~kg}$ ) custa $\mathrm{R} \$ 1,00=0,60$ (preço do mercado) $+0,40$ (subsídio $/ \mathrm{kg}$ de borracha produzido) (US\$0,40). A renda do transporte é a média que 10 seringueiros gastam apresentado na Tabela 3.3.

Castanha : Uma lata de castanha molhada (12 kg) custa R $\$ 5,00$ (US\$ 2,00). A renda do transporte é a média que 10 seringueiros gastam apresentado na Tabela 3.4

Açaí : Uma lata de Açaí $(15 \mathrm{~kg}$ ) custa R $\$ 4,50$ (US\$ 1,80). O transporte para o seringueiro custa $\mathrm{R} \$ 10,00$ ída e volta Porto Acre - Rio Branco + R \$ 0,50 por lata de Açaí.

Foram calculados o custo boi (vacina + sal mineralizado) e a embalagem para carregar a produção de 1 dia de trabalho ( 8 horas). O custo boi foi obtido a partir da soma do valor ( $\mathrm{R} \$$ ) de sal mineralizado consumido por dia ( $R \$ 0,03)$ e do custo da vacina aplicada anualmente $(\mathrm{R} \$ 0,90 / 365=\mathrm{R} \$ 0,002)$. O Custo/dia da embalagem (sacos de estopa) foi obtido considerando-se que a cada três dias de trabalho gasta-se aproximadamente 2 sacos ou $R \$ 1,00(R \$ 1,00 / 3$ dias $=R \$ 0,30$ por dia).

Renda líquida : obtida a partir da Renda bruta - custo total (transporte + custo boi).

Algumas pesquisas realizadas na Amazônia Central estimaram as rendas diárias conseguidas através da extração de frutos de Açaí como sendo de $\mathrm{R} \$ 15,00$ a R \$ 18,75 (US\$ 6,00 a US\$ 7,50) (Lescure, 2000) e de R $\$ 17,00$ a R $\$ 18,75$ (US\$6,80 a US\$ 7,50) (Castro, 2000). 
Os rendimentos obtidos com os produtos florestais não madeireiros podem ter flutuações sazonais grandes e estas devem ser consideradas quando se estima a renda anual. O uso de preços médios do produto superestima as rendas anuais. Para obter as medidas precisas destas rendas, é importante observar e considerar os preços mensais e os níveis de produção durante o ano (Muñiz-Miret et. al. 1996).

Wallace (1999) apresenta o preço de venda da lata $(15 \mathrm{~kg})$ de frutos de Açaí do maior processador no mercado municipal central de Rio Branco no período de Junho de 1996 a Junho de 1997. Os preços coletados em vários momentos ao longo de cada mês variaram de R $\$ 4,00$ (US\$ 1,60) durante a alta estação a R $\$ 7,00$ (US\$ $2,80)$ fora da estação. Os processadores afirmaram que o preço da lata de Açaí pode chegar até $\mathrm{R} \$ 10,00$ fora da estação (novembro a fevereiro). Todos os cálculos de rendas respondem pela variação nos preços devido à sazonalidade da produção, apesar disso, foi utilizado neste estudo para o cálculo da renda diária o preço de R\$4,50 a lata de Açaí, que foi o pago aos produtores no Caquetá em 1998, 1999 e 2000 no pico da safra (Abril/Julho).

\subsection{CONCLUSÃO}

A comunidade do Seringal Caquetá estudada é extrativista. Possui a floresta como o principal uso da terra, tirando dela a renda da comercialização da castanha e borracha e a subsistência como a caça, frutos, madeira e remédios.

A agricultura praticada é de subsistência. O trabalho remunerado é pouco freqüente entre as famílias estudadas.

Euterpe precatoria tem um alto potencial econômico para ser utilizado pela comunidade extrativista do Caquetá como forma de complementar a renda anual por família. A remuneração que pode ser conseguida com a extração do Açaí é maior que a obtida com a extração de borracha e também com a diária local de trabalho. Enquanto que a remuneração com a castanha apresentou-se um pouco maior que a do Açaí.

As quantidades de frutos de Açaí colhidas foram pequenas em relação ao potencial estimado e o sistema de transporte e comercialização precisam ser 
aprimorados. Os custos de produção podem ser reduzidos com uma maior eficiência nas atividades de transporte. As longas distâncias a serem percorridas para transportar o Açaí elevam os custos de mão de obra no escoamento da produção.

A pequena extração de Açaí para a comercialização está diretamente relacionada com a falta de políticas públicas tais como: (1) subsídios para o transporte do produto até os mercados, (2) facilitação do processo de organização comunitária para a atividade.

O subsídio para alavancar a atividade produtiva do Açaí no Seringal Caquetá deve ser para o transporte da produção assim como é feito para a castanha e a borracha. Neste caso a remuneração com o Açaí poderia ser maior, o que poderia compensar os custos despendidos da organização comunitária e da procura de mercados para a nova atividade produtiva.

A organização para o trabalho com o Açaí no Seringal Caquetá pode ser feita em estrutura familiar ou em mutirão. O fundamental é que esta organização deve se adequar à demanda de recursos das famílias envolvidas na atividade produtiva. Para famílias com recursos completos para a atividade extrativista do Açaí, a estrutura familiar torna-se a mais adequada, visto que esta organização é a forma mais comum de produção no local. Por outro lado, para viabilizar a entrada de várias famílias de poucos recursos para a produção de Açaí em uma economia de mercado mais regular, torna-se necessário que sejam testados e utilizados outros tipos de organização como por exemplo o mutirão. 


\section{CAPÍTULO 4}

\section{IMPLICAÇÕES PARA O MANEJO DE Euterpe precatoria MART. NO SERINGAL CAQUETÁ.}

\subsection{INTRODUÇÃO}

Neste capítulo foram feitas algumas recomendações ecológicas e sócioeconômicas para o "bom manejo" das populações de Euterpe precatoria no Seringal Caquetá utilizando as informações levantadas nos capítulo 2 e 3 e uma revisão da literatura. As recomendações propostas visam ser úteis e servir como base de um modelo para alcançar a sustentabilidade do manejo do Açaí. Para isto foi feita uma estimativa da quantidade de frutos de Açaí que pode ser colhida por hectare de floresta sem danificar a regeneração a longo prazo.

O conceito de "manejo florestal sustentável” diz respeito "as práticas ideais de gestão de uma unidade de manejo florestal, capazes de assegurar a sua sustentabilidade sócio-cultural, ambiental e econômica"; enquanto que o conceito de "bom manejo florestal" diz respeito "as melhores práticas de gestão aplicáveis para uma determinada unidade de manejo florestal, considerando-se suas características e condicionantes socio-culturais, ambientais e econômicas e o conhecimento técnico e científico existente”. (Viana, comunicação pessoal). O bom manejo aqui proposto para Euterpe precatoria no Seringal Caquetá possui basicamente dois tipos de práticas, a jardinagem e o monitoramento. Ele deve estar sujeito a ajustes ecológicos, sociais e econômicos quando necessário, "visto que pode variar numa mesma unidade de manejo ao longo do tempo" (Viana, comunicação pessoal)

A jardinagem neste estudo inclui a quantificação da produção de frutos/palmeira, a forma de coleta dos frutos do Açaí, a semeadura em clareiras e o desbaste de plantas competidoras com o intuito de favorecer o crescimento e reprodução e portanto a produtividade de Euterpe precatoria em áreas de florestas. $\mathrm{O}$ monitoramento inclui avaliações periódicas da regeneração e ajustes de aproveitamento em relação a graus variados de extração, com o intuito de alcançar a 
sustentabilidade da colheita de frutos. As recomendações sócio-econômicas incluem a forma de organização comunitária, a rentabilidade e as demandas da comunidade do Seringal Caquetá para tornar o Açaí mais um produto a fazer parte da diversificação florestal.

\subsection{RECOMENDAÇÕES ECOLÓGICAS}

\subsubsection{JARDINAGEM}

Euterpe precatoria é utilizado no Vale do Rio Acre pelos seringueiros para a construção de casas, fins medicinais e principalmente para a fabricação do "vinho" do Açaí (depoimentos de moradores do Caquetá e RECM, 2000).

$\mathrm{O}$ rendimento de frutos (estimativa da quantidade total de frutos produzidos por palmeiras) de Açaí deve ser quantificado em indivíduos adultos marcados de diferentes tamanhos e distribuídos na floresta de Baixio e Terra Firme. No item Material e Métodos - Produção de frutos foi descrito um método simples e rápido aplicado no manejo do Seringal Caquetá. Como a variação na produção de frutos entre indivíduos e cachos é alta, então para ter estimativas mais representativas, a quantificação do rendimento deve ser feita em indivíduos de diferentes tamanhos, durante vários anos, para conhecer a variação do rendimento com o passar do tempo. Esta avaliação deve ser feita pelos próprios extrativistas a partir do treinamento para a pesagem dos cachos. Como existe uma alta correlação entre peso de cachos e peso do raquis $(\mathrm{r}=0.95)$, para fazer estimativas do potencial produtivo de frutos de Açaí, pode-se utilizar apenas a pesagem dos cachos, conforme foi descrito no item Produção de Frutos do capítulo 2.

A mão de obra representa o principal custo associado ao manejo. Para implementar a avaliação da produção de frutos nas florestas de Baixio e Terra Firme utilizando 15 indivíduos em cada tipo florestal 2 homens gastariam 2 dias, sendo 1 no Baixio e 1 na Terra Firme. Os gastos envolvidos neste caso seriam de R $\$ 40,00$ (US\$ 16,00) por ano considerando a diária local de R\$ 10,00 (U\$ 4,00) conforme demonstra a tabela 4.2 . 
Existem duas técnicas que são praticadas pelas comunidades extrativistas do Vale do Rio Acre para a colheita dos frutos de Euterpe precatoria, (1) escalar a palmeira e cortar os cachos e /ou (2) cortar o estipe.

A extração de frutos para o mercado é uma atividade muito diferente da extração para uso doméstico porque requer frutos de muito mais palmeiras. $\mathrm{O}$ corte intensivo de indivíduos adultos de Euterpe precatoria para dispor ao mercado devastaria a população, desta forma, as famílias que esperam participar na economia de comercialização do Açaí, teriam que extrair escalando (Wallace, 1999). A extração intensiva de adultos de Euterpe precatoria para a comercialização do palmito na Bolívia poderá provocar a extinção local da espécie nestas florestas (Zuidema \& Boot, 2000), assim como o corte intensivo da palmeira de dossel Mauritia flexuosa para a coleta de frutos diminui populações e o potencial de colheita futura em algumas partes da Amazônia peruana (Vasques \& Gentry 1989).

Outro exemplo deste tipo de impacto foi dado por Bodmer et al. (1999) que estudaram sobre as relações entre as palmeiras, os ungulados (veados, antas, porquinhos, queixadas), e as pessoas. Segundo estes autores a capacidade de crescimento (densidade) da população de ungulados provavelmente depende da disponibilidade de frutos das palmeiras. Caso estes animais estejam contando com os mesmos frutos que as pessoas, e a prática de manejo seja o corte do caule da palmeira para a colheita de frutos, tanto as pessoas como as populações da palmeira e as de ungulados estariam prejudicadas a longo prazo. Para as populações das palmeiras o corte de indivíduos reprodutivos ocasionaria grandes alterações na estrutura das suas populações, e isto, futuramente diminuiria a disponibilidade local de frutos, o que consequentemente abaixaria o número de indivíduos de ungulados e a caça para as pessoas. As populações das palmeiras perderiam populações de ungulados que ajudam a manter a sua produtividade dispersando as suas sementes (Bodmer, 1991; Fragoso, 1994, citados por Bodmer, et. al., 1999). Caso nenhum passo fosse dado para restringir as derrubadas das palmeiras, os residentes locais a médio prazo necessitariam andar distâncias maiores nas florestas tanto para colher os frutos quanto para caçar. Desta forma, a extração com a manutenção da palmeira reprodutiva permite que os animais consumam seus frutos ocasionando assim maiores chances da colheita de frutos ser sustentável. Ao contrário, se o corte das 
palmeiras continuam para trazer benefícios a curto prazo, então o recurso pode se esgotar e os benefícios ao longo prazo deste e de outros recursos não estarão disponíveis. Na Mata Atlântica Galetti \& Aleixo (1998) trabalhando com Euterpe edulis encontraram que pássaros das famílias Ramphastidae e Contigidae foram afetados negativamente com a remoção do palmiteiro da floresta.

As análises de sensibilidade para as populações de Euterpe precatoria estudadas mostraram que o parâmetro demográfico em plântulas e jovens 1 que mais contribuiu para o crescimento populacional foi o de crescer para a próxima classe de tamanho e em adultos foi o de sobreviver e permanecer na mesma classe. Desta forma, a manutenção dos adultos e a utilização do método de coleta de escalar a palmeira são fundamentais para fazer o bom manejo da espécie; visto que a sobrevivência de adultos tem um grande efeito no valor de $\lambda$ e por isso no crescimento populacional (Viana, et. al., 1986).

A simulação da colheita de frutos utilizando o método de corte da palmeira foi feita reduzindo o coeficiente $\mathrm{P}_{4,4}$ (probabilidade da classe de adultos sobreviver e permanecer nesta classe durante o período de 1 ano) da matriz de transição para se ter uma estimativa da quantidade máxima de palmeiras que podem ser cortadas mantendo ao mesmo tempo a estabilidade demográfica da população. Como resultado apenas $5 \%$ da probabilidade de sobrevivência de jovens 2 e adultos pode ser reduzida para manter a estabilidade da população manejada e consequentemente a continuidade da colheita. Para garantir a sustentabilidade da produção de Açaí, as pessoas tem que subir no estipe para a retirada do cacho. O costume de derrubar a palmeira para a coleta do cacho, evitando a subida diminuirá significativamente a densidade da espécie comprometendo a produção em pouco tempo.

A utilização de práticas de manejo que maximizem o crescimento de plântulas e jovens 1 também poderia ser uma forma de aumentar o valor de $\lambda$, já que este parâmetro demográfico para estas classes de tamanho contribui muito para o crescimento populacional.

A maior densidade de Euterpe precatoria ocorreu em florestas de Baixio, mais úmidas e com maior penetração de luz no subosque nas áreas amostradas do Vale do Rio Acre, como ficou evidenciado pelo estudo da abertura do dossel e no estabelecimento das parcelas de monitoramento em locais de florestas de Baixio e de 
Terra Firme. Estes dados sugerem que florestas úmidas tem o potencial muito grande para o manejo da espécie.

A diferença de densidade de adultos entre Colocações (Figura 2.7) sugere que a disponibilidade de frutos para a comercialização das famílias também é diferente. A maior distância entre os indivíduos de Açaí (tabela 2.4)e a maior homogeneidade na distribuição do número de palmeiras adultas (tabela 2.3) ao longo da Terra Firme sugerem que os extrativistas gastem mais tempo para encontrar os indivíduos reprodutivos neste tipo de floresta do que gastariam em uma área densa de Baixio.

A tolerância à sombra de Euterpe precatoria implica que as suas populações formam bancos de plântulas, assim como o encontrado para Euterpe edulis na Mata Atlântica (Reis, 1992, citado por Reis, 1995; Fisch, 1998).

A probabilidade de crescimento em plântulas e jovens contribui muito para o crescimento populacional e a espécie tem uma maior densidade no Baixio onde houve uma maior penetração de luz no subosque. Assim, caso Euterpe precatoria não tiver a sua sobrevivência dependente da densidade, como o encontrado para Euterpe edulis (Matos, 1999), a prática de semear as sementes em áreas mais abertas deste tipo florestal pode ser uma forma de favorecer a manutenção da estabilidade da população e da produtividade.

De acordo com os dados de produção levantados neste estudo, em 2000, a produção de frutos/palmeira no Baixio foi maior que na Terra Firme. Além disso, a fecundidade também foi maior. Isto provavelmente ocorre porque há uma maior penetração de luz no Baixio, e esta interfere na produção, germinação e desenvolvimento de espécies de plantas tropicais (Gomes-Pompa, \& VazquezYanes, 1985; Martinez- Ramos, 1985; Del Amo \& Nieto De Pascual, 1985). Se o crescimento e a reprodução de Euterpe precatoria depende do nível de competição por nutrientes e luz, alguns tratamentos silviculturais podem ser aplicados para reduzir esta competição, favorecendo assim o aumento de produtividade.

O desbaste seletivo de espécies competidoras da floresta feito em populações de Euterpe oleracea proporcionou um aumento significativo na produtividade $\left(\mathrm{kg} / \mathrm{ha}^{-1} \mathrm{ano}^{-1}\right)$ de frutos por estipe (Jardim \& Anderson, 1987; Anderson \& Jardim, 1989). Este desbaste inclui a retirada do excesso de cipós do estipe e/ou ao redor da palmeira distando aproximadamente 3 metros desta (Amaral et. al. 1998). 
A mão de obra para implementar os desbastes seletivos representa um alto custo associado ao manejo, mas a necessidade dessa mão de obra é variável, dependendo do estado inicial que está o dossel onde se encontra cada indivíduo reprodutivo.

A figura 4.1 representa um esquema do dossel sobre os indívíduos de Euterpe precatoria. Considerando que em média 60 indivíduos adultos/ha no Baixio se encontrem nas situações A, B e C apresentadas na Figura 4.1 e que destes 60, 20 indivíduos se encontrem na situação A; 20 se encontrem na situação B e 20 na $C$. Uma forma de aumentar a produtividade é fazer a abertura de copa (desbaste seletivo de espécies competidoras) nos 20 indivíduos localizados em dossel intermediário (situação B, Figura 4.1).

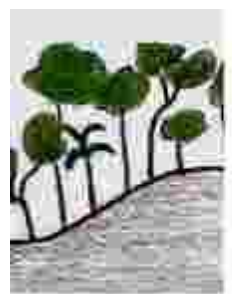

A

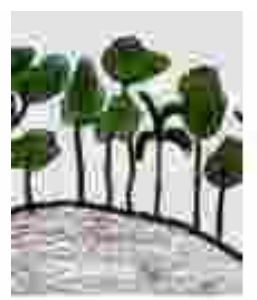

B

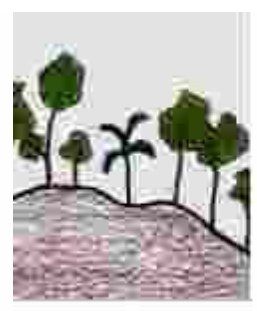

Figura 4.1 Esquema do dossel sobre os indivíduos de Euterpe precatoria. (A) Açaí sob um dossel fechado (100 a 75\% de cobertura); (B) Açaí sob um dossel semi aberto (75 a 25\% de cobertura); (C) Açaí sob um dossel aberto ( 25 a $0 \%$ de cobertura).

O aumento de luz decorrente do desbaste pode resultar em um aumento da floração (Bovi \& De Castro, 1993) e da frutificação ou da produção de frutos (Jardim \& Anderson, 1987).

Além disso a maior penetração de luz no subosque poderia favorecer a taxa de transição de plântulas e jovens o que contribuiria para o aumento da taxa de crescimento populacional.

O preço do desbaste em plantas adultas pequenas da Castanheira (Bertholletia excelsa) em Viana et. al. (1998) foi de US\$ 0,08 planta $^{-1}$ (R $\$ 0,20$ por planta). Este valor foi utilizado para o desbaste de espécies competidoras por palmeira de Açaí. Se para cada hectare de floresta fazermos o manejo em 20 indivíduos que se encontrem 
abaixo de um dossel intermediário (Figura 4.1B) gastaríamos aproximadamente US\$1,60/ha (R\$4,00/ha) ou a cada 20 palmeiras (tabela 4.2$)$.

Considerando-se que o desbaste é desta forma uma alternativa para aumentar a produtividade do Açaí em áreas extrativistas a curto e médio prazo, e que também muitas espécies competidoras têm funções ecológicas e sociais fundamentais para a manutenção do ecossistema de floresta, como por exemplo, fonte de alimento para várias espécies de animais ou de valor medicinal, esta técnica de manejo deve ser feita utilizando o conhecimento das populações tradicionais. Os próprios seringueiros devem avaliar o custo benefício do corte de outras espécies em detrimento do Açaí.

Considerando que o desbaste provocaria um aumento de penetração de luz no subosque poderia também beneficiar indivíduos de Euterpe precatoria de outras classes de tamanho como os jovens 1 e os jovens 2 (indivíduos pré-reprodutivos). A sensibilidade para mudanças na taxa de transição de jovens 2 no Baixio da Colocação São Pedro foi maior que em qualquer outra classe medida. Desta forma, o desbaste do dossel do tipo intermediário (Figura 4.1B) acima de alguns indivíduos jovens 2 poderia também provocar um aumento da taxa de crescimento populacional pela mudança na taxa de transição de jovens 2 .

Um aumento de 20, 30 e 40\% na probabilidade de transição de jovens 2 acarreta em um aumento nas taxas de crescimento populacional $(\lambda)$ que vão de 1.021 a 1.031. O aumento de $\lambda$ significa que a população tem um aumento do crescimento populacional que corresponde a fração que deve ser extraída. O tratamento silvicultural da poda de cipós deve ser orientado com o objetivo de aumentar o $\lambda$. Neste estudo o elemento da matriz cuja alteração provoca o maior efeito no valor de $\lambda$ foi a probabilidade de jovens 2 passarem à classe de tamanho adultos $(G 3,4)$ como mostra a Tabela 2.14. Este dado sugere a importância de testar o desbaste de cipós em indivíduos jovens 2 (como propõe Viana, 1986). 


\subsubsection{MONITORAMENTO}

Uma forma de detectar a colheita intensiva de produtos não madeireiros é fazer uma comparação de populações naturais não colhidas, com populações naturais colhidas equivalentes (Hall \& Bawa, 1993). Uma outra forma seria monitorar os mesmos parâmetros, como por exemplo, estrutura populacional, produção ao longo do tempo na mesma população em relação aos diferentes graus de aproveitamento. Este monitoramento pode detectar efeitos danosos diretos na população de Açaí colhida porque isto é evidenciado na alteração da estrutura da população (Peters, 1996).

O monitoramento inicia-se com os inventários florestais que devem ser feitos com o objetivo de estimar o número total de palmeiras reprodutivas por hectare em diferentes tipologias florestais, através de dados sobre a densidade e classes de tamanho. Hall \& Bawa (1993) e Peters (1995) sugerem que o melhor método para amostrar uma área grande heterogênea é estabelecer transectos múltiplos, preferentemente paralelos, que correm ao longo de qualquer topografia.

Existem outros métodos na literatura como por exemplo o método de parcelas aleatórias, muito adequado para variações em áreas heterogêneas de florestas, porém de difícil adequação às condições de manejo, tempo e dinheiro que requerem. Um método, cujo desenho experimental seja simples é fundamental para que os próprios moradores locais façam as avaliações da densidade de Euterpe precatoria em suas áreas de florestas.

A distribuição de classes de tamanho (Figura 4.2) do inventário servirá para ter uma avaliação preliminar tanto da quantidade de recurso quanto da regeneração da espécie e portanto da reposição do recurso frutos. A estrutura das populações avaliadas no capítulo 2 sugere que o recurso e a regeneração do Açaí são abundantes nas florestas medidas.

No caso da extração de frutos ou sementes, os efeitos da colheita intensiva são percebidos nos estágios iniciais de desenvolvimento muito claramente, ou seja, em plântulas e jovens. (Peters, 1996). Desta forma, a partir do inventário inicial deve ser feito histogramas de distribuição de classes de tamanho que representarão a estrutura da população medida antes da extração dos frutos para a comercialização 
(Figura 4.2 no Tempo 0). Este histograma com as densidades de plântulas e jovens será comparado com o histograma da distribuição de classes de tamanho construído na mesma área de inventário após cinco anos de extrações sucessivas. Ele será usado como padrão para o monitoramento das flutuações das densidades conforme o grau de aproveitamento (ou extração) do recurso (Figura 4.2 no Tempo 1). A partir daí torna-se possível a avaliação do impacto causado pela intensa retirada de frutos. Esta técnica é denominada Avaliação Periódica da Regeneração (Figura 4.2) (Peters, 1996).

Considerando-se que o fenômeno El Nino provoca secas acentuadas na Amazônia em períodos de tempo de 2 a 5 anos (INPE, 2001), o prazo de cinco anos para realizar as avaliações periódicas da regeneração proposto por Peters (1996) foi aqui escolhido porque neste prazo é possível avaliar anos de alta e baixa pressão de colheita, visto que se estará avaliando anos com maior e menor quantidade de chuvas.

Tabela 4.1 Nível de extração recomendada em termos de parâmetros demográficos; precaução (reserva para a fauna) e proposta por hectare de floresta de Baixio e Terra Firme da Colocação São Pedro, Seringal Caquetá, AC. Julho de 2000.

\begin{tabular}{|c|c|c|c|c|c|}
\hline \multirow{2}{*}{$\begin{array}{l}\text { Floresta de Baixio } \\
\text { Colocação São Pedro } \\
\text { Seringal Caquetá }\end{array}$} & \multicolumn{3}{|c|}{ Parâmetros Demográficos } & \multirow{2}{*}{$\begin{array}{l}\text { Precaução } \\
\text { Permanece } \\
(5 \%)\end{array}$} & \multirow{2}{*}{$\begin{array}{l}\text { Proposta } \\
\text { Coletado } \\
(50 \%)\end{array}$} \\
\hline & $\begin{array}{l}\text { Total } \\
(100 \%)\end{array}$ & $\begin{array}{l}\text { Coletado } \\
(55 \%)\end{array}$ & $\begin{array}{l}\text { Permanece } \\
(45 \%)\end{array}$ & & \\
\hline aa & 60 & 33 & 27 & 3 & 30 \\
\hline & 6.581 & 3.619 & 2.961 & 3.290 & 3.290 \\
\hline STe & 394.842 & & 77.679 & 19.742 & 197.421 \\
\hline 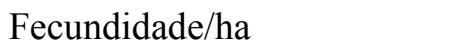 & 9,3 & & 4,2 & 0,5 & 4,7 \\
\hline & 450 & & 2,5 & 22,5 & 225 \\
\hline & 30 & & & 1,5 & 15 \\
\hline & 135 & & 0,75 & 6,75 & 67,5 \\
\hline & & $\operatorname{tros~d}$ & cáficos & Iução & \\
\hline & Total & & Permanece & Permanece & Coletado \\
\hline & & & & & $(75 \%)$ \\
\hline & & 0 & 3 & 7 & 21 \\
\hline & & & 7 & .369 & .108 \\
\hline & 153.3 & & .356 & 9.583 & 86.268 \\
\hline & & & 2 , & 0,7 & \\
\hline & & & 173 & 43,4 & 130,2 \\
\hline & & & & 2,8 & 8,6 \\
\hline Reais (\$)/ha & 51,75 & 51,75 & 51,75 & 12,6 & 38,7 \\
\hline
\end{tabular}


Para testar o rendimento sustentável no Baixio da Colocação São Pedro foi utilizado a informação da Figura 2.16 que mostra que pelo menos 55\% do recrutamento inicial é necessário para manter a estabilidade da população $(\lambda=1)$ de Açaí.

A Tabela 4.1 mostra a produtividade total de frutos e indivíduos na floresta de Baixio e a produtividade que pode ser coletada e também a que permanece na floresta sem modificar a taxa de crescimento da população de Euterpe precatoria estudada. Somada a 5\% deixados como precaução (para a fauna e/ou possíveis variações demográficas devido às variações de condições climáticas) entre o período das avaliações periódicas da regeneração (5 anos) recomenda-se a colheita de frutos de modo a reduzir no máximo $50 \%$ do recrutamento inicial. Isto significa reduzir a fecundidade de 9,3 (60 indivíduos adultos/ha) para 4,7 (30 indivíduos adultos/ha). Desta forma a cada 60 indivíduos por hectare que produzem em média $450 \mathrm{~kg}$ de frutos/hectare deve ser coletado frutos de 30 indivíduos que produzem aproximadamente $225 \mathrm{~kg}$ de frutos/hectare, o que corresponde a 15 latas (Tabela 4.1).

Em termos práticos isto significa que deve-se coletar frutos em metade dos indivíduos existentes, isto é, a cada 2 indivíduos coleta-se frutos em apenas 1. Segundo depoimentos dos seringueiros do Seringal Caquetá, aproximadamente 25\% das suas áreas são cobertas por florestas chamadas de Baixio e $75 \%$ são cobertas por Terra Firme. Considerando-se que cada família interessada na extração de Açaí tenha 25 hectares de floresta de Baixio, (já que cada família possui 100 hectares), a cada 1500 palmeiras neste tipo florestal recomenda-se que se extraia de 750 .

Para testar o rendimento sustentável na floresta de Terra Firme recomenda-se a colheita de frutos de modo a reduzir em no máximo $75 \%$ do recrutamento inicial, deixando portanto, $25 \%$ dos indivíduos sem coletar na floresta de Terra Firme. Isto significa reduzir a fecundidade de 2,7 (28 indivíduos adultos/ha) para 2 (21 indivíduos adultos/ha). Desta forma a cada 28 indivíduos por hectare que produzem em média $173 \mathrm{~kg}$ de frutos/hectare deve ser coletado frutos de 21 indivíduos que produzem aproximadamente 130,2 $\mathrm{kg}$ de frutos/hectare, o que corresponde a 8,6 latas (Tabela 4.1). 
Em termos práticos isto significa que a cada 4 indivíduos coleta-se frutos em apenas 3. Considerando-se que cada família utilize 70 hectares de floresta de Terra Firme para a produção de frutos, neste espaço podemos encontrar aproximadamente 1960 indivíduos, nos quais, devemos coletar frutos em aproximadamente 1470.

A variabilidade genética da população manejada talvez possa ser mantida porque raramente o Açaí está com todos os cachos maduros ao mesmo tempo, e assim o coletor sempre deixa cachos (sementes) de diferentes indivíduos para regenerar a população. Porém para confirmar esta afirmação há a necessidade de estudos genéticos das populações de E. precatoria.

Os ajustes de aproveitamento devem ser realizados após as avaliações periódicas da regeneração. Eles regulam o número de plantas a serem extraídas ou as áreas totais de onde se extraem os recursos. Caso na avaliação periódica da regeneração seja detectada uma redução da densidade de plântulas em relação às contagens iniciais (Figura 4.2A), é alta a probabilidade que os níveis de extração estejam acima do limite suportado pelas populações. Como a variância do número de plântulas é maior que a variância do número de jovens1 (Tabela 2.3) de ano para ano, os ajustes periódicos de aproveitamento devem ser feitos apenas no caso de se detectar a redução do número de jovens 1 . Isto minimizaria dúvidas se a alteração do histograma é devido ao impacto provocado pela extração, ou se é devido à variação anual, naturalmente muito grande, do número de plântulas.

Assim como ocorre com Euterpe edulis uma possível causa da variação no número de indivíduos que entram na classe 1 (plântulas) se deve a variação do volume de produção de frutos pelas plantas matrizes a cada ano (Reis,1995). A variação no número de plântulas e jovens 1 pode acontecer então devido às variações climáticas (pluviosidade, temperatura) e variações bióticas como a predação, dispersão, produção de frutos que podem ocorrer de ano para ano (Viana, comunicação pessoal).

Os ajustes de aproveitamento têm o objetivo de alcançar um nível de colheita que seja sustentável ao longo do tempo. Desta forma, caso na avaliação periódica da regeneração seja detectada uma diminuição do número de plântulas e jovens, este é um sinal que os níveis de aproveitamento devem ser ajustados de forma a reduzir o 
número de palmeiras coletadas por hectare, ou ainda reduzindo a área de colheita de frutos.

A avaliação da estrutura da população ao longo de vários ciclos de extração (de 5 em 5 anos) e a sua manutenção (Figura 4.2C) podem ser indicadores de que o rendimento da extração de frutos (Peters, 1996) da população local de Açaí está sendo sustentável. Também pode servir como indicador indireto que os níveis de interação (dispersão, polinização) estão sendo mantidos, já que a estrutura populacional é altamente dependente das interações com outras espécies. 

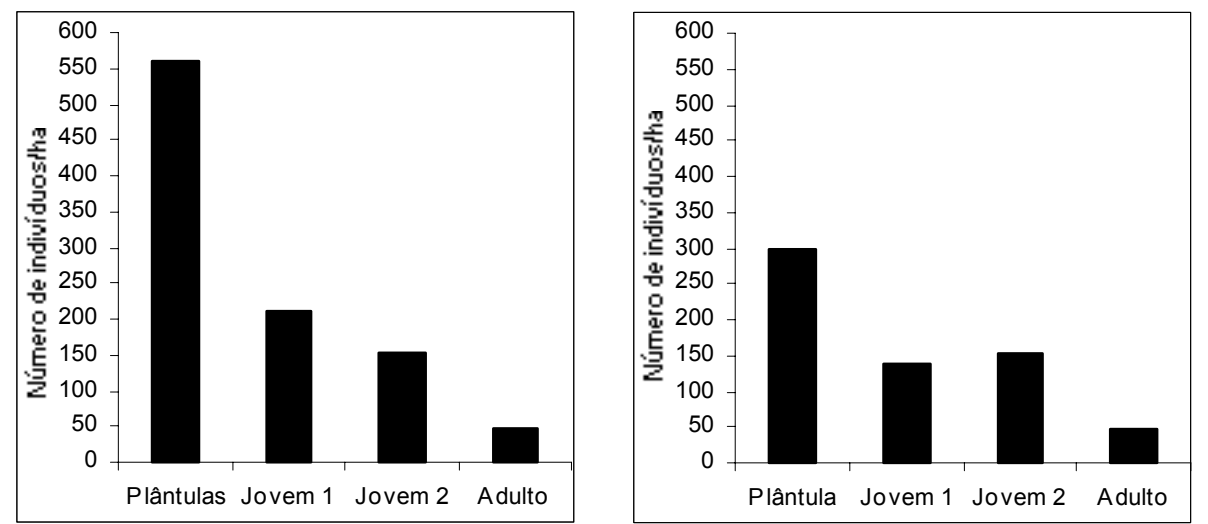

A
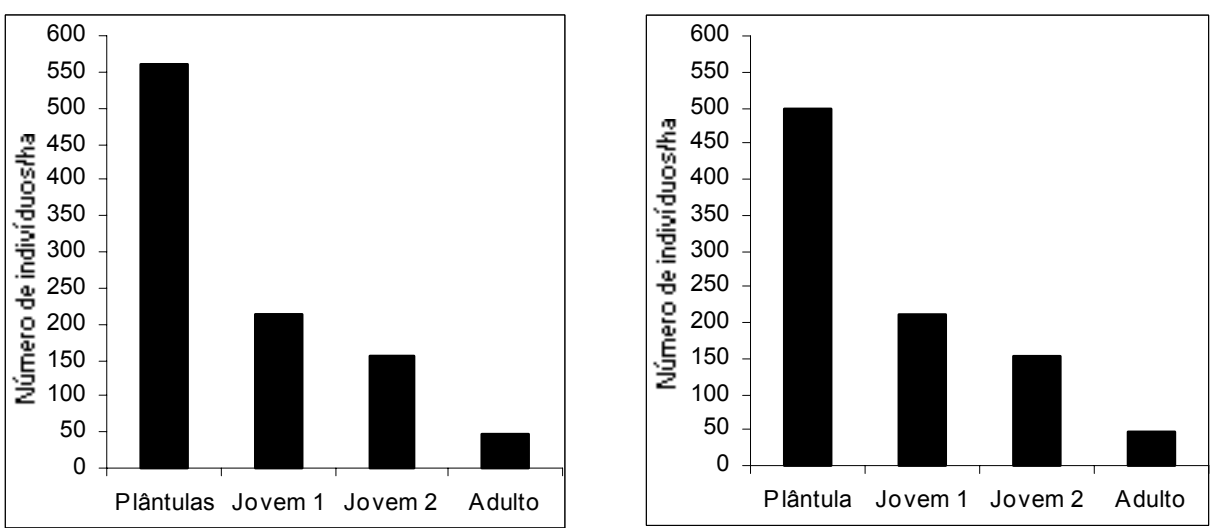

B
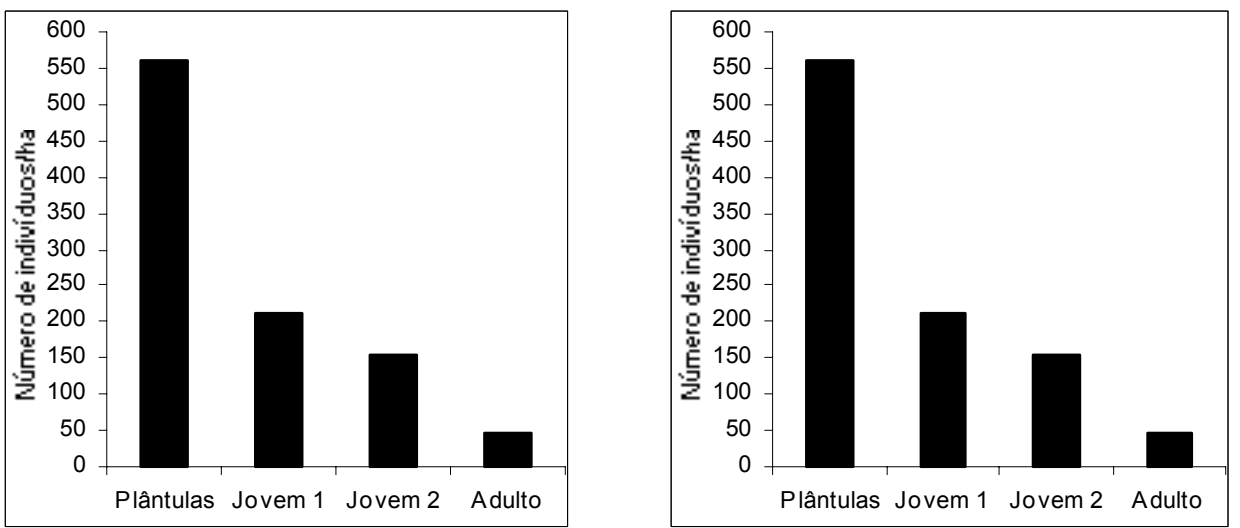

$\mathrm{C}$

TEMPO 0 (tempo inicial)

TEM PO 1 (5 anos depois)

Figura 4.2 Diagrama do efeito da intensidade de colheita sobre a distribuição de classes de tamanho para ilustrar o processo de avaliações periódicas da regeneração.O tempo 0 representa o histograma da distribuição de classes de tamanho de uma população de Euterpe precatoria, feito com o inventário inicial das parcelas de regeneração. O tempo 1 mostra a estrutura da população depois de cinco anos de extração anual. (A) Representa a exploração excessiva do recurso com efeito na diminuição de plântulas e jovens abaixo do valor quantificado no inventário inicial. (B) Representa baixa exploração de recursos com efeito na pouca mudança do número de plântulas e nenhuma mudança no número de jovens. (C) Representa a extração com rendimento sustentável. 
A mão de obra para implementar o monitoramento da extração representa um alto custo. A mão de obra necessária para fazer os inventários florestais são de quatro paraflorestais $^{13}$ que deverão trabalhar aproximadamente 3 dias por Colocação nas florestas de Baixio e nas de Terra Firme. Para tanto, considerando a diária de $\mathrm{R} \$ 10,00$ (US\$ 4,00) seriam gastos aproximadamente $\mathrm{R} \$ 120,00 /$ ano nas avaliações periódicas da regeneração (Tabela 4.2).

Tabela 4.2. Custo (R\$) de mão de obra e materiais por área de manejo por ano e durante o período de cinco anos para fazer o inventário e realizar o manejo de Açaí.

\begin{tabular}{|c|c|c|c|c|c|c|}
\hline Custo de manejo & $1^{0}$ ano & $2^{0}$ ano & $3^{0}$ ano & $4^{0}$ ano & $5^{0}$ ano & $\begin{array}{l}\text { Total }(\mathrm{R} \$) / 5 \\
\text { anos }\end{array}$ \\
\hline \multicolumn{7}{|l|}{$\begin{array}{l}\text { 1. Inventário e } \\
\text { monitoramento }\end{array}$} \\
\hline Plaquetas & 100,00 & 60,00 & 60,00 & 60,00 & 60,00 & 340,00 \\
\hline Arame & 10,00 & 0 & 0 & 10,00 & 0 & 20,00 \\
\hline Prego & 24,00 & 0 & 0 & 0 & 24,00 & 48,00 \\
\hline Balança & 6,00 & 0 & 6,00 & 0 & 6,00 & 18,00 \\
\hline Martelo & 15,00 & 0 & 0 & 0 & 0 & 15,00 \\
\hline Mão de obra & 120,00 & 120,00 & 120,00 & 120,00 & 120,00 & 600,00 \\
\hline \multicolumn{7}{|l|}{ 2. jardinagem } \\
\hline Mão de obra - desbaste & 4,00 & 4,00 & 4,00 & 4,00 & 4,00 & 20,00 \\
\hline Mão de obra - produção frutos & 40,00 & 0 & 40,00 & 0 & 40,00 & 120,00 \\
\hline Total (R\$)/ano & 319,00 & 184,00 & 230,00 & 194,00 & 254,00 & 1181,00 \\
\hline
\end{tabular}

Cada plaqueta vale R\$ 0.10 centavos. Considerando-se que seja utilizado 1000 plaquetas por área de manejo;

Rolo de arame;

Pregos de alumínio;

Balança com capacidade de $20 \mathrm{~kg}$ e graduação $0.5 \mathrm{~kg}$;

$\mathrm{R} \$ 2,50=1 \mathrm{U} \$$

Diária local $=\mathrm{R} \$ 10,00(\mathrm{US} \$ 4,00)$

Mão de obra para inventário e monitoramento : Considerando uma diária de $\mathrm{R} \$ 10,004$ pessoas trabalhando durante 3 dias por área de manejo por ano $(40 \times 3=120)$;

Mão de obra para desbaste: cada palmeira custa R\$ 0,20, para desbastar ao redor de 20 palmeiras por hectare custa $\mathrm{R} \$ 4,00$. Feito por 1 pessoa por área de manejo em 1 dia de trabalho/ano.

Mão de obra para a pesagem dos frutos: avaliação de 30 indivíduos 15 no Baixio e 15 na Terra Firme considerando uma diária de $\mathrm{R} \$ 10,00$ e 2 pessoas trabalhando durante 2 dias por ano $(20 \times 2=40)$.

Vamos considerar que para cada 100 hectares de floresta houvesse o manejo no Baixio e Terra Firme em áreas do tamanho aqui proposto (1 hectare por tipo florestal). Neste caso o manejo de frutos de Euterpe precatoria na Colocação São

\footnotetext{
${ }^{13}$ pessoas da comunidade extrativista responsáveis pelas ações de manejo
} 
Pedro do Seringal Caquetá custaria anualmente, em média, $\mathrm{R} \$ 236,20 \pm \mathrm{R} \$ 40,20$ (US\$94,80) e durante cinco anos R $\$ 1181,00$ (US\$472,40).

Duas mil duzentos e vinte palmeiras (1470 na Terra Firme +750 no Baixio) podem produzir aproximadamente $14739 \mathrm{~kg}$ de frutos que correspondem a aproximadamente 982,6 latas de frutos (1 lata $=15 \mathrm{~kg}$ ). Considerando-se que o seringueiro transporte 7 latas de frutos por dia (um boi de carga), para coletar e transportar 982,6 latas de frutos de Açaí levaria 280,6 dias por ano [Baixio $\rightarrow 750$ palmeiras $\times 7,5 \mathrm{~kg}$ de frutos por palmeira $=5625 \mathrm{~kg}$ de frutos $=375$ latas. 375 latas $/ 7$ latas $=53,5$ dias $($ coleta $)+375$ latas $/ 7$ latas $=53,5$ dias $($ transporte $)=107$ dias no Baixio. Terra Firme $\rightarrow 1470$ palmeiras x $6.2 \mathrm{~kg}$ de frutos por palmeira $=9114 \mathrm{~kg}$ de frutos $=607,6$ latas. 607,6 latas $/ 7$ latas $=86,8$ dias $($ coleta $)+607,6$ latas $/ 7$ latas $=86,8$ dias $($ transporte $)=173,6$ dias na Terra Firme. Total Baixio + Terra Firme $\rightarrow 107$ dias $+173,6$ dias $=280,6$ dias/ano]. Cada lata vendida a R 4,50 forneceria ao seringueiro uma renda líquida aproximada de $\mathrm{R} \$ 2263,50 /$ ano considerando o cálculo abaixo:

$=\mathrm{R} \$ 4421,70-\mathrm{R} \$ 491,30-\mathrm{R} \$ 1403,00-\mathrm{R} \$ 236,20-\mathrm{R} \$ 23,40-\mathrm{R} \$ 4,35=\mathrm{R} \$$ 2263,50

Onde: Renda total $=\mathrm{R} \$ 4421,70(\mathrm{R} \$ 4,50 \times 982,6$ latas $)$

Transporte do Açaí $=\mathrm{R} \$ 491,30(982,6$ latas $\times \mathrm{R} \$ 0,50)$

Transporte do seringueiro $=\mathrm{R} \$ 1403,00(140,3$ dias $\mathrm{x} \mathrm{R} \$ 10,00)$

Custo médio anual do manejo $=\mathrm{R} \$ 236,20$ (tabela 4.2)

Embalagem $=\mathrm{R} \$ 23,40$ (1 saco de estopa é utilizado 3 dias, carrega 21 latas e custa $\mathrm{R} \$ 0,50$, então 982,6 latas x R \$ 0,50/21 latas)

Custo Boi/ano ${ }^{14}=\mathrm{R} \$ 4,35$

Este cálculo sugere que a produção de Açaí no Seringal Caquetá pode ser auto-suficiente, considerando que gera lucros ao produtor e paga todos os custos de transporte da produção. Por outro lado, caso o transporte do Açaí fosse subsidiado, o seringueiro poderia ganhar, em média, uma renda líquida de R\$ 4157,75 considerando o cálculo:

$\mathrm{R} \$ 4421,70-\mathrm{R} \$ 236,20-\mathrm{R} \$ 23,40-\mathrm{R} \$ 4,35=\mathrm{R} \$ 4157,75$.

Onde: Renda total $=\mathrm{R} \$ 4421,70$

Custo médio anual do manejo $=\mathrm{R} \$ 236,20$

Embalagem $=\mathrm{R} \$ 23,40$ 
Custo Boi/ano $=\mathrm{R} \$ 4,35$

Como demonstrado o custo de transporte corresponde a $42,8 \%$ da renda total enquanto o manejo perfaz aproximadamente 5,3\%. Este dado sugere que o custo de manejo é relativamente baixo em relação ao ganho total e que caso fosse subsidiado o transporte do Açaí a atividade produtiva seria muito mais rentável.

\subsection{RECOMENDAÇÕES SÓCIO-ECONÔMICAS}

A organização para o trabalho da coleta de Açaí na forma de mutirões feita pelos sócios da ASPAC não é comum para outras atividades tais como a extração da borracha, castanha e plantios de subsistência. Mas se o objetivo é incluir famílias interessadas na atividade, outros tipos de organização devem ser testadas e estar em constante processo de ajuste com o objetivo de minimizar o custo da extração.

O método de mutirão para a produção de frutos de Euterpe precatoria pode não dar certo, pois não é a maneira tradicional de produzir do Seringal, onde como já dito, a organização para o trabalho é familiar. No entanto a forma de organização familiar pode excluir muitas famílias jovens e de poucos recursos interessadas na comercialização do produto, mas impedidas por limitações individuais de recursos como mão de obra especializada, ausência de animal de carga para o transporte da produção e falta de contatos de comercialização de frutos em Rio Branco. Desta forma, acredita-se que a organização para o trabalho deva se adequar à situação de cada família, o que só pode ser possível através de formas alternativas de organização. No Seringal Caquetá, das 11 famílias que adotaram o sistema de mutirão apenas uma alegou que não compensava o trabalho com o Açaí a partir do segundo ano, e outras 3 famílias alegaram que a organização familiar era a mais adequada.

Estas 3 famílias interessadas em fazer uma organização familiar na atividade produtiva possuem pai e/ou filho que sobem no estipe da palmeira e animais de carga, isto é, disponibilidade de mão de obra, e meio para transportar a produção.

As famílias que permaneceram se organizando em mutirão a partir do segundo ano talvez optaram por este tipo de organização devido à limitação de

\footnotetext{
${ }^{14}$ Sal mineralizado + Vacina
} 
recursos, a laços familiares, visto que os membros destas famílias tem um alto grau de parentesco, e sobretudo, porque desta forma seria possível realizar a extração orientada para o mercado em Rio Branco. Este tipo de organização facilita a participação de mais famílias quando as limitações individuais de recursos inibirem a extração orientada para o mercado. Este foi o caso por exemplo das duas famílias que iniciaram a produção em mutirão a partir do segundo ano de extração.

A divisão de recursos para iniciar a atividade produtiva com o Açaí no Seringal Caquetá foi fundamental para a realização da atividade produtiva, visto que o manejo de frutos de Açaí neste local surgiu não apenas para complementar a renda das famílias mas sobretudo para tornar as florestas produtivas e assim fundamentar a transformação de parte do Seringal Caquetá em área de Assentamento Agroextrativista.

O Conselho Nacional dos Seringueiros (CNS) no Acre, o Parque Zoobotânico (Universidade Federal do Acre) que auxiliaram as famílias no Seringal Caquetá com pesquisas e atividades de extensão foram de fundamental importância na ajuda de alguns desencadeamentos, como por exemplo, servir de interlocutor entre os grupos de seringueiros ou cooperativas e processadores locais e regionais de frutos. Estas ações auxiliam os seringueiros a entender e se adequar as necessidades dos compradores com as suas necessidades e de sua comunidade (Wallace, 1999).

Considerando-se que os preços de venda de frutos do maior processador no mercado municipal central de Rio Branco variaram de $\mathrm{R} \$ 4,00$ durante a alta estação a $\mathrm{R} \$ 7,00$ fora da estação, e que o preço da lata de Açaí pode chegar até $\mathrm{R} \$ 10,00$ fora da estação (Wallace, 1999), a extração nestes períodos de baixa produção pode facilitar a comercialização do produto e gerar maiores rendas diárias.

Algumas políticas públicas que tratem do subsídio para a inserção do Açaí na economia extrativista devem considerar o custo do manejo. Este subsídio é essencial para a manutenção do mercado entre extrativistas e beneficiadores de Açaí, da mesma forma como é feito com as atividades da agricultura e pecuária, e também para o extrativismo de outros produtos, como a borracha. O subsídio para a produção do Açaí no Seringal Caquetá deve ser para o transporte da produção dos pontos coletores aos ponto compradores, visto que este é o item mais caro da cadeia produtiva. 
Se para as comunidades locais deve ser dada a responsabilidade de monitorar as suas próprias florestas, projetos desenvolvidos que visem auxiliar comunidades extrativistas devem desenvolver métodos com elas e incluir treinamentos para inventariar, monitorar e manejar os seus recursos. Esta é uma forma de possibilitar a participação efetiva de grupos comunitários locais como os principais agentes do manejo.

Considerando que a jardinagem e o monitoramento são atividades que requerem dinheiro, se a intenção é realmente manter a sustentabilidade do manejo do Açaí a longo prazo, estas atividades devem ser vistas como um custo fixo que deve ser retirado dos lucros advindos da comercialização do produto. Porém, inicialmente algumas provisões devem ser feitas para assegurar que estes custos sejam cobertos continuamente dos lucros gerados pela venda do produto. Tais provisões significam maiores incentivos (financeiros e políticos) dados para a produção com bom manejo dos frutos de Açaí e de outros produtos florestais não madeireiros. Isto seria uma forma de garantir que o monitoramento e as atividades de manejo continuassem.

Vamos considerar a seguinte situação hipotética : (1) foram criados mercados para a comercialização dos frutos de Açaí no Seringal Caquetá; (2) todos os dados básicos de inventário e produção foram coletados e os sistemas de monitoramento estão funcionando; (3) a produção de Açaí foi incentivada e as vendas de frutos estão aumentando todos os anos e tendo uma contribuição significativa para o bem estar da comunidade. Considerando-se ainda que durante a pesquisa da regeneração as taxas de colheita não estejam sendo sustentáveis, e que, o recurso esteja sendo extraído em quantidades muito grandes. Neste caso a prescrição apropriada do manejo é que os níveis de colheita deverão ser reduzidos, o que causaria uma redução imediata nos lucros do empreendimento. A pergunta que se faz é: De onde virá o incentivo para seguir o caminho da sustentabilidade? (Peters, 1995)

Além da fiscalização da atividade que deve ser feita pelos próprios moradores, o incentivo virá mediante os benefícios gerados na comunidade através da comercialização do Açaí, pela prática de manejo e organização comunitária, assim como, pela manutenção apenas dos subsídios dados a produção que vise a alcançar a sustentabilidade, ou seja, a produção que seja feita mediante o bom manejo. 
Euterpe precatoria deve ser considerada em estratégias de desenvolvimento sustentável para as comunidades extrativistas, levando em conta os meios de avaliar e ajustar sistematicamente o manejo das populações, visto que todas as formas de produção desenvolvidas em grande escala na Amazônia envolvem a sub-utilização dos recursos, a má distribuição de renda, o empobrecimento do solo, a perda da biodiversidade e alterações dos ecossistemas (Barro \& Clement, 1993).

Considerando-se a história de lutas do seringueiro para manter a floresta, a experiência que ele tem culturalmente com o extrativismo, o recente interesse na conservação e os benefícios sociais e financeiros dos produtos florestais não madeireiros, espera-se uma maior atenção dada para monitorar a sustentabilidade do recurso do qual todos estes benefícios provêm (Peters, 1995).

Uma organização social da produção e comercialização adequada aos diferentes tipos de famílias que compõem a comunidade do Caquetá são fundamentais para que o sistema de manejo continue. Esta organização deve se adequar de modo a facilitar o fornecimento regular de frutos para os mercados em Rio Branco, mas ao mesmo tempo tentando manter a integridade sócio-cultural da comunidade. Desta forma, a organização comunitária aqui proposta é uma organização ora familiar, ora em mutirão dependendo do tipo de famílias e/ou grupos envolvidos.

Arranjos políticos, sócio-econômicos e ecológicos devem ser propostos, testados e ajustados pelas comunidades extrativistas, Universidades, ONGS, Governos se a idéia é de utilizar a floresta para gerar renda de forma a mantê-la. Exemplos de arranjos são (1) fornecer fomentos à cooperativas de produtores para assegurar que os lucros revertam para os próprios cooperados (2) fornecer eventuais créditos e estímulos fiscais direcionados apenas para o extrativismo visando o bom manejo; (3) estabelecer áreas experimentais em diversos locais da região para testar sistemas de manejo e para coletar informações básicas necessárias ao desenvolvimento destes sistemas; (4) estabelecer ensaios junto a algumas comunidades extrativistas para o levantamento da viabilidade do manejo; (5) estabelecer critérios para regularizar o manejo de Euterpe precatoria; (6) adotar técnicas de manejo como uma alternativa de produção sustentável da floresta, com intervenções baseadas em sistemas tradicionais já existentes e outros desenvolvidos 
por pesquisas; (7) fortalecer os órgãos responsáveis pela fiscalização e manejo dos recursos naturais e de controle ambiental buscando sempre a capacitação e treinamento de pessoal local para se exigir o cumprimento efetivo da legislação; (8) Desevolver e aplicar um programa de educação nas escolas que vise a extensão florestal (Pesacre, 1990).

Para a comunidade do Seringal Caquetá a comercialização do Açaí foge do sistema tradicional de aviamento, que caracteriza a comercialização da borracha e castanha quando há a ausência de subsídios. Desta forma o Açaí pode tornar-se uma fonte de rendimento sem endividamento do coletor, considerando que seu mercado consumidor está em plena expansão.

A introdução dos frutos de Açaí na economia de comunidades extrativistas para complementar a renda obtida através da castanha e borracha dependerá diretamente das políticas de incentivo prestadas para este tipo de produção. $O$ fornecimento de subsídios para os seringueiros através das associações, cooperativas e centrais de produtores para que produzam o Açaí, e ainda, a comercialização para as mesmas cooperativas e Associações pode gerar uma política importante para assegurar que os lucros revertam para os próprios cooperados das comunidades envolvidas. Desta forma a atividade produtiva representa uma melhora em relação a qualidade de vida, autonomia e manutenção da cultura das populações extrativistas.

Uma outra estratégia é a venda destes produtos apenas em mercados pequenos onde os lucros grandes e líquidos são devolvidos aos produtores. Mesmo porque os custos por unidade de venda de quantidades menores são maiores que aqueles para quantidades maiores o que resulta em preço final é mais alto para o consumidor. Isto significa que os produtos serão usados apenas por pessoas de poder aquisitivo mais alto (Clay, 1992). A comercialização de recursos florestais deve ser aliada a sistemas para assegurar que a quantidade de produtos retirados da floresta não destrua o produto que os consumidores estão pagando para ajudar a proteger, o que só pode ser garantido se a colheita for feita considerando as taxas de impacto ambiental e os sistemas de monitoramento. Tais sistemas devem examinar desde o princípio da colheita para o comércio o impacto da colheita nas taxas demográficas das espécies (Peters, 1995). Além disso, precisam ser desenvolvidos com o envolvimento das comunidades locais, universidades e governos, se a intenção é a 
utilização dos recursos florestais como alternativa para a manutenção das florestas tropicais.

"Um dos deveres da Universidade é implantar suas práticas profissionais no seio do povo" 


\section{REFERÊNCIAS BIBLIOGRÁFICAS}

Alho, C. J. R. 1999. Extrativismo na Amazônia - Proteção da Floresta mais Benefícios Sociais. Ciência Hoje n 33.

Amo, R. S. \& Nieto De Pascual, J. 1985. Crescimiento y edad en árboles tropicales. In: Investigaciones sobre la regeneracion de selvas altas en Veracruz, México, II. (Gomez-Pompa, A. \& Del Amo, R. S. R. eds.) Editorial Alhambra Mexicana, Xalapa, pp.129-145.

Allegretti, M. H. 1990. Extractive Reserves: An alternative for reconciling development and environmental conservation in Amazonia. In: Alternatives to deforestation: Step toward sustainable use of the Amazon rain forest (Anderson, A. B. ed.) Columbia University press, New York, pp.252-264.

Amaral, P. H. C. ; Veríssimo, J. A. O. ; Barreto, P. G. V.; Vidal, E. J. S. 1998. Floresta para sempre: um manual para a produção de madeira na Amazônia. Belém, IMAZON.

Anderson, A.B. \& Jardim, M. A. G. 1989. Cost and benefits of floodplain forest management by rural inhabitants in the Amazon Estuary: A case study of Açaí palm production. In: Fragile lands of Latin America, strategies for sustainable development (Browder, J. O. ed.) University of Tulane, pp. 114-129.

Anderson, A. B. A.; Gely, J. ; Strudwick, G. L.; Sobel \& Pinto M.G.C. 1985. Um sistema agroflorestal na várzea do estuário Amazônico (Ilha da Onças, Município de Barbecena, Estado do Pará). Acta Amazonica supplement 15 pp.195- 224.

Augspurger, C.K. 1983. Offspring recruitment around tropical trees: changes in cohort distanyce with time. Oikos 40 pp.189-196.

Barro, J. W. \& Clement, C. R. 1993. Development and conservation. In: Selected species and strategies to enhance income generation from amazonian forests, FAO Forestry Paper. 
Bernal, R. 1998. Demography of vegetable ivory palm Phytelephas seemannii in Colombia, and the impact of seed harvesting. Journal of Applied Ecology 35 pp.64-74.

Bodmer, R. E.; Puertas, P. E.; Garcia, J. E.; Dias, D. R.; Reyes, C. 1999. Game animals, palms, and people of the flooded forests: Management considerations for the Pacaya Samiria National Reserve, Peru. In: Várzea diversity, development, and conservation of Amazonia's whitewater floodplains (Padoch , C.; Ayres, J. M.; Pinedo-Vasquez, M \& Henderson, H. eds.). The New York Botanical Garden Press.

Boom, B. M 1986. A forest inventory in Amazonian Bolivia. Biotropica 18:4 pp.287-294.

Bullock, S. H. 1980 Demography of and undergrow the palm in litoral Cameroon. Biotropica 12 pp.247-255.

Campbell, L.; Daly, D. ; Prance, G.; Maciel, U. 1986. Quantitative ecological inventory of Terra Firme and varzea tropcal forest on the Rio Xingú, Brazilian Amazon. Brittonia 38 pp.369-393.

Castro, A. \& Bovi, M. L. A. 1993. Assaí. In: Selected species and strategies to enhance income generation from amazonian forests, FAO Forestry Paper.

Castro, A. 2000. O extrativismo do Açaí na amazônia central. Em: A floresta em jogo - o extrativismo na Amazônia Central (Emperaire L ed.) Editora UNESP pp.129-138.

Cassilas, C. B. 1985. Demografia de arboles tropicales. In: Investigaciones sobre la regeneracion de selvas altas en Veracruz, México. V.II (Gomez-Pompa, A. e Del Amo, R.S. R eds) Editorial Alhambra Mexicana Xalapa.

Caswell, H. 1989. Matrix populations models. Sinaver, Sunderland.

Chapman \& Hall 1992. Global Biodiversity - Status of the Earth's Living Resources. World Conservation Monitoring Centre.

Chazdon 1986 Light variation and carbon gain in rain forest understory palm. Journal Ecology 74 pp.995-1012. 
Clay, W. \& Clement, C. R. 1993. Selected species and strategies to enhance income generation from amazonian forests, FAO Forestry Paper.

Clark, D.A. \& Clark, D.B. 1984. Spacing dynamics of a tropical rain forest tree: evaluation of the Janzen-Connell model. The american naturalist 124: pp. 69-788.

Clay, J. 1992. Some general principles and strategies for developing markets in North America and Europe for nontimber forest products. In: Sustainable harvest and marketing of rain forest products. (Plotkin, M. \& Famolare L, eds.) Conservation international, Island press. Washington, D.C.

Conselho Nacional dos Seringueiros (CNS) 1993. Diretrizes para um programa de Reservas Extrativistas na Amazônia. Rio Branco- AC.

Conselho Nacional dos Seringueiros (CNS); Fundação de Tecnologia do Acre (FUNTAC); Agência Canadense para o Desenvolvimento (ACDI) 1992. Relátorio do Levantamento sócio-econômico da Reserva Extrativista Chico Medes e Projetos de Assentamentos extrativistas da região do Vale do Rio Purus. Rio Branco, Acre.

Crawley, M. J. 1986. Plant ecology. Blackwell, Melksham.

Centro de Trabalhadores da Amazônia (CTA). 1997. Reserva Extrativista de São Luís do Remanso: Plano de Manejo Florestal de Uso Múltiplo - Recursos não madeireiros.

Denslow, J. L. 1980. Gap partitioning among tropical rain-forest trees. Biotropica $12 \mathrm{pp}$. 47-55.

De Steven, D. 1994. Tropical tree seedling dynamics: recruitment patterns and population consequences for canopy species in Panamá. Journal of Tropical Ecology 10 pp.369383.

Diegues, A. C. 2000. Etnoconservação novos rumos para proteção da naturaza nostrópicos. Editora Hucitec. NUPAUB-USP 
Enright, N. J. 1992. Factors affecting reproductive behaviour in the New Zealand. Journal of botany, $30 \mathrm{pp} .69-80$

Feitosa, M. L. 1995. Chico Mendes Extractive Reserves. In: Extractive Reserves. (Murrieta Ruiz, J. \& Rueda Pinzón, M. eds.) IUCN, Gland, Switzerland e Cambridge, UK.

Fearnside, P. M. 1992. Reservas Extrativistas: uma estratégia de uso sustentável. Ciência Hoje, v14, n.81, pp.15-17.

Fearnside, P M. 1989. Extractive Reserves in Brasilian Amazonia. Bioscience 39 (6) pp.387-393.

Fearnside, P. M. 1992. Reservas Extrativistas: uma estratégia de uso sustentável. Ciência Hoje, v14, n.81, pp.15-17.

Fisch, S. T. V. 1998. Dinâmica de Euterpe edulis Mart. na floresta Ombrófila Densa Atlântica em Pindamonhangaba - SP. Tese de doutorado. USP, São Paulo.

Fisch, S. T. V.; Noqueira, Jr. L. R. ; Mantovani, W. 2000. Fenologia reprodutiva de Euterpe edulis Mart. na Mata Atlântica (Reserva Ecológica do Trabiju, Pindamonhangaba - SP). Rev. Biociênc.,Taubaté, v.6,n1, pp.11-14.

Galetti, M. ; Aleixo, A. 1998. Effects of palm heart harvesting on avian frugivores in atlantic rain forest of Brazil. Journal of Applied Ecology 35: pp.286-293.

Gentry, A.H. 1982. Patterns of neotropical plant species diversity. Evolutionary Biology 15 pp. $1-84$

Gomes-Pompa, A . E \& Vazquez-Yanes, C. 1985. Estudios sobre la regeneracion de selvas em regiones cálido-húmedos do México. In: Investigaciones sobre la regeneracion de selvas altas en Veracruz, México, II. (Gomez-Pompa, A. \& del Amo R. S. R. eds.) Editorial Alhambra Mexicana, Xalapa, México pp.1-25.

Goulding, M. 1985. Forest Fishes of the Amazonia. In: Key Environments Amazonia. Editora Pergamon Press. (Prance, G. T. \& Lovejoy, T. E. eds.). 
Governo do Acre 2000 Zoneamento ecológico-econômico do Acre (Zee). Ministério do Meio Ambiente \& PPG-7.

Governo do Brasil 1994 Programa piloto para proteção das florestas tropicais do Brasil. Projeto unidades de conservação de uso direto Subprojeto reservas extrativistas.

Hall, P. \& Bawa, K. 1993. Methods to assess the impact of extraction of non-timber tropical forest products on plant populations. Economic botany 47 (3) pp.234-247.

Harper, J. L. 1977. Population biology of plants. Academic Press, London.

Henderson, A. 1995. The palms of the Amazon. New York, Oxford. University Press. 362p.

Homma, A. K. O. 2000. Amazônia: os limites da opção extrativa. Ciência Hoje, Vol. 27 n159 pp. $70-73$.

Hubbel, S. H. 1984. Pseudoreplication and the design of ecological fields experiments Ecological Monographs 54(2), pp.187- 211

Instituto Nacional de Colonização e Reforma Agrária (INCRA) 1997. Plano de utilização do Projeto de Assentamento Caquetá Rio Branco -AC. Processo número 54260000183/97-82. Divisão de Assentamento SR. 14/Z. Junho.

Instituto Nacional de Colonização e Reforma Agrária (INCRA). 1997. Ante- projeto de viabilidade técnica do projeto de Assentamento Caquetá. Rio Branco - AC. Processo número 54260000183/97-82. Divisão de Assentamento. SR 14/Z. Agosto.

Instituto Brasileiro de Geografia e Estatística (IBGE). 1993. Mapa da vegetação do Brasil. Secretaria de Planejamento, Orçamento e Coordenação da presidência da República.

Instituto Nacional de Colonização e Reforma Agrária (INCRA). 1996. Laudo de vistoria e avaliação. Rio Branco -AC. Processo número 21560000584/94. Divisão de Assentamento. Julho. 
Instituto Nacional de Colonização e Reforma Agrária (INCRA). 1997. Plano de utilização do Projeto de Assentamento Caquetá. Rio Branco -AC. Processo número 54260000183/97-82. Divisão de Assentamento SR. 14/Z. Junho.

Instituto Nacional de Pesquisas Espaciais (INPE). 2001. www.inpe.br

Janzen, D. H. 1970. Herbivores and the number of tree species in tropical forests. The American Naturalist 104 (904): pp.501 - 528.

Jardim, M. A. \& Anderson, A. B. 1987. Manejo de populações nativas de Açaízeiro no estuário amazônico resultados preliminares. Bol. Pes. Flor, Curitiba 15 pp.1- 18.

Kageyama, P. Y \& Lepsch-Cunha, N. M. 1996. Singularidade da biodiversidade nos trópicos. Trabalho apresentado no Simpósio de Biodiversidade. Rio de Janeiro.

Kahn, F. \& De Granville, J. J. 1992. Palms in forest ecossystems of Amazonia. Springer, Berlim.

Kahn, F. 1993. Amazonian palms: food resources for the management of forest ecosystems. In: Tropical forests, people And food: biocultural interactions and applications to development (Hladik, C. M; Hladik, A.; Linares, O.F; Pagezy, H; Semple, A; Hadley, M. eds.). Parthenon Publishing Group Carnforth UK. pp.153-162.

Kahn F.; Henderson A . 1999. An Overview of the Palm of the Várzea in the Amazon Region. In: Várzea diversity, development, and conservation of Amazonia's whitewater floodplains. (Padoch, C. ; Ayres, J. M.; Pinedo-Vasquez, M.; Henderson, H eds.) The New York Botanical Garden Press.

Krebs, C. J. 1989. Ecological Metodology. New York, Library of congress.

Kroon, H. ; Plaisier, A ; Groenendael, J. V. \& Caswell, H. 1986. Elasticity : The Relative Contribution of Demographic Parameters to Population Growth Rate. Ecology 67(5), pp. 1427-1431. 
Küchmeister, H. ; Gottsberger, I. S. ; Gottsberger, G. 1997. Flowering pollination, nectar standing crop, and nectaries of Euterpe precatoria (Arecaceae) an Amazonian rain forest palm, Pl. Syst. Evol. 206: pp.71-97

Lamotte, S. 1990. Fluvial dynamics and Sucession in the lower Ucayali basin, Peruvian Amazonia. For Ecol Manage 33/34 pp.141 - 156.

Lefkovitch, L. P. 1965 The study population growth in organisms grouped by stages. Biometrika 21 pp.1-18.

Leite, A. M. C; Rankin, J.M. E Lieras, E. 1982. Ecologia de plântulas de Pithecelobium rancemosum Ducke. O Comportamento populacional de plântulas. Acta. Amaz. 12(3) pp. 123

Lobo, P. C. 1993. Tolerância a inundação de plantas de Talauma ovata St. Hil. e aspecto do seu comportamento em uma mata ciliar da bacia do rio Jacaré-Pepira, Brotas, SP. Dissertação de mestrado - UNICAMP, SP.

Lescure, J. P. 2000. Algumas questões a respeito do extrativismo. Em: A floresta em jogo - O extrativismo na Amazônia Central (Emperaire L.ed.) Editora UNESP pp.191203.

Martinez- Ramos, M.; Alvarez-Buylla, E.; Sarukhán, J. ; Pinero, D. 1988. Treefall age determination and gap dynamics in a tropical forest. Journal of ecology $76 \mathrm{pp} .700-$ 716.

Martinez- Ramos, M. 1985. Claros, ciclos vitales de los arboles tropicales y regeneracion natural de las selvas altas perenifolias. In: Investigaciones sobre la regeneracion de selvas altas en Veracruz, México. (Gomez-Pompa, A. \& Del Amo, R. S. R. eds.) Editorial Alhambra Mexicana, Xalapa.

Matteucci, S. D. \& Colma, A. 1982 Metodologia para El Estudio de La Vegetacion. Secretaria General de la Organizacion de los Estados americanos; Programa Regional de Desarrollo Cientifico y Tecnológico, Washington, D. C. 
Moraes, M. 1996. Diversity and distribution of palms in Bolívia. Principes 40 pp.75-85.

Montenegro, C.; Lima, C.; Oliveira, J.; Lima, M.; Andrade, W; Amorim. 1999. Diagnóstico da realidade Projeto de Assentamento Caquetá. COOPEAGRO, Projeto Lumiar. Rio Branco.

Muñiz-Miret, N. ; Vamos, R.; Hiraoka, M. ; Florencia, M; Mendelsohn, R. O. 1996. The economic value of managing the Açaí palm (Euterpe oleracea Mart.) in the floodplains of the Amazon estuary, Pára, Brazil. Forest ecology and management 87 pp.163-173.

Peres, C. A . 1994 Composition, Density, and Fruiting Phenology of Arborescent Palms in an Amazonian Terra Eirmi Forest, Biotropica 26(3) pp. 285-294.

Pesacre 1990. Alternativas ao desmatamento na Amazônia: Conservação dos recursos naturais. Funatura - Fundação Pró natureza, Rio Branco, AC.

Peters, C.M 1990. Population Ecology and Management of forest fruit tree in Peruvian Amazonia. In: Alternatives to deforestation: Step toward sustainable use of the Amazon rain forest. (Anderson, A. B. ed.) Columbia University press, New York.

Peters, C.M. 1991 Plant demography and the management of tropical forest resources: a case study of Brosimum alicastrum in México. In: Rain forest and managment.

Peters, C. M. 1996 The Ecology e Management of Non-Timber Forest Resources. The World Bank Washington, D.C. Paper number 322.

Peters, C. M. 1995 Observations on the Sustainable Exploitation of Non-Timber Tropical Forest Products - An Ecologist's Perspective. In: Current Issues in Non-Timber Forest Products Research. (Ruiz Peres, M. \& Arnold, J. E. M. eds.) CIFOR.

Peters, C. M.; Gentry, A. H. ; Mendelsohn, R. O. 1989. Valuation of an Amazonian Rainforest. Nature 339, pp.655-656.

Pinard, M. A. \& F. E. Putz. 1992. Population matrix models and palm resource management . Bulletin de institut francais de etudes andines. 21 pp.637- 649 
Pinard, M. 1993 Impact of stem harvesting on populations of Iriartea deltoidea (Palmae) in an Extractive Reserve in Acre, Brazil. Biotrópica 25(1) pp.2-14.

Pinero, D. ; Martinez -Ramos, M. ; Sarukhán, J. 1984 A population model of Astrocaryum mexicanum and a sensivity analysis of its finite rate of increase. Journal od Ecology 72 pp.997-991.

Pinero, D. ; Martinez -Ramos, M. ; Mendonza, A. ; Sarukhán, J. 1986. Demographic studies in Astrocaryum mexicanum and their use in understanding community dinamics. Principes 30 pp.108-116.

Pinto, N. P. A. 1984. Política da borracha no Brasil: a falência da borracha vegetal. Editora Vozes, São Paulo.

Pinton, F. \& Emperaire, L. 2000. A farinha de Mandioca, um elo dos sistemas extrativistas. Em: A floresta em jogo - O extrativismo na Amazônia Central (Emperaire L. ed.) Editora UNESP .

Prance, G. T.; Rodrigues, W. A. ; Silva, M. F. 1976. Inventário florestal de 1 hectare de mata de Terra Firme, km 30 da estrada de Manaus-Itacoatiara. Acta Amazônica 6 pp.935.

Radam Brasil 1976 Folha SC.19 Rio Branco. Ministerio das Minas e Energia, Departamento Nacional da Produção Mineral, Projeto RADAM BRASIL, Rio de Janeiro.

Reis, A. 1995. Dispersão de sementes de Euterpe edulis Martius - (Palmae) em uma Floresta Ombrófila Densa Montana da encosta atlântica em Blumenau, SC. Tese de Doutorado. UNICAMP.

Reis, A. \& Kageyama, P.Y. 2000. Dispersão de sementes do Palmiteiro (Euterpe edulis Martius - Palmae). Em : Euterpe edulis Martius - (Palmiteiro) Biologia, conservação e manejo. (Reis, M. S. e Reis, A. eds.) Itajaí - Herbário Barbosa Rodrigues. 
Ros-Tonen, M. ; Dijkman, W. ; Bueren, E. L. 1995. Commercial and sustainable extraction of Non-Timber forest products. The Tropenbos Foundation Wageningen, The Netherlands.

Rueda R. P. 1995. Desenvolvimento histórico do extrativismo. In: Extractive Reserves (Murrieta Ruiz, J. \& Rueda Pinzón, M. eds.) IUCN, Gland, Switzerland e Cambridge, UK.

Sarukhán, J. ; Martinez -Ramos, M; Pinero, D. 1984 The analysis of demographic variability at the individual level and its population consequences. In: Persperctives on plant population ecology. (Dirzo, R. \& Sarukhán, J. eds.). Sinauer Massachusetts.

Silva-Matos, D. M. S; Freckleton, R. P. ; Watkinson, A. R. 1999. The role of density dependence in the population dynamics of tropical palm. Ecology 80 (8) pp.26352650.

Silva- Matos, D. M. 1995. Population Ecology of Euterpe edulis Mart. (Palmae). Tese de doutorado apresentada na University of East Anglia, Norwich. England.

Silvertown, J. W. ; Franco, M.; Pisanty, I. ; Mendonza, A. 1993. Comparative plant demography - relative importance of life-cycle components to the finite rate of increase in woody and herbaceous perennials. Journal of ecology. 81 pp.465-476.

Sobrinho, P. V. C. 1992. Capital e trabalho na Amazônia Ocidental . Editora Cortez, São Paulo, SP e Universidade Federal do Acre, Rio Branco AC.

Swaine, M. D. ; Lieberman, D. \& Putz, F. E. 1987. The dynamics of tree populations in tropical forest: A review. Journal of tropical Ecology 3 pp.359-366.

Vasques, R. \& Gentry, A. H. 1989. Use and misuse of forest-harvested fruits in the Iquitos area. Conservation Biology 3 pp.350-361.

Veloso, H. P.; Rangel, F.A.L. R; Lima, J. C. A. 1991. Classificação da vegetação brasileira, adaptada a um sistema universal. IBGE, Rio de Janeiro. 
Viana, V. M. 1986. Uma nova perspectiva para o manejo de florestas densas da Amazônia. Trabalho apresentado no Congresso Florestal Brasileiro.

Viana, V. M. ; Mello, R. A.; Moraes, L. M.; Mendes, N. T. 1998. Ecologia e manejo de populações de castanha-do-Pará em reservas extrativistas Xapuri, Estado do Acre. Em : Floresta Amazônica: Dinâmica, Regeneração e Manejo. INPA.

Viana, V. M. ; Mendes, N. ; Mello, A. ; Teixeira, R. ; Amaro, M.; Mendes, A.; Carvalho, L; Amaral, E.; Filho, L. M. R. 2000. Jardinagem Florestal Participativa - Projeto de Assentamento Agroextrativista Chico Mendes. Trabalho apresentado no Simpósio Internacional da IUFRO sobre Manejo Integrado de Florestas Úmidas Neotropicais por Indústrias e Comunidades. Belém, Pará.

Viana, V. M. 2001. Mães, filhas e netas: criando práticas simples para o manejo de ecossistemas complexos. Texto apresentado na VII Oficina de Manejo Florestal Participativo do PAE Chico Mendes, Acre.

Zuidema, P. A. \& Boot, R. G. A. 2000. Demographic constraints to sustainable palm heart extraction from a sub-canopy palm in Bolivia. In: Demography of exploited tree species in the Bolivian Amazon. (Zuidema, P. A. ed.) Universiteit Utrecht e PROMAB.

Wallace, R. H. 1999. A study of Açaí (Euterpe precatoria) Bacaba (Oenocarpus mapora) and Pataúa (Oenocarpus bataua) in the Extractive Reserve Chico Mendes and the city of Rio Branco, Acre, Brazil. Building Sustainable Marketing models for Non-Timber: A Critical Link to Environmentally Benign Socio-Economic Development in Extractive Reserves in Acre, Brazil. The Rainforest Alliance Kleinhans Fellowship. 